US Army Corps

of Engineers ${ }_{\circledast}$

Engineer Research and

Development Center

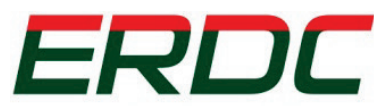

INNOVATIVE SOLUTIONS

for a safer, better world

\title{
Revised Rapid Soils Analysis Kit (RSAK) - Wet Methodology
}

Ernest S. Berney IV, Naveen B. Ganesh, and David R. Daily

January 2018
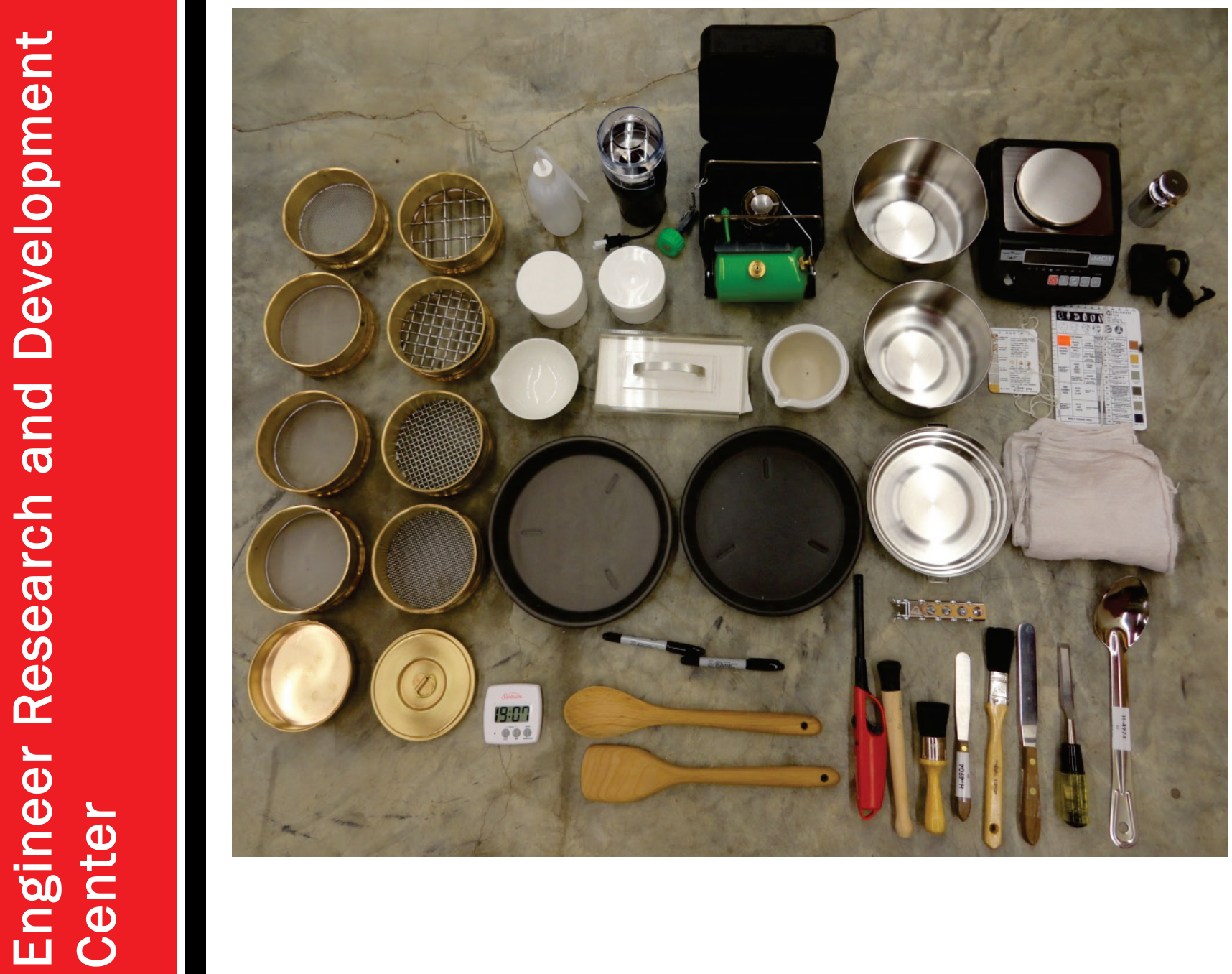
The U.S. Army Engineer Research and Development Center (ERDC) solves the nation's toughest engineering and environmental challenges. ERDC develops innovative solutions in civil and military engineering, geospatial sciences, water resources, and environmental sciences for the Army, the Department of Defense, civilian agencies, and our nation's public good. Find out more at www.erdc.usace.army.mil.

To search for other technical reports published by ERDC, visit the ERDC online library at http://acwc.sdp.sirsi.net/client/default. 


\title{
Revised Rapid Soils Analysis Kit (RSAK) - Wet Methodology
}

\author{
Ernest S. Berney IV \\ Geotechnical and Structures Laboratory \\ U.S. Army Engineer Research and Development Center \\ 3909 Halls Ferry Rd. \\ Vicksburg, MS 39180 \\ Naveen B. Ganesh \\ Coastal and Hydraulics Laboratory \\ U.S. Army Engineer Research and Development Center \\ 3909 Halls Ferry Rd. \\ Vicksburg, MS 39180 \\ David R. Daily \\ Information Technology Laboratory \\ U.S. Army Engineer Research and Development Center \\ 3909 Halls Ferry Rd. \\ Vicksburg, MS 39180
}

Final report

Approved for public release; distribution is unlimited.

\author{
Prepared for National Ground Intelligence Center \\ Combat Analysis Center \\ Charlottesville, VA 22911 \\ Under Project Number 354894
}




\section{Abstract}

ERDC research on crater formation from detonation of improvised explosive devices identified the significance of soil type on crater shape and size. Military Explosive Ordinance Disposal (EOD) teams required an expedient means of classifying soil from small field samples, according to the Unified Soil Classification System, to help identify characteristics of buried explosives. The existing Rapid Soils Analysis Kit (RSAK), developed at ERDC, was modified to shrink its cube volume, improve its accuracy, and adapt it to the EOD mission. As such the RSAK was changed from a dry, pulverization-based (D-RSAK) system to a wet, wash-based (W-RSAK) system similar to that used in a commercial laboratory to improve accuracy of determining fines content. Modifications were focused on increasing speed and accuracy from the original D-RSAK. This report presents comparisons of classification results on 14 different soil types by both the traditional laboratory, dry-based and wet-based systems to demonstrate the strengths and weaknesses of the new W-RSAK procedure. The kit in its current configuration with the wet process was demonstrated to significantly improve classification estimations. Revised software to process the data obtained from the W-RSAK equipment was developed using Matlab and Android platforms to enable deployment on multiple software platforms.

DISCLAIMER: The contents of this report are not to be used for advertising, publication, or promotional purposes. Citation of trade names does not constitute an official endorsement or approval of the use of such commercial products. All product names and trademarks cited are the property of their respective owners. The findings of this report are not to be construed as an official Department of the Army position unless so designated by other authorized documents. 


\section{Contents}
Abstract ii
Figures and Tables...
...

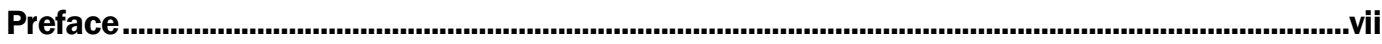
Unit Conversion Factors .............................................................................................................. vili

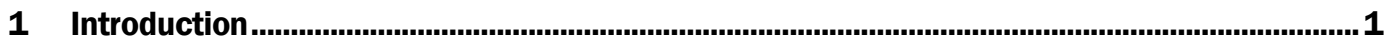

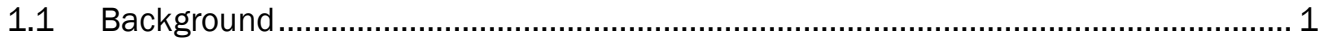

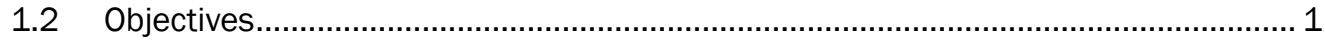

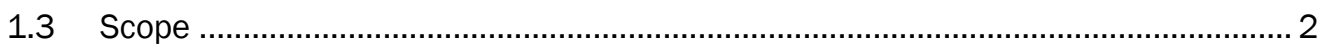

2 Current State of Expedient Soil Classification........................................................................ 3

2.1 Typical geotechnical testing ............................................................................ 3

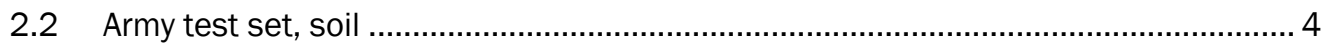

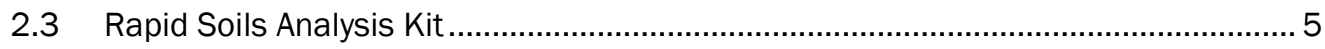

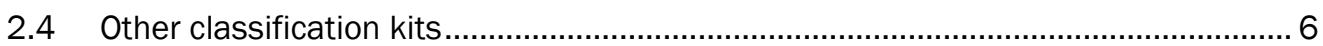

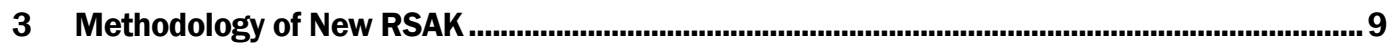

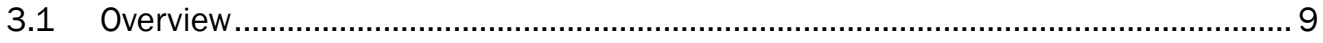

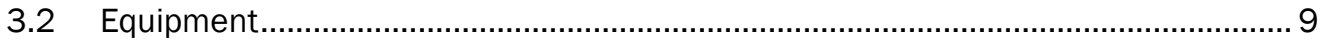

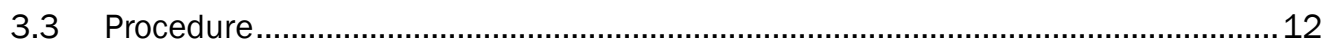

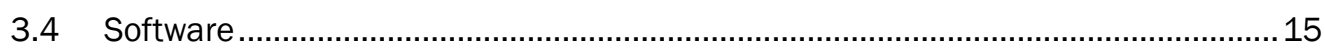

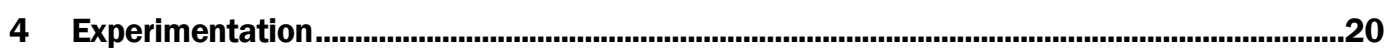

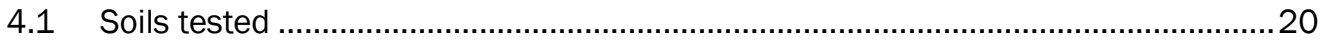

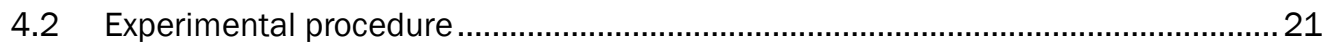

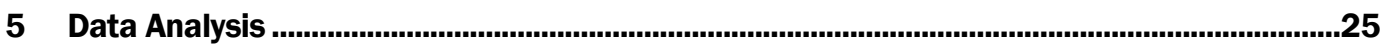

5.1 Particle size distribution ............................................................................ 25

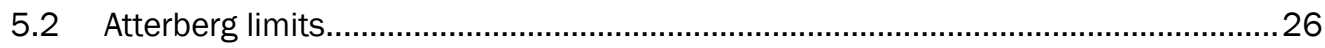

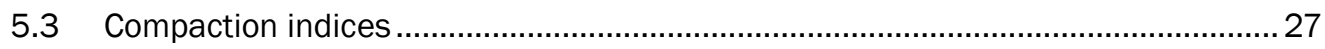

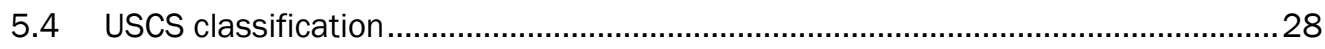

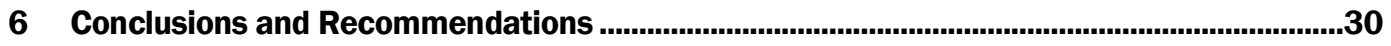

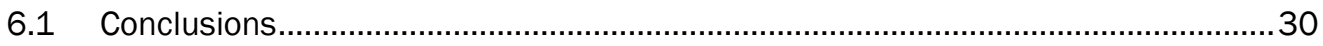

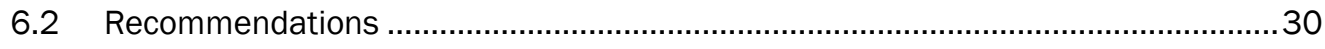

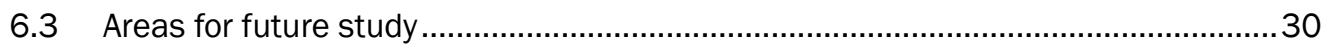

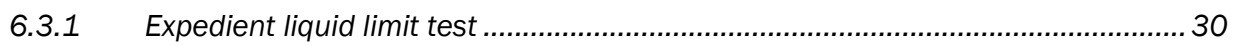

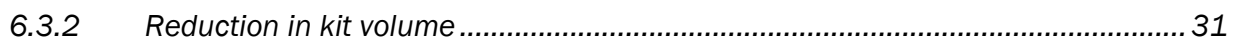

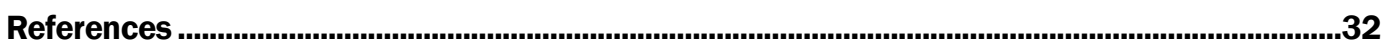

Appendix A: Expanded Expedient Soil Classification .........................................................................34 


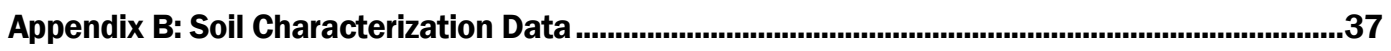

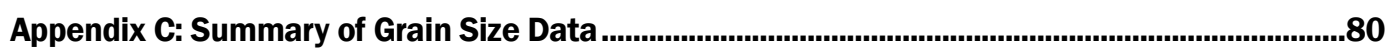

Appendix D: Army Soils Kit LIN-V92959

Report Documentation Page 


\section{Figures and Tables}

\section{Figures}

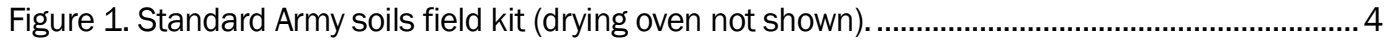

Figure 2. Army soils kit drying oven in comparison to RSAK drying apparatus. ................................... 4

Figure 3. Components of the D-RSAK system............................................................................. 5

Figure 4. Components of the W-RSAK system.

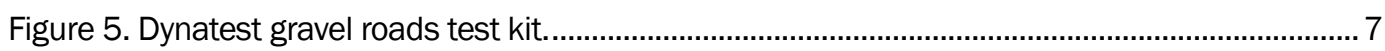

Figure 6. Wash and decanting process for removing fines (minus \#200 sieve) material using the Cornell quick wash procedure...................................................................................... 8

Figure 7. Dry-based Rapid Soils Analysis Kit (D-RSAK) as packaged for the JRAC program................ 9

Figure 8. Wet-based Rapid Soils Analysis Kit as developed for the CALDERA program.....................10

Figure 9. Wet-based RSAK (W-RSAK) packaged in a single 1620 Pelican Case................................12

Figure 10. Procedural differences between wet and dry RSAK methods. .........................................13

Figure 11. Illustration of procedural steps in conducting a wet RSAK experiment.............................14

Figure 12. Introductory screen to begin RSAK data input in Matlab executable. ..............................16

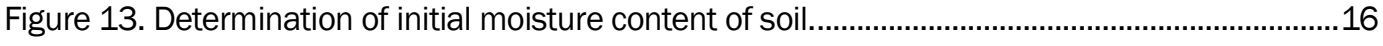

Figure 14. Drying of washed soil to prepare for sieve analysis........................................................17

Figure 15. Input of sieve weights empty and after soil has been introduced......................................17

Figure 16. Determination of plastic limit by weighting rolled threads..............................................18

Figure 17. Final input screen in RSAK to determine texture and output final USCS

classification and index properties. ...........................................................................................18

Figure 18. Data analysis window demonstrating grains size distribution curve. ...............................18

Figure 19. Data analysis window displaying modified proctor density curve. ..................................19

Figure 20. Data analysis window displaying modified proctor CBR curve. .......................................19

Figure 21. Three replicates of Limestone soil ready for washing for ASTM grain size determination.

Figure 22. Clay gravel dried and after washing over \#200 sieve (note large ASTM sample

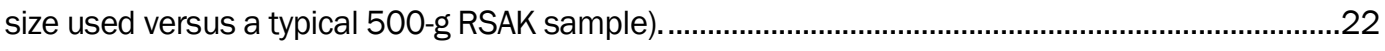

Figure 23. Washing fines in deep \#200 sieve for ASTM procedure.................................................23

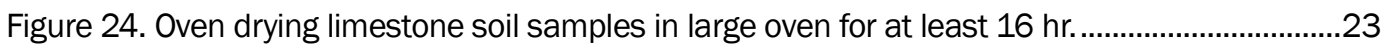

Figure 25. Average Coefficient of Determination between ASTM and RSAK sieve methodologies by sieve opening size for all soils tested. ....................................................................25

Figure 26. Simplified soil classification chart for CALDERA. ……......................................................34

Figure 27. USCS classification breakdown for coarse-grained soils. ..................................................35

Figure 28. USCS classification breakdown for fine-grained soils based on textural analysis. ..........36

Figure 29. Comparison of percent passing each sieve between RSAK techniques and ASTM procedure for all soils tested.

Figure 30. Comparison of percent passing each sieve between RSAK and ASTM procedure for soils classified as coarse grained ( $<50 \%$ fines). 


\section{Tables}

Table 1. Parts list for the wet-based Rapid Soils Analysis Kit...........................................................10

Table 2. Modifications made from the original dry-based RSAK to the wet-based RSAK..................11

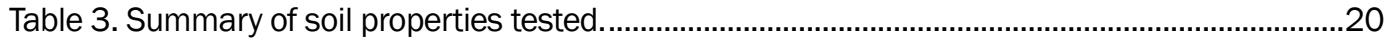

Table 4. Standard laboratory tests conducted for soil classification. ..................................................21

Table 5. Atterberg limit comparison between laboratory and RSAK methods....................................26

Table 6. RSQ summary from Atterberg limit comparison. .............................................................26

Table 7. Comparison of optimum moisture content and maximum dry density between

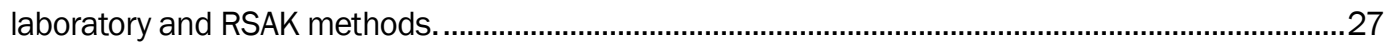

Table 8. Comparison between USCS soil classifications between Laboratory, ASTM, and

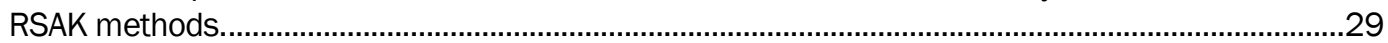

Table 9. Average of percent passing each sieve from 3 replicates for all soils and techniques evaluated. 


\section{Preface}

This study was conducted for the National Ground Intelligence Center (NGIC) Combat Incidence Analysis Division (CIAD) under Project 354894 CALDERA. The technical monitor was Dr. John Q. Ehrgott Jr.

The principal investigator for this study was completed by the Airfields and Pavements Branch (GMA) of the Engineering Systems and Materials Division (GM), U.S. Army Engineer Research and Development Center, Geotechnical and Structures Laboratory (ERDC-GSL). Other personnel who assisted in this research effort were Mr. David R. Daily, Information Technology Laboratory (CEERD-ITL) and Mr. Naveen Ganesh, Coastal and Hydraulics Laboratory (CEERD-CHL). Laboratory testing was conducted by the Concrete and Materials Branch (GMC) by Mr. Charles E. Carter, Mr. Larry D. Dunbar and Ms. Alfreda S. Thomas. At the time of publication, Dr. Timothy W. Rushing was Chief, GMA; Mr. Chris Moore was Chief, GMC; Dr. Gordon W. McMahon was Chief, GM; Mr. Charles W. Ertle was Acting Deputy Director, ERDC-GSL; and Mr. Bartley P. Durst was Director.

COL Bryan S. Green was the Commander of ERDC. Dr. David W. Pittman was Director. 


\section{Unit Conversion Factors}

\begin{tabular}{|l|l|l|}
\hline Multiply & By & To Obtain \\
\hline cubic yards & 0.7645549 & cubic meters \\
\hline feet & 0.3048 & meters \\
\hline inches & 0.0254 & meters \\
\hline pounds (force) & 4.448222 & newtons \\
\hline pounds (force) per foot & 14.59390 & newtons per meter \\
\hline pounds (force) per square foot & 47.88026 & pascals \\
\hline pounds (force) per square inch & 6.894757 & kilopascals \\
\hline pounds (mass) per cubic foot & 16.01846 & kilograms per cubic meter \\
\hline square feet & 0.09290304 & square meters \\
\hline tons (force) & $8,896.443$ & newtons \\
\hline
\end{tabular}




\section{Introduction}

\subsection{Background}

The CALDERA program (Ehrgott et al. 2016) is focused on developing tools to enable the soldier to estimate the size and depth of a buried improvised explosive device (IED) based on factors such as soil type, soil density, soil moisture, and dimensional characteristics of the crater left behind from an explosion. This research effort is a key component in the crater forensic capabilities necessary for the success of the CALDERA program at ERDC to better identify the soil conditions as part of the analysis procedure. Companion research efforts ongoing within CALDERA address the integration of field data collection with predictive models to estimate the charge size and depth of burial.

Previous to this research effort, it was understood that the volume of air voids played a role in the ultimate air-blast effect of a buried explosive on an object (Ehrgott 2011). The research focused primarily on coarse-grained sand or gravel material that has a uniform response to blast effects in both the laboratory and numerically. The size and shape of the post-blast crater was not considered, since the ultimate goal was identifying blast effects on neighboring objects. However, most soils are not uniform sand or gravel, and experimentation has shown that similar air void contents between soil types result in markedly different crater shapes. The CALDERA program sought to identify soil factors that contribute to the change in crater dimension; soil classification, density and moisture content were pinpointed as essential parameters. To enable military Explosive Ordinance Disposal (EOD) personnel to obtain this information during forensic analysis, a rapid yet durable capability for obtaining these parameters was required. This report discusses the solutions provided to meet this demand.

\subsection{Objectives}

The objective of this study was to modify the current Rapid Soils Analysis Kit (D-RSAK) developed by ERDC (Berney and Wahl 2008), to shrink its cube volume, improve its accuracy and adapt it to the nature of the EOD mission. As such the D-RSAK was adapted from a dry, pulverization-based soil processing system to a wet, wash-based soil processing system (W-RSAK) similar to that used in a commercial laboratory to improve 
accuracy of determining fines content. Sieve capacity was expanded; heating was converted from microwave to hot plate. These changes and manual sieving all allowed reduction in size while increasing speed and accuracy from the D-RSAK. A comparison was then made between the original dry-based D-RSAK and the new wet-based W-RSAK to show improvements in time and accuracy. Further, a comparison was made between this new technology and the existing Army soils kit to show extension of this system to a broader engineering audience.

\subsection{Scope}

In order to make an accurate post-blast prediction of the effective net explosive weight, the analyst must have some idea of the soil type and the in-place soil conditions. This research project was designed to provide soldiers who have minimal to no experience in soil analysis simple, repeatable tools that will enable them to determine the soil classification, density, and moisture state of the ground at the site of an existing crater location. As a more accurate approach to obtaining field classification than the textural-based expedient soil classification process developed early in the CALDERA program (Ehrgott et al. 2016) (Appendix A), this research details the deliberate procedure modifying the existing D-RSAK, an expedient technology developed for contingency construction (Berney and Wahl 2008) to obtain a near-ASTM standard accurate soil classification, moisture content, and an estimate of field density in less than $60 \mathrm{~min}$. 


\section{Current State of Expedient Soil Classification}

\subsection{Typical geotechnical testing}

The ability to determine an accurate engineering soil classification without the need for time-consuming laboratory testing is critical to enabling realtime site analysis for crater forensics. Currently, when a soil sample is obtained from a field setting, the engineering classification can be obtained via a visual classification (ASTM D2488) or TM 3-34.43 (Dept. of the Army, 2015). This procedure provides a rough estimate of the ASTM soil engineering classification (ASTM D2487) and an estimate of the plasticity of the soil by identifying it as either silt or clay at a high or low plasticity. However, several of the aforementioned field techniques require an experienced user to obtain repeatable results given the large number (20) of engineering classifications possible. As well, the field tests for plasticity typically involve wetting and later drying of the soil to determine the strength of dried silt/clay. This is not feasible in the short timeframe (5 min to $1 \mathrm{hr}$ ) demanded of the CALDERA program (Ehrgott et al. 2016). Nor does the field visual classification provide any estimate of field moisture or density.

For obtaining density and moisture content there are a number of manual, electronic, and nuclear methodologies to accomplish this task (Berney et al. 2013, 2016). Notably are the sand cone test for density, the nuclear densometer for density and moisture (Troxler, 2007), and a host of electronic devices that can measure density and moisture. Determining density in this way requires an expensive and bulky piece of test equipment that must be carried into the battlespace. For nuclear methods, additional radiation protection must be provided for the user and team. Electronic means require calibration of the soil prior to obtaining a valid reading using a secondary technique, making application of this technology moot. For moisture content, a number of means can be employed in the field and are discussed in Berney et al. 2011. For a microwave and electric burner, power must be supplied to dry the soil, but the technique can be accomplished in a few minutes. A gas burner can also provide an expedient drying technique given ready access to fuel. 


\subsection{Army test set, soil}

The military state of the practice for assessing soil classification and engineering properties in the field is performed using the Army test set, soil (LIN V99259), whose components are detailed in Appendix D, and those specifically related to the capabilities of the RSAK shown in Figure 1 and Figure 2 courtesy of the Fort Leonard Wood training facility.

Figure 1. Standard Army soils field kit (drying oven not shown).

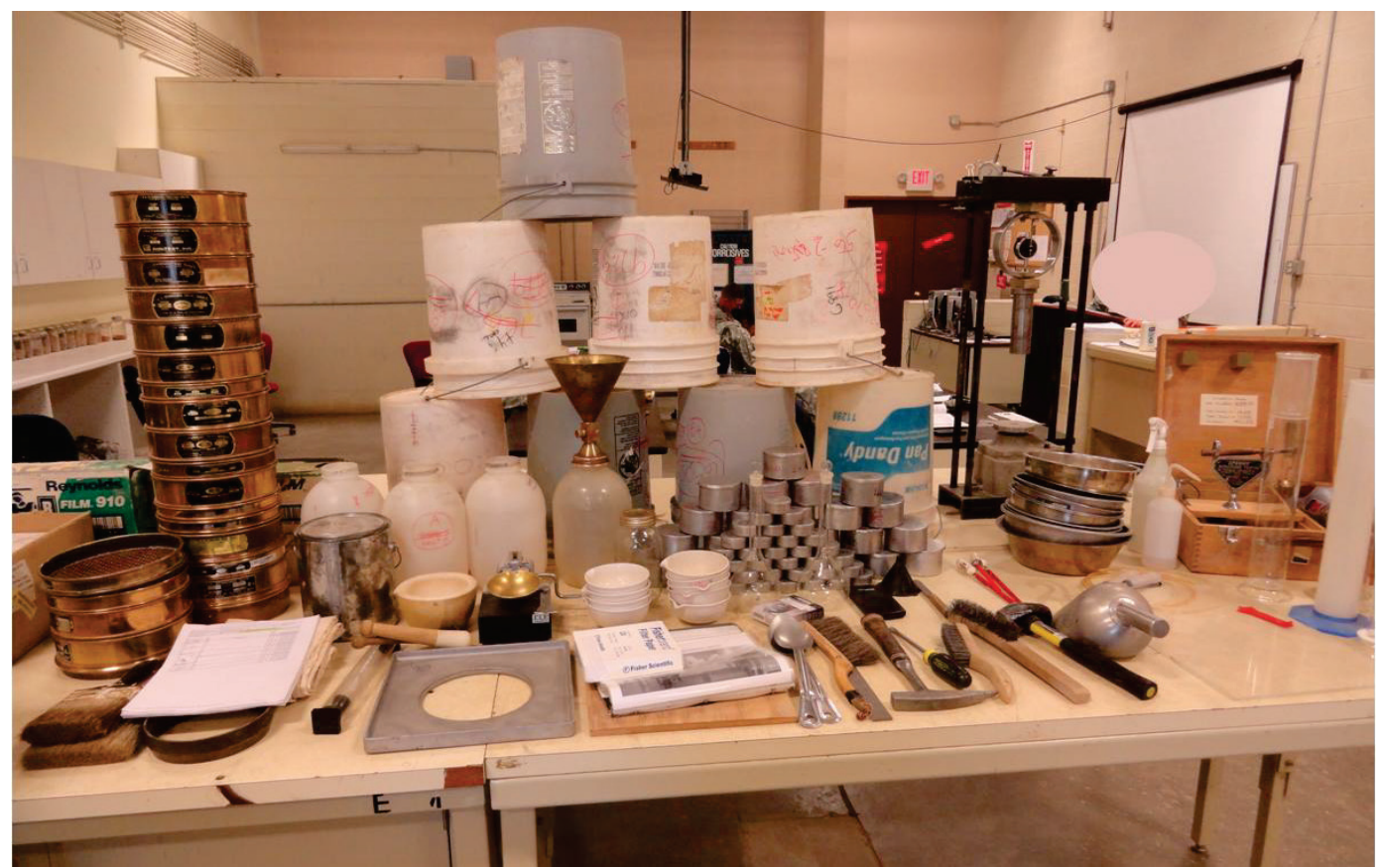

Figure 2. Army soils kit drying oven in comparison to RSAK drying apparatus.

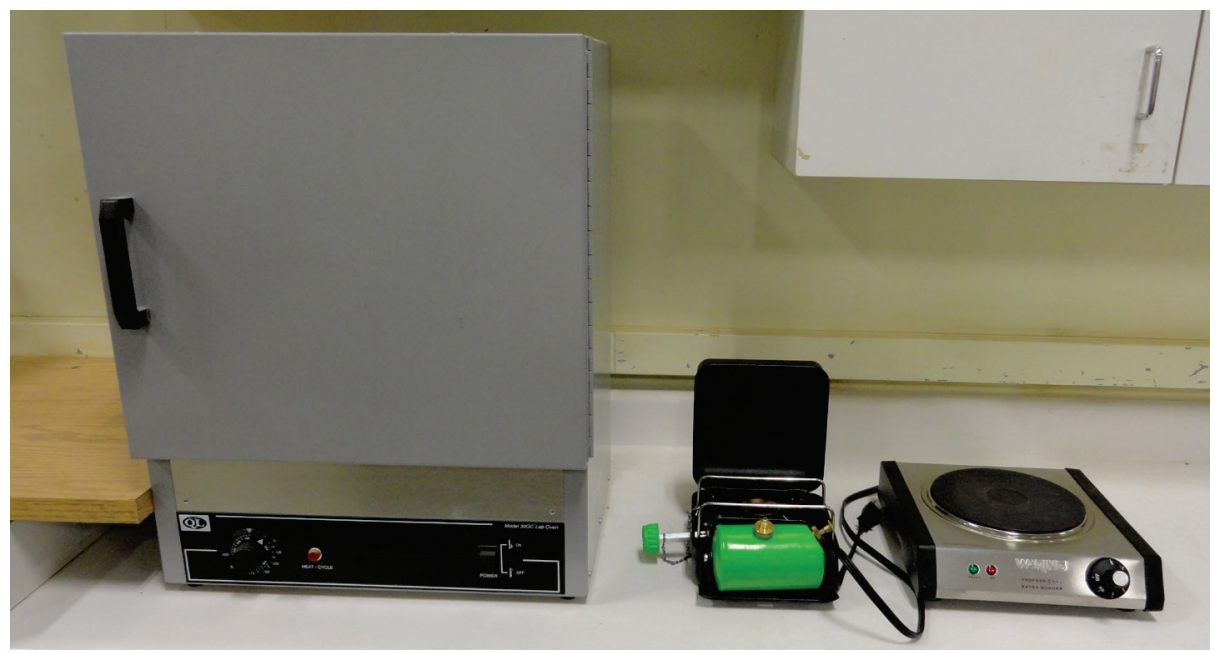


The size and weight of the Army Soil Test Kit make it impractical for most field exercises. Very few of these test kits exist in the Army inventory, and they are typically not moved once set up. Likewise, their permanent locations are at great distances from the operational needs of the soldier and, hence, they are not often used. Soil analysis is often ignored due to an inability to have test equipment on site, or lack of time to conduct the experiments necessary to obtain the required classifications following traditional ASTM guidelines.

\subsection{Rapid Soils Analysis Kit}

To provide a means of determining soil classification in a compact deployable kit, the ERDC dry-based Rapid Soils Analysis Kit (Berney and Wahl 2008) (D-RSAK) (Figure 3) was developed as part of the Joint Rapid Airfield Construction (JRAC) Program (Anderton et al. 2008). The intent of the technology was to provide soldiers a means of determining the soil classification, in-situ moisture content and the moisture-density curves, and California Bearing Ratio strength curves within a 60-min time frame to establish quality control parameters and enable construction to begin. Physically, the D-RSAK represents a scaled-down version of the Army field soils using standardized equipment to provide numerical data that, when integrated with ERDC developed software, leads to a USCS classification. Detailed descriptions of the D-RSAK in its JRAC configuration as first presented to NGIC and the subsequent redesign are discussed in Chapter 3.

Figure 3. Components of the D-RSAK system.

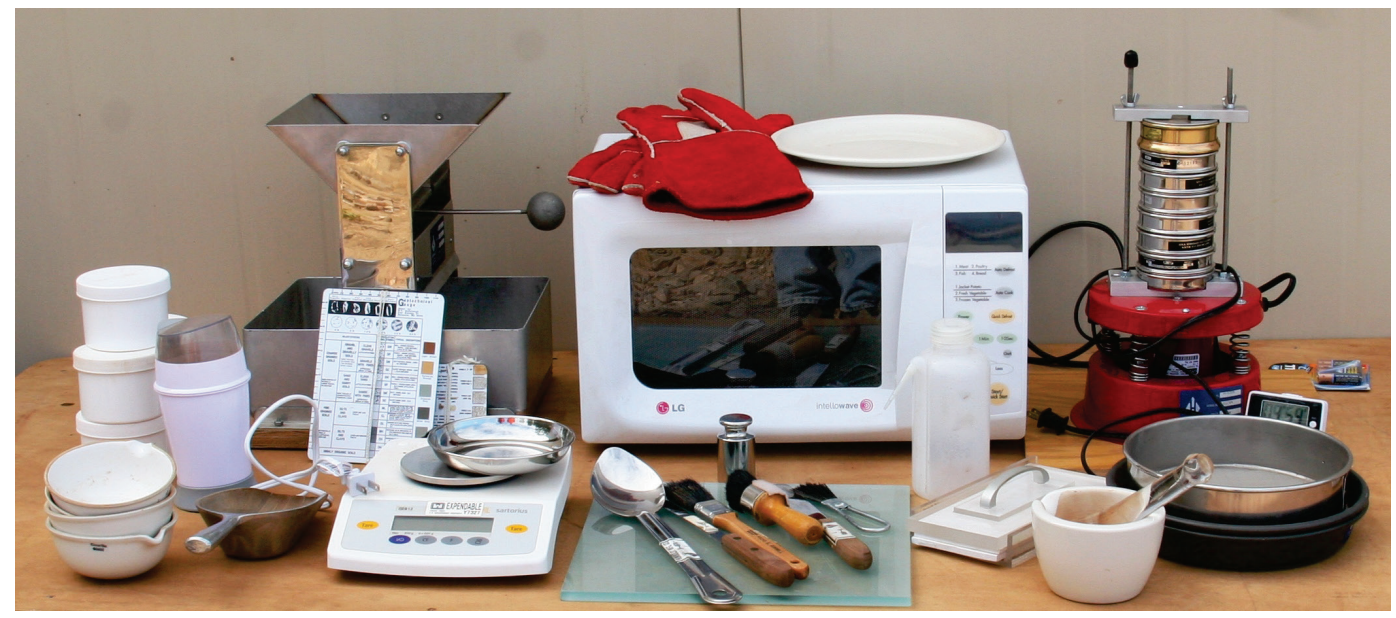

For comparison, Figure 4 illustrates the components of the new wet-based W-RSAK system that removes many of the bulkier items from the D-RSAK to further improve transport logistics. 
Figure 4. Components of the W-RSAK system.

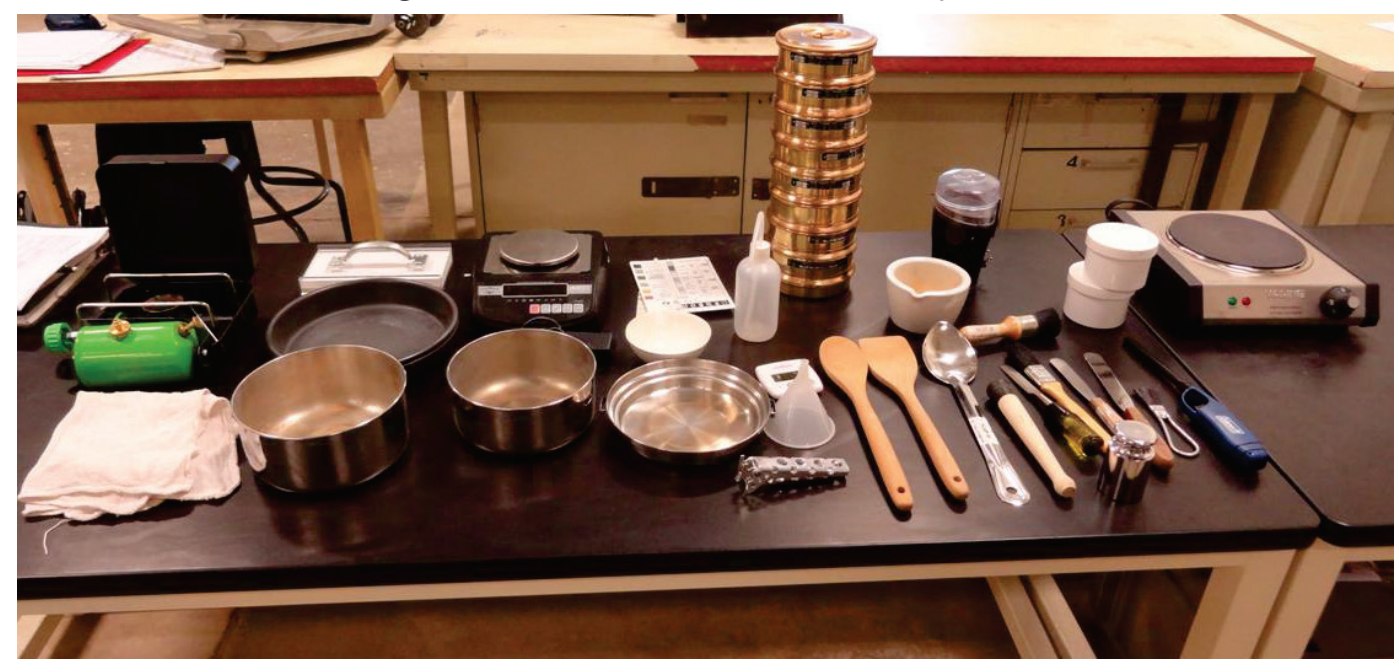

\subsection{Other classification kits}

Other than the D-RSAK, there is currently only one commercial product and one formalized procedure available to obtain a series of physical properties of soils in the field known as The South African Gravel Roads Test Kit (Paige-Green 2011) manufactured by Dynatest Pavement Engineering (Figure 5 Figure 5). The manufacturer states in the sales literature that this kit:

“...allows materials grading, cohesion (liquid limit and linear shrinkage), compacted strength and aggregate strength of the borrow material to be determined."

This kit is designed primarily for measuring the properties of coarsegrained materials and assessing their strength and suitability as road surface material. The tests themselves take much longer (12 to $24 \mathrm{hr}$ or longer to capture liquid limit and bar linear shrinkage) to conduct than the D-RSAK, and any drying of the soil is accomplished using solar power, which can delay results depending on location. 
Figure 5. Dynatest gravel roads test kit.

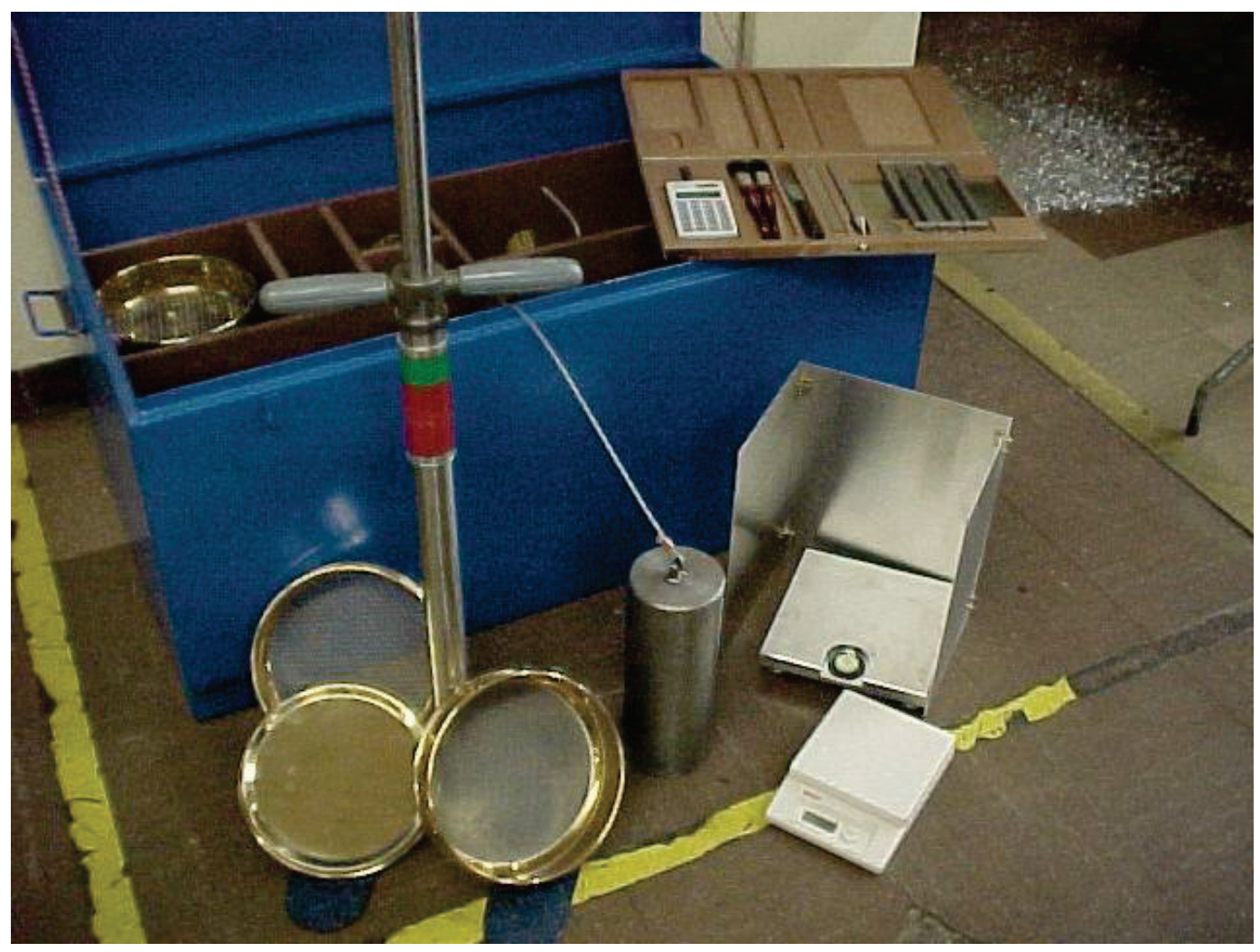

Cornell University (Irwin 2011) developed a simplified procedure for assessing the gradation of road materials using a wash technique, portions of which were incorporated into the new W-RSAK system. They suggest determining a rough gradation of road aggregate by obtaining a large field sample size $(20 \mathrm{~kg}$ ), hand-separating particles greater than 1-in. in diameter, and obtaining their weight. The next step is drying and weighing the minus 1-in. particle diameter sample before washing over a \#200 sieve. As an alternative, they suggest washing the soil in a bucket and decanting the material that has not settled after 15-20 sec, repeating for approximately 10 wash cycles (Figure 6). Then dry and reweigh the washed sample and screen over the \#10 sieve (or 1/8" hardware cloth). This provides an assessment of coarse gravel (plus \#10 fraction), sand (\#10-\#200 fraction), and fines (washed material). The bucket and decanting procedure is the key piece adopted from this procedure that enables the W-RSAK system to operate as it does. 
Figure 6. Wash and decanting process for removing fines (minus \#200 sieve) material using the Cornell quick wash procedure.
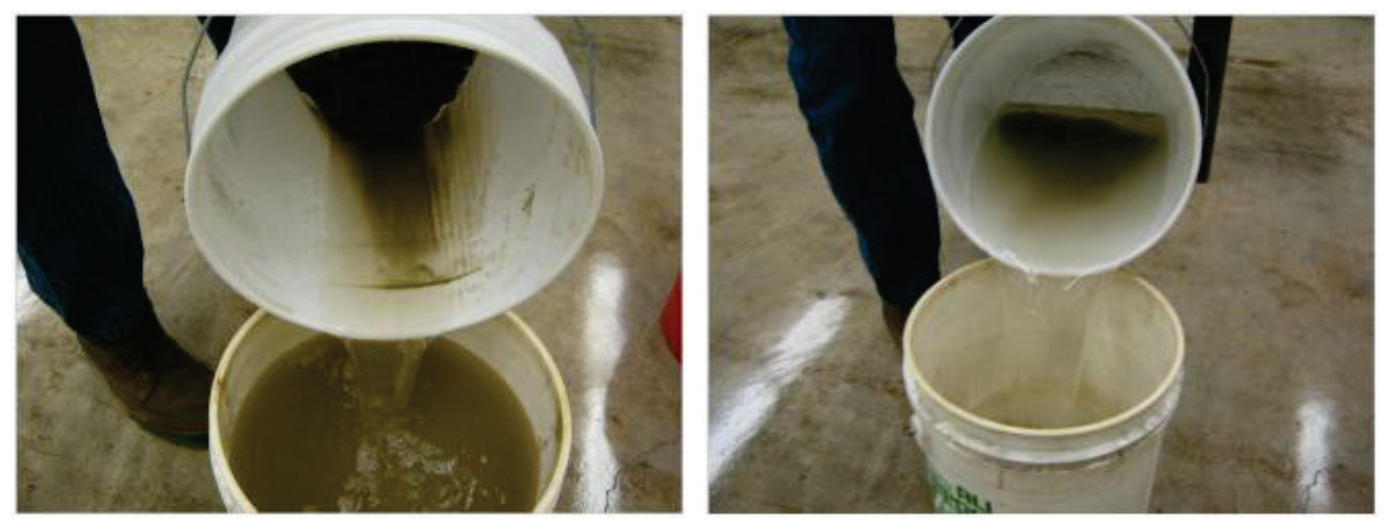


\section{Methodology of New RSAK}

\subsection{Overview}

EOD personnel have minimal time at the incident site so the CALDERA expedient technique is typically employed at the blast location (Windham 2015). A summary of the classification system and a new modification made for the case of obtaining USCS classification is given in Appendix A. In instances when a severe event occurs and a more detailed soil assessment is required, a deliberate soil classification technique may be employed.

\subsection{Equipment}

The RSAK kit was selected as an ideal candidate to provide a rapid means of obtaining a deliberate soil assessment in theater. In its original JRAC configuration, the D-RSAK equipment set was considered too large for EOD personnel, making it impractical for deployment during a post-blast site reconnaissance (Figure 7). Therefore, for the CALDERA program, the RSAK was modified from its original configuration and process in order to reduce the amount of equipment required and increase the accuracy of the measurements with the resulting equipment list shown in Figure 8 and Table 1.

Figure 7. Dry-based Rapid Soils Analysis Kit (D-RSAK) as packaged for the JRAC program.

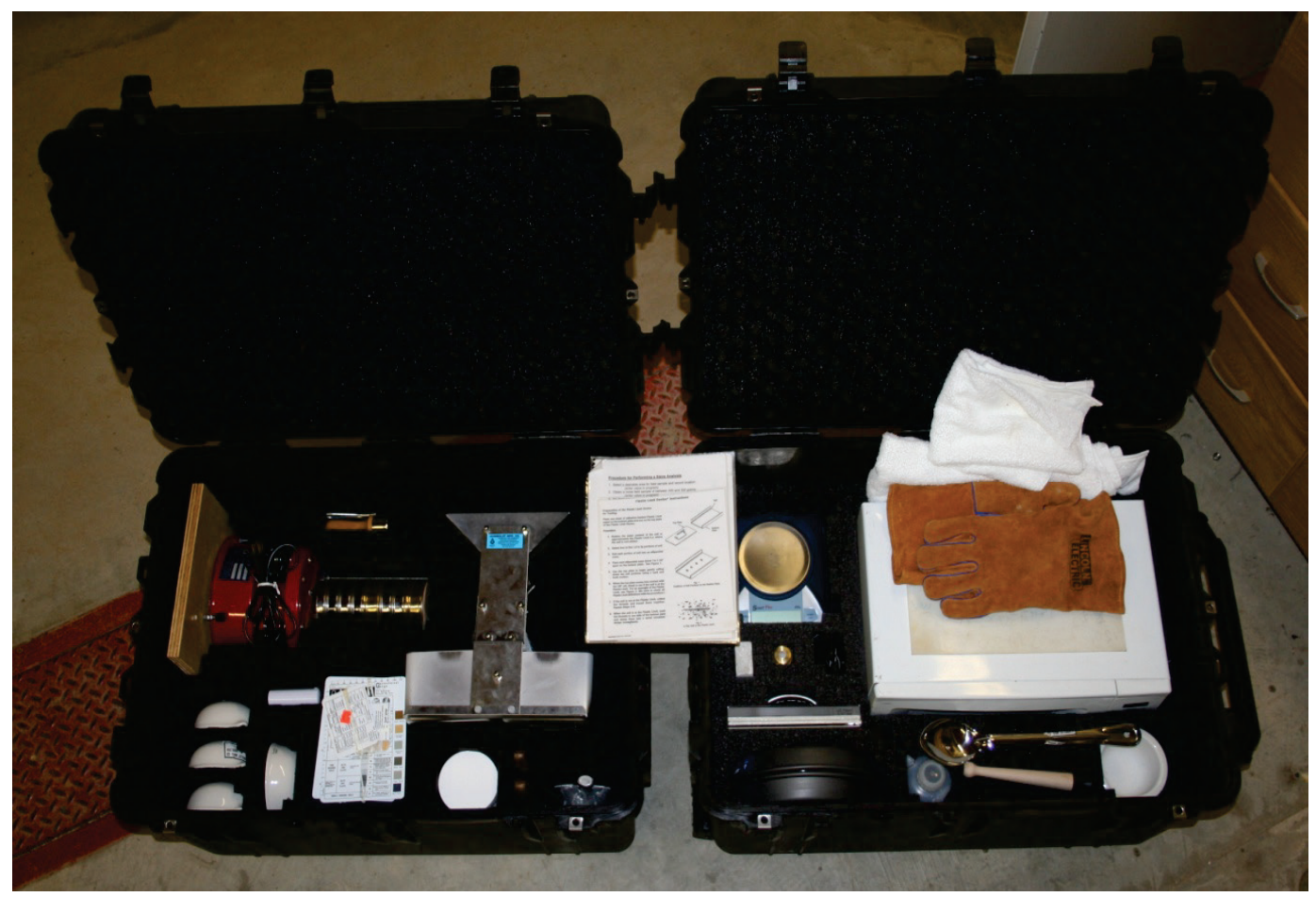


Figure 8. Wet-based Rapid Soils Analysis Kit as developed for the CALDERA program.

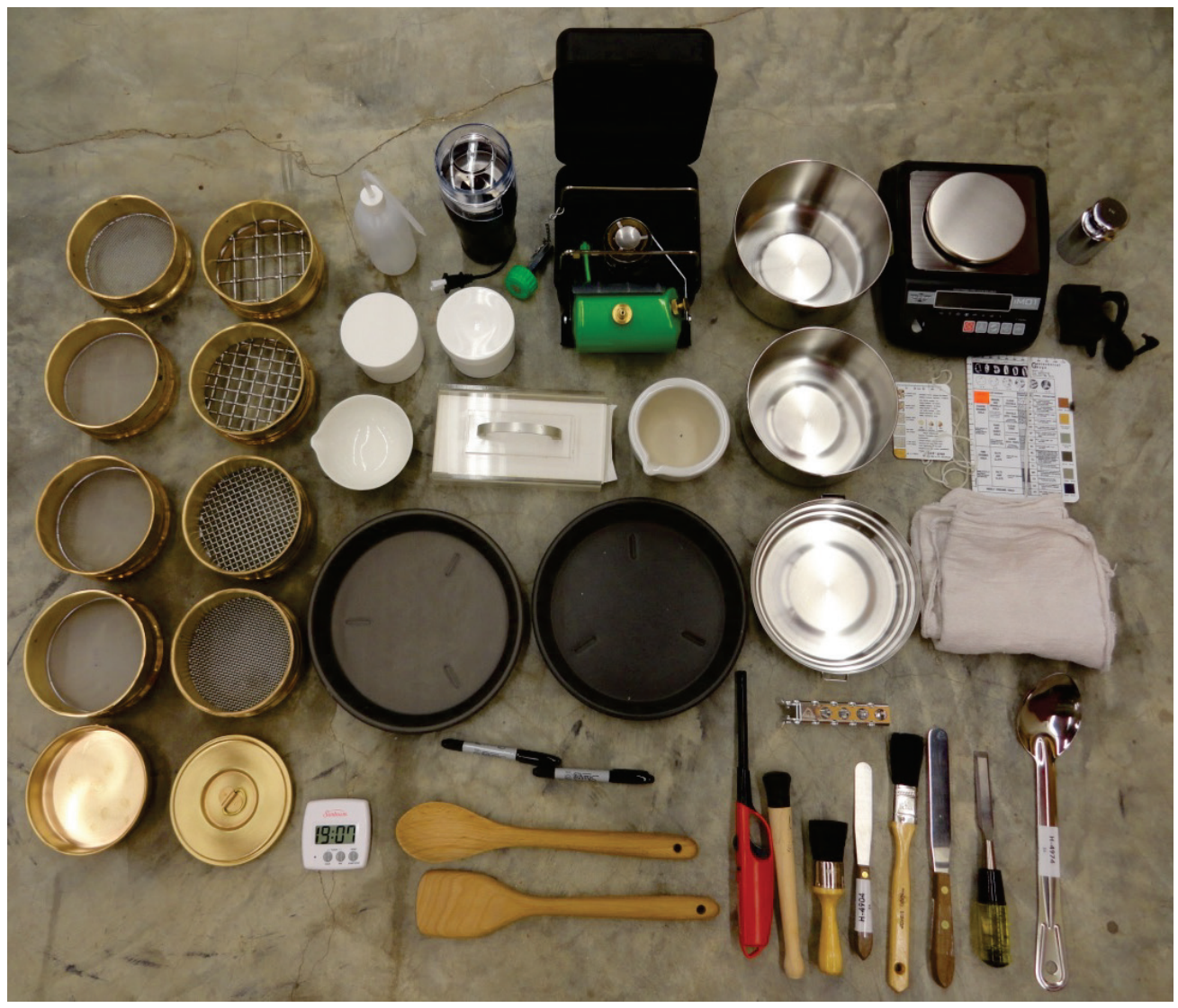

Table 1. Parts list for the wet-based Rapid Soils Analysis Kit.

\begin{tabular}{|l|c|l|c|}
\hline Plastic Limit Roller with paper & 1 & Multi fuel stove & 1 \\
\hline Porcelain Bowls & 1 & Alpine Cookset & 1 \\
\hline Long spoon & 1 & Plastic funnel & 1 \\
\hline Rubber pestle & 1 & Electric Burner & 1 \\
\hline Long spatula & 1 & 20oo-gram scale & 1 \\
\hline Short spatula & 1 & Geotechnical Gauge & 1 \\
\hline Sample Cups & 2 & Sand Gauge & 1 \\
\hline Sample Pans & 2 & Small pack of towels & 1 \\
\hline Water Bottle (Squeeze) & 1 & $1 / 2 "$ Scraper & 1 \\
\hline Sieve Brush - Fine & 1 & 15 amp 50' extension cord & 1 \\
\hline Sieve Brush - Coarse & 1 & Timer & 1 \\
\hline Wire Sieve Brush & 1 & Sharpie Pens & 2 \\
\hline Set of 5 inch diameter brass sieves ind & 1 & Stirring spoons & 2 \\
\hline 1", 1/2", \#10, \#20, \#40, \#100, \#200 & & Coffee Grinder & 1 \\
\hline Sampling trowel & 1 & 1620 Pelican Case & 1 \\
\hline Plastic Bowl & 1 & 1560 Pelican Case & 1 \\
\hline
\end{tabular}


The new version of the RSAK developed for the CALDERA program (W-RSAK) eliminates the original dry-based analysis in favor of a waterbased analysis. The water-based approach is analogous to the ASTM wash sieve technique (ASTM C117 2004). This approach simplified the soil preparation from the earlier D-RSAK version and provided a more accurate determination of the fines content of the soil. By washing the fines out of the soil the sieving process also became easier as only coarsegrained material remained. A summary of the key hardware changes in development of the W-RSAK kit is shown in Table 2. Employing the wash technique allowed the use of larger sample sizes and removal of bulkier components of D-RSAK, namely the $1 / 2$-in. diameter splitter and the sieve shaker. Using an electric hotplate or multi-fuel stove eliminated the need for a bulky microwave, and the stove allowed for a non-electric-based drying approach for environments when no AC power was accessible. Removal of the microwave also increased the range of soils that could be dried as very gravelly soils can lead to exploding particles and metallic minerals can cause arcing. Each of these would result in damage to the sample and failure of the moisture measurement test. The overall cube volume of the kit was reduced by a factor of 3 or greater, from two large 1660 Pelican cases (11.32 cu ft) to a single 1620 pelican case $(2.56 \mathrm{cu} \mathrm{ft}$ ) and a 1560 case $(1.55 \mathrm{cu} \mathrm{ft})$ for the hot plate if necessary, as shown in Figure 9. Weight wise, this reduced the kit from two 75-lb packages to a single 48-lb package (not including water). The low logistic requirement and high data quality of the W-RSAK were key parameters to its acceptance in CALDERA.

Table 2. Modifications made from the original dry-based RSAK to the wet-based RSAK.

\begin{tabular}{|l|l|}
\hline Original Dry RSAK & New Wet RSAK \\
\hline Microwave oven drying & $\begin{array}{l}\text { Replaced with electric hot plate and/or gas burner } \\
\text { (gas burner requires no power source) }\end{array}$ \\
\hline Porcelain bowls & $\begin{array}{l}\text { No longer necessary without microwave. Replaced } \\
\text { with plastic and aluminum bowls }\end{array}$ \\
\hline Crush and pulverize dried field sample for sieving. & $\begin{array}{l}\text { Wash dried field sample to remove fines prior to } \\
\text { sieving coarse fraction. }\end{array}$ \\
\hline 3-inch diameter sieves & Replaced with 5-inch diameter sieves \\
\hline $\begin{array}{l}\text { Sample splitter to reduce sample size for 3-inch } \\
\text { diameter sieves }\end{array}$ & $\begin{array}{l}\text { No longer necessary as the entire sample can be run } \\
\text { through 5-inch diameter sieves }\end{array}$ \\
\hline Sieve Shaker & $\begin{array}{l}\text { Replaced by manual sieving of 5-inch sieve stack. } \\
\text { Without fines, sieve process required less intensity. }\end{array}$ \\
\hline 500-gram scale & 2000-gram scale for heavier sample/sieve weighing \\
\hline Software in .NET environment & Software in Matlab executable and Android App \\
\hline
\end{tabular}


Figure 9. Wet-based RSAK (W-RSAK) packaged in a single 1620 Pelican Case.

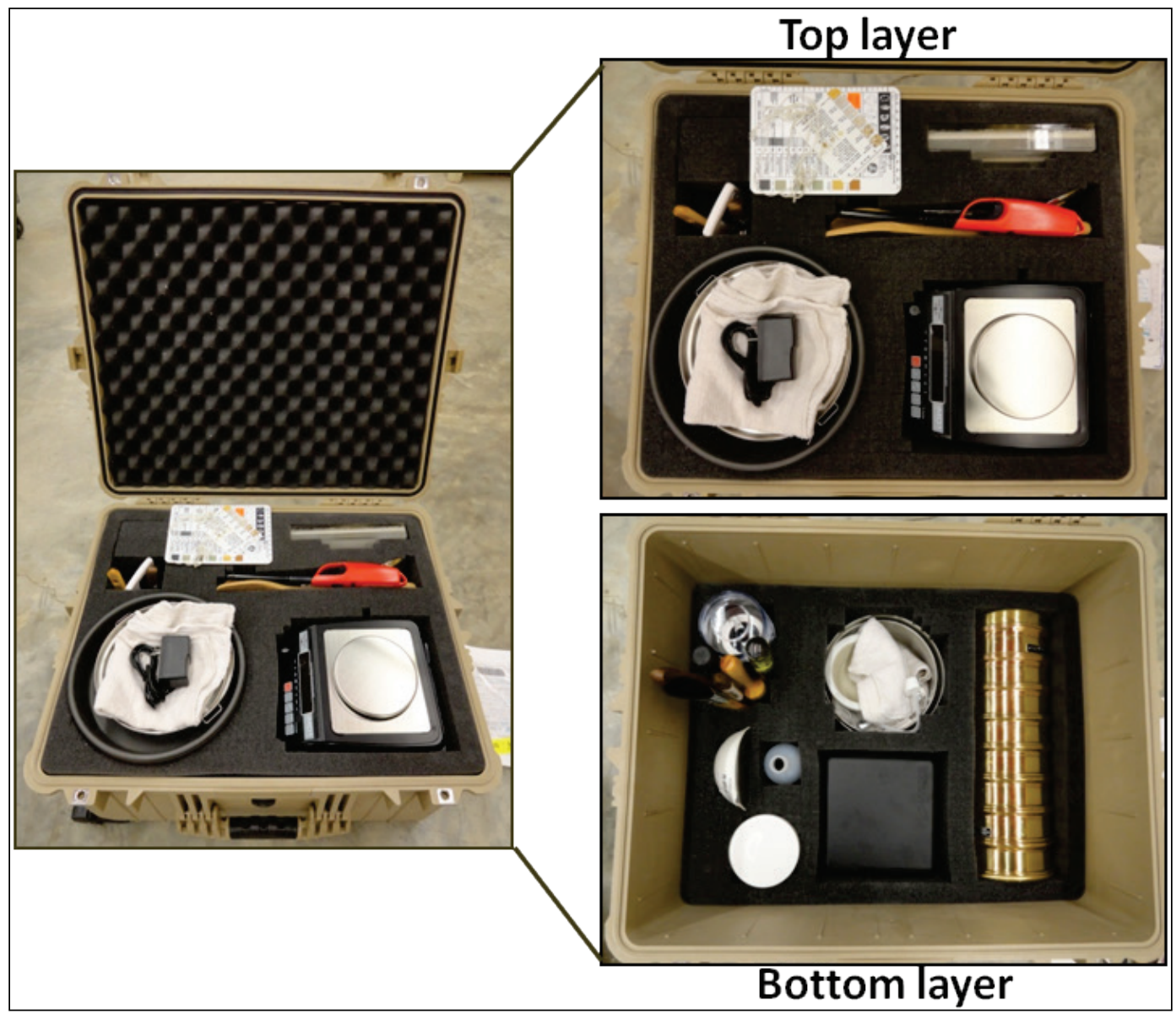

\subsection{Procedure}

Figure 10 introduces the basic steps in conducting a RSAK experiment both from the wet and dry approach. Figure 11 illustrates the procedural steps required in conducting the wet RSAK procedure. These steps are outlined in the ERDC Post-Blast Crater Collection and Analysis Guide (Windham 2015) used for training EOD personnel.

In the RSAK, a relatively small $200-500 \mathrm{~g}$ sample is obtained from a field specimen. The sample is dried to obtain the initial moisture content. Drying consists of cooking and weighing the soil on a burner or hot plate repeatedly, until a mass change of less than $1 \%$ occurs, indicating that constant moisture content has been achieved. Once dried, the fines are washed from the soil by stirring the dried sample in a small aluminum pan filled with water. After setting for $30 \mathrm{sec}$, the water is decanted off along with the fines in the soil. The washing procedure is repeated six or more times (ten times was suggested by Irwin 2011), until the water becomes 
much less cloudy and a majority of the fines have been removed. Then the sample is dried on the hot plate/burner and passed through the sieve stack to achieve a coarse grain size distribution. Sieving occurs by the user shaking a sieve stack for approximately $2 \mathrm{~min}$. Smaller size fractions may need to be pulverized using the accompanying coffee grinder or mortar and pestle to reduce hard bound clay masses that pose as small sand grains into a powder form and then reinserted into the sieve stack to pass the \#200 sieve. The mass of dry soil lost through washing is appended to the coarse grain size sieve information to provide a complete grain size distribution including the fines content.

To determine the Atterberg limits, a portion of the remaining original sample is dried until only a $2 \%$ mass differential occurs to reduce error in determining the plastic limit due to over drying certain soil types. Then the soil is ground, passed through the \#40 sieve, and rewetted until threads can be rolled based on the principles of the plastic limit test (ASTM D4318 2010). The threads are then dried similarly to the original sample and the moisture content of the threads recorded as the plastic limit. A textural evaluation of the \# 40 fraction during workup of the threads to identify primarily silty or clayey material is noted and entered into the software. This dictates which regression curve approximates the liquid limit based on the plastic limit measured to finalize the USCS classification. Determination of the fine-grained soil texture can be accomplished by techniques detailed in Windham 2015 and the Dept. of the Army TM 3.34-43.

Figure 10. Procedural differences between wet and dry RSAK methods.

\footnotetext{
WET mode steps

1. Collect a 200 to 500 -gram field soil sample

2. Dry the field sample with a burner

3. Wash fine soil (silt/clay) from dried sample using water in repeated cycles

4. Re-dry the washed soil

5. Sieve the dried soil through the brass sieves

6. Prepare a $20-40$ gram sample of dried field sample passing the \#40 sieve

7. Perform the plastic limit test

8. Determine the soil texture

9. Soil classification is returned
}

\section{DRY mode steps}

1. Collect a 200 to 500 -gram field soil sample

2. Dry the field sample with a burner

3. Separate out coarse and fine soil from the dried sample

4. Pulverize fine soil to remove clumps

5. Sieve the dried soil through the brass sieves

6. Collect all soil passing the \#40 sieve

7. Perform the plastic limit test

8. Determine the soil texture

9. Soil classification is returned 
Figure 11. Illustration of procedural steps in conducting a wet RSAK experiment.

1. Collect field sample

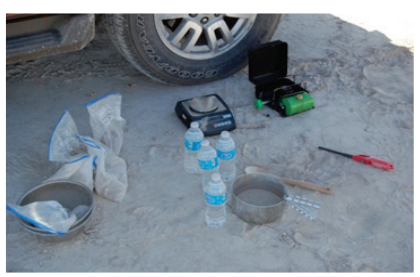

2. Dry field sample

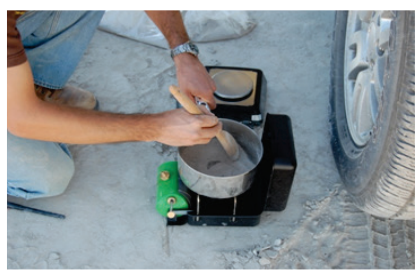

Pour off fines after $30 \mathrm{sec}$

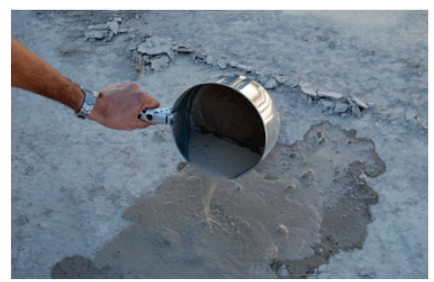

5. Sieve coarse sample

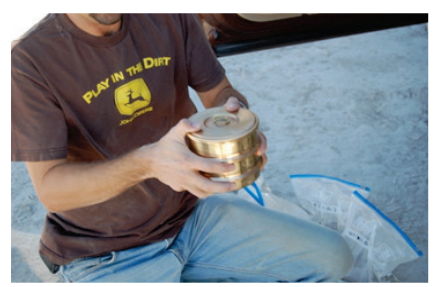

Pour fuel into stove

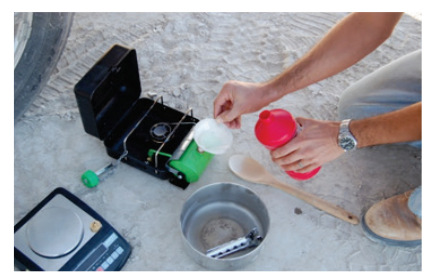

3. Wash fines - add water

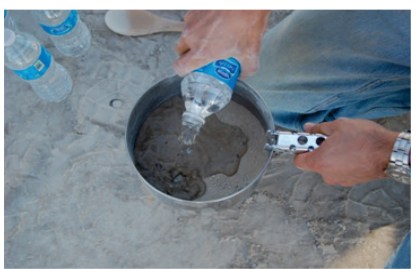

Repeat rinsing until water begins to clear

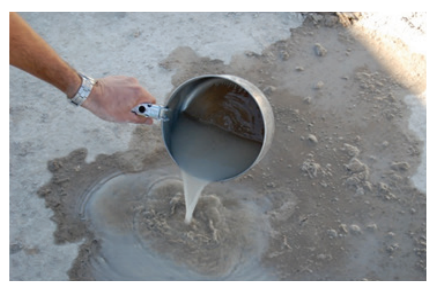

Illustration of soil on sieve

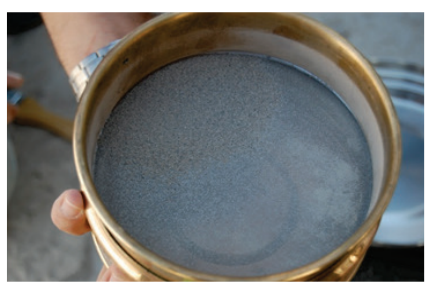

Ignite burner

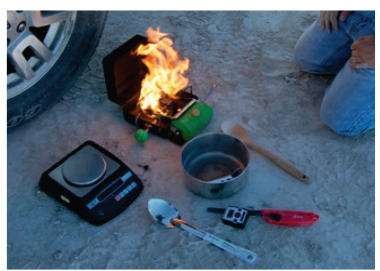

Stirring sample for 20 sec.

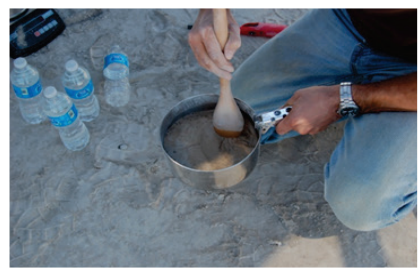

4. Redry washed sample

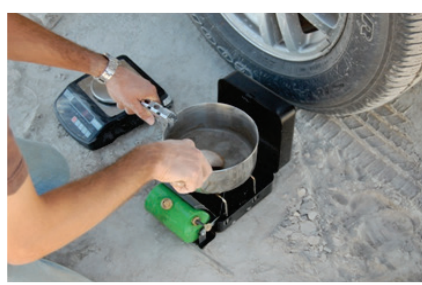

Weigh each sieve full

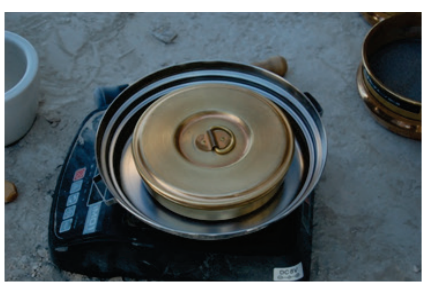

6. Prepare soil for plastic limit test

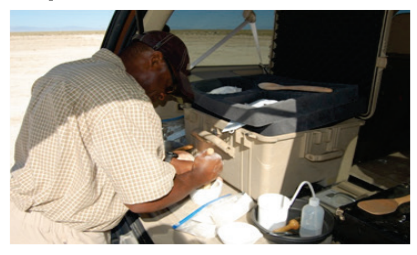

Example of proper thread

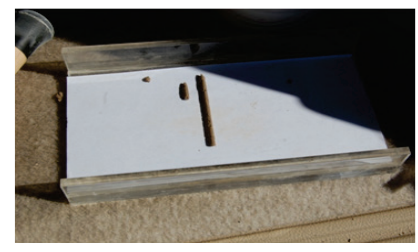

7. Perform plastic limit

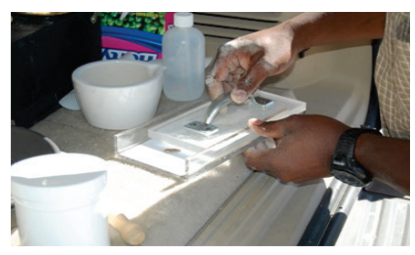

8. Establish soil texture

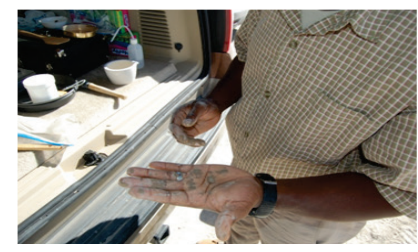


In the D-RSAK, after drying, the intial sample had to be processed to release fines from coarse aggregate as well as grinding of material down to its smallest native particle size. This was a long task, often longer than the wash technique, and yielded much fewer fines. Handling of the soil, lack of proper fine removal from aggregae, and improper grinding techniques often led to loss of fines and/or creation of improper grain sizes in friable soils that collapsed during the grinding process. The wash technique removes much of this burden on the user, only requiring judgment as to when to stop the decanting process. Any remaining fines in the original sample that have not been decanted can then easily be ground when dried and captured in the sieve stack.

\subsection{Software}

The software for the W-RSAK was rewritten from the D-RSAK version to account for the changes in procedure found in the wet-based approach. The base algorithms for determining the moisture-density curves and CBR curves remained unchanged. Further, the software was implemented in a variety of methodologies to accommodate various IT scenarios. The original software was developed in a DotNet environment, which proved to be troublesome with ever-changing operating systems. The W-RSAK software was written in OpenGL to enable use on Android devices such as portable phones or tablets. It was also rewritten as a MatLab executable, so that it could be run on any PC or device that had a MatLab compiler installed on it. The MatLab version also ties in with the overarching CALDERA software requested by EOD and CALDERA Android applications. Figure 17 through Figure 17 illustrate the software operation of the MatLab executable for the steps outlined in Figure 11.

Once the user has completed entering the data into the software, an analysis window is displayed in either the Matlab or Android software. This window enables the user to display the grain size distribution (Figure 18) (ASTM D422 2007), select a moisture density curve at standard or modified proctor energy (Figure 19) (ASTM D698 2010), and display the California Bearing Ratio (CBR) (ASTM D1883 2016) value of a compacted soil in standard or modified energy in either soaked or unsoaked conditions (Figure 20). The grain size curve is the key element employed by the EOD teams. The construction guidance is of more value to engineering and field design. The algorithms used to calculate the construction curves are provided in Berney and Wahl (2008). 
Figure 12. Introductory screen to begin RSAK data input in Matlab executable.

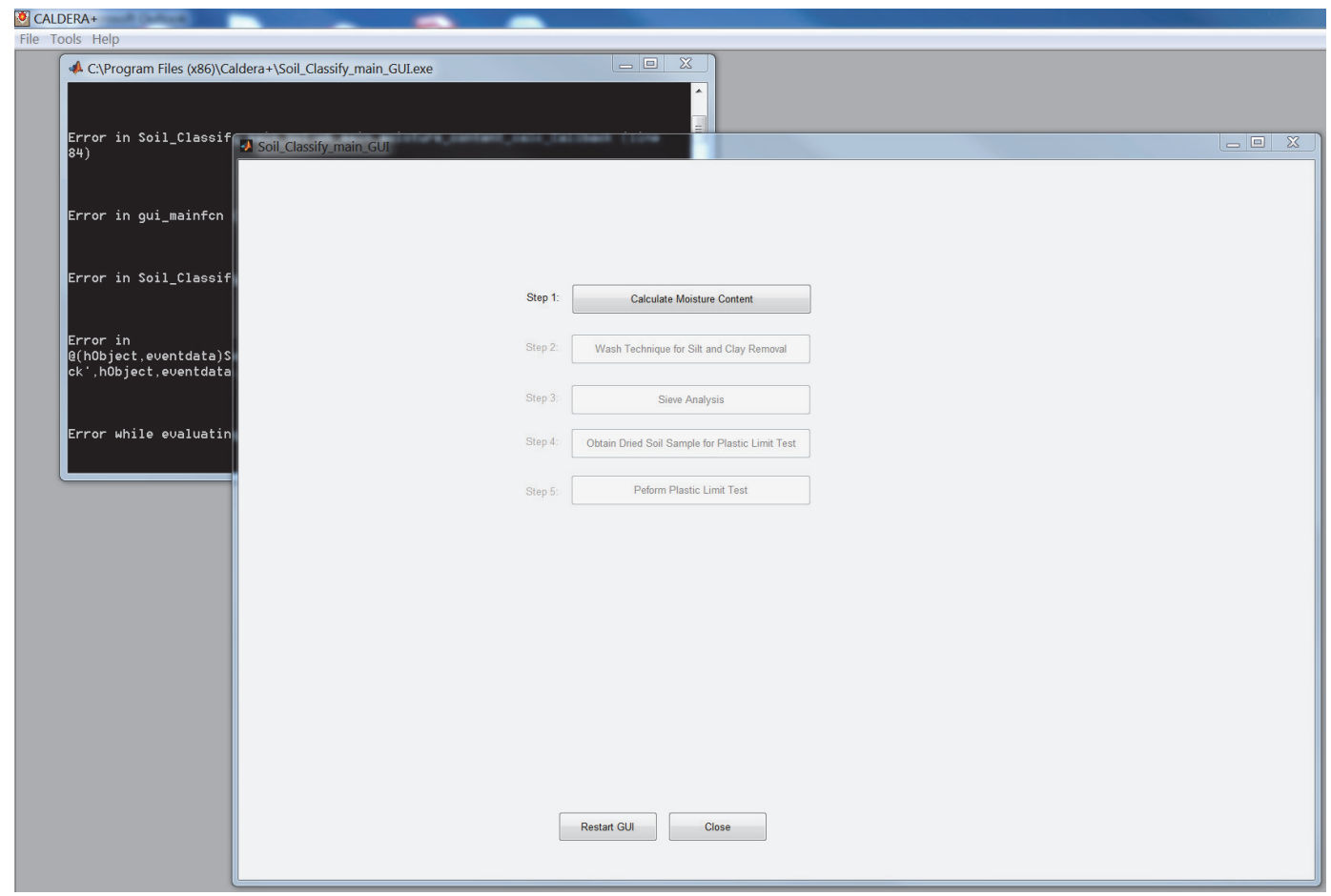

Figure 13. Determination of initial moisture content of soil.

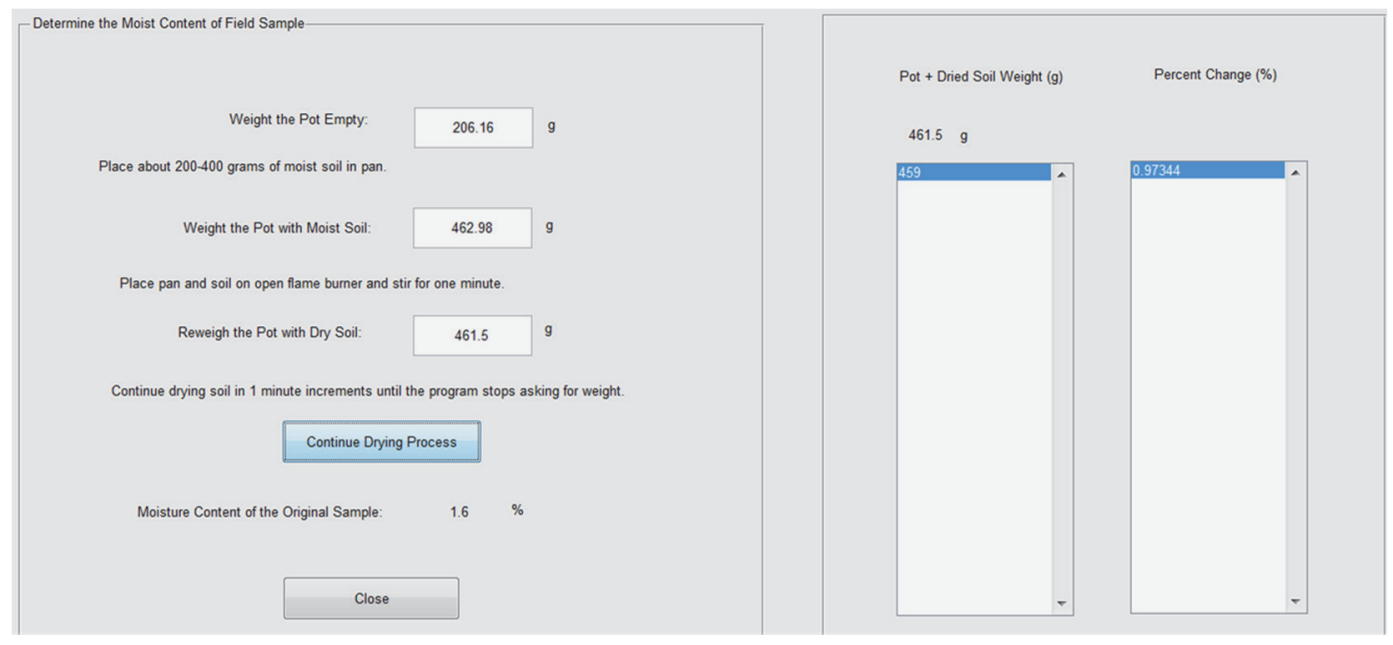


Figure 14. Drying of washed soil to prepare for sieve analysis.

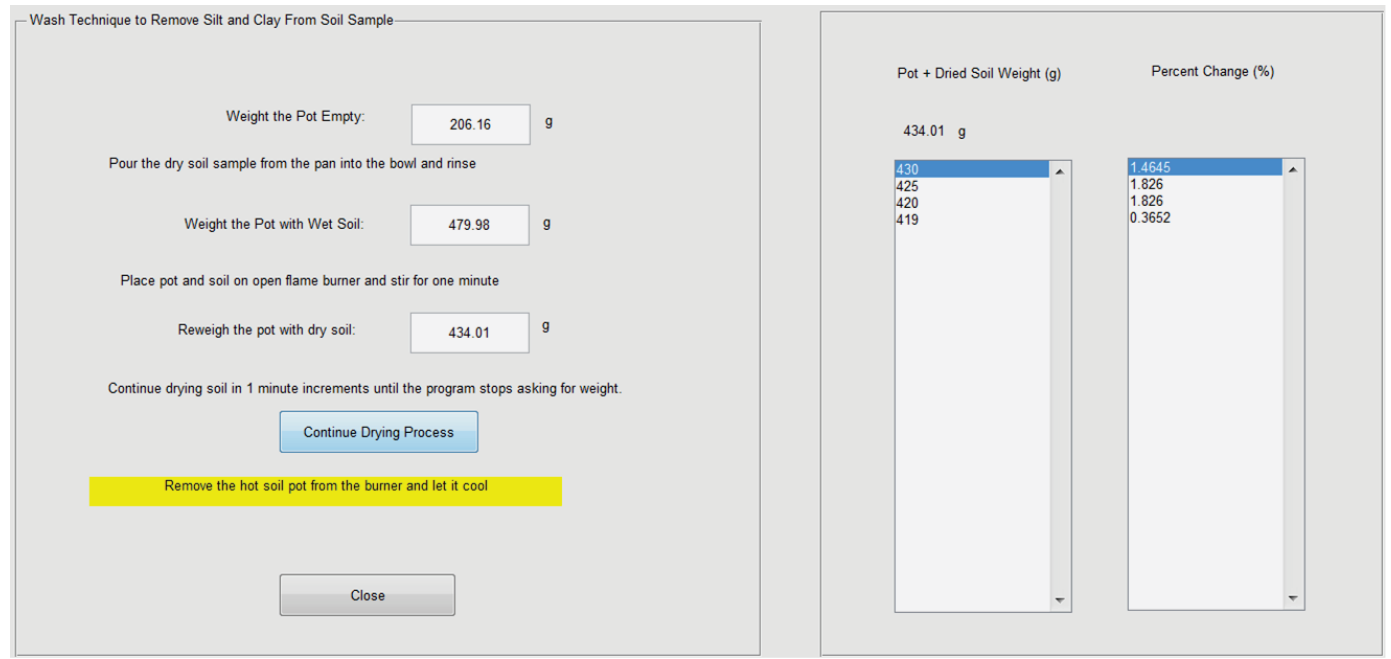

Figure 15. Input of sieve weights empty and after soil has been introduced.

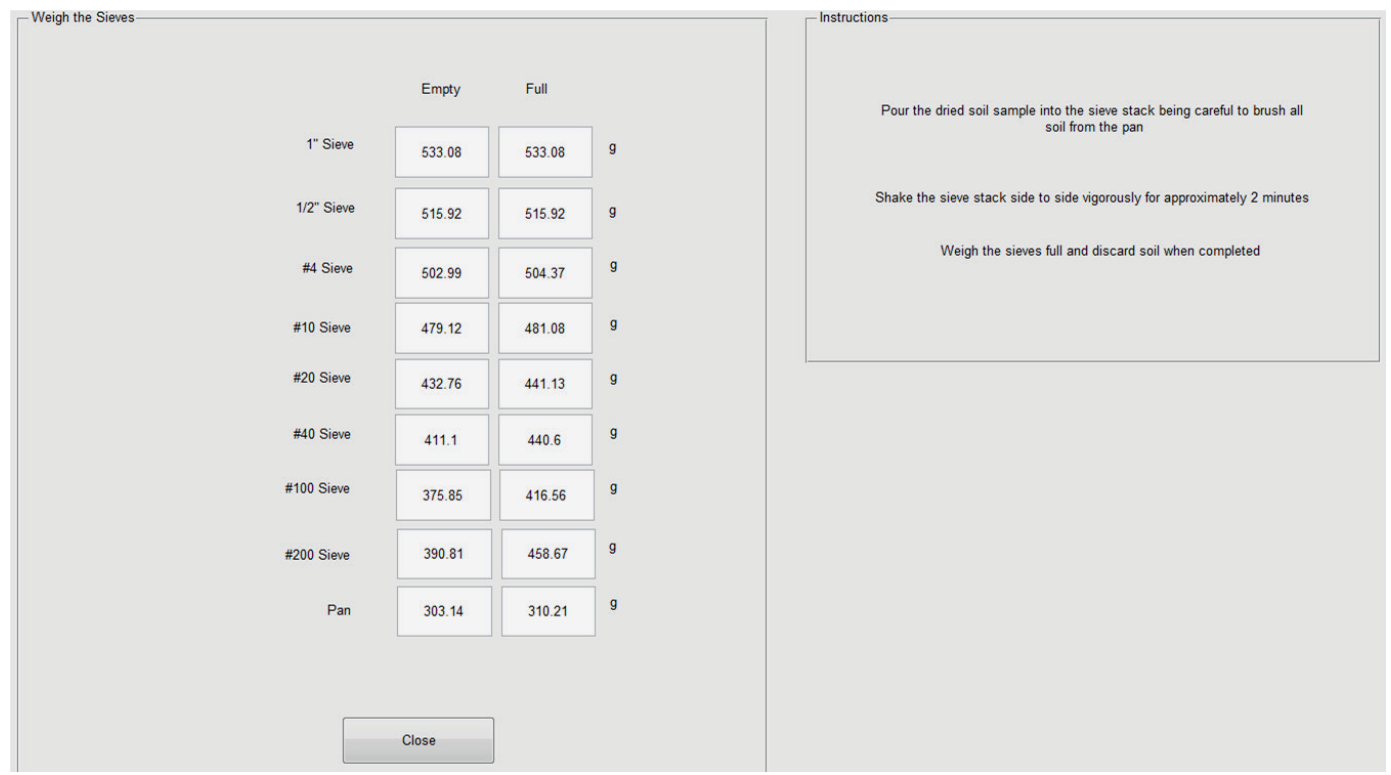


Figure 16. Determination of plastic limit by weighting rolled threads.

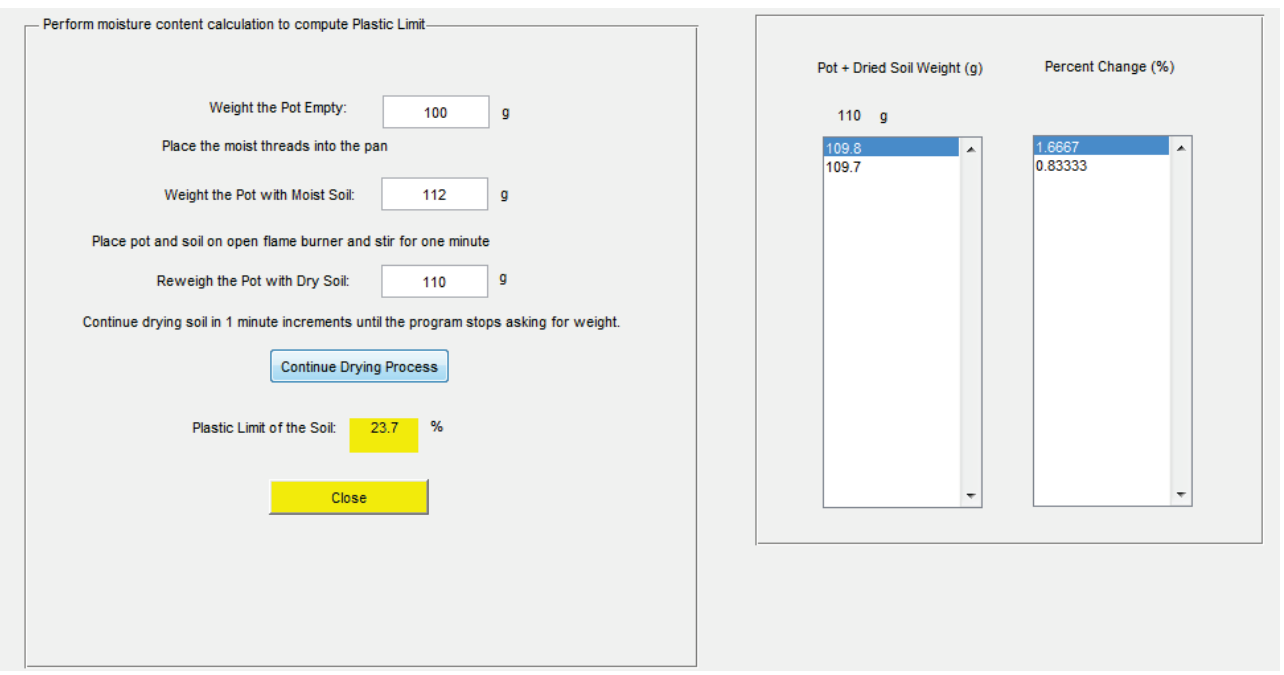

Figure 17. Final input screen in RSAK to determine texture and output final USCS classification and index properties.

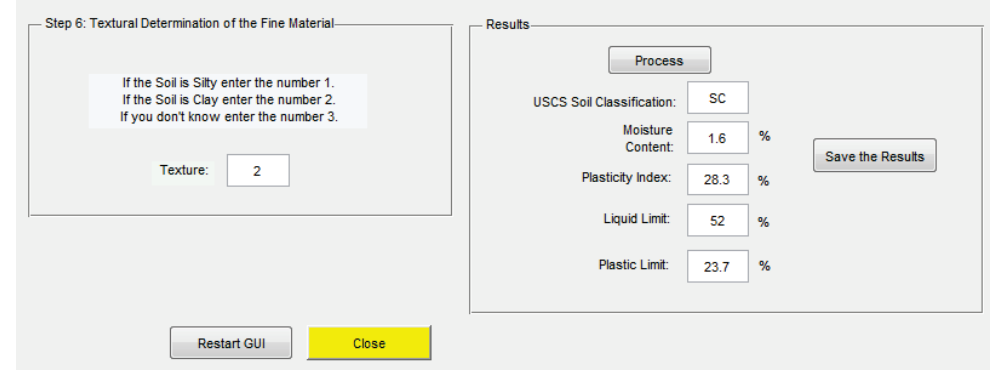

Figure 18. Data analysis window demonstrating grains size distribution curve.

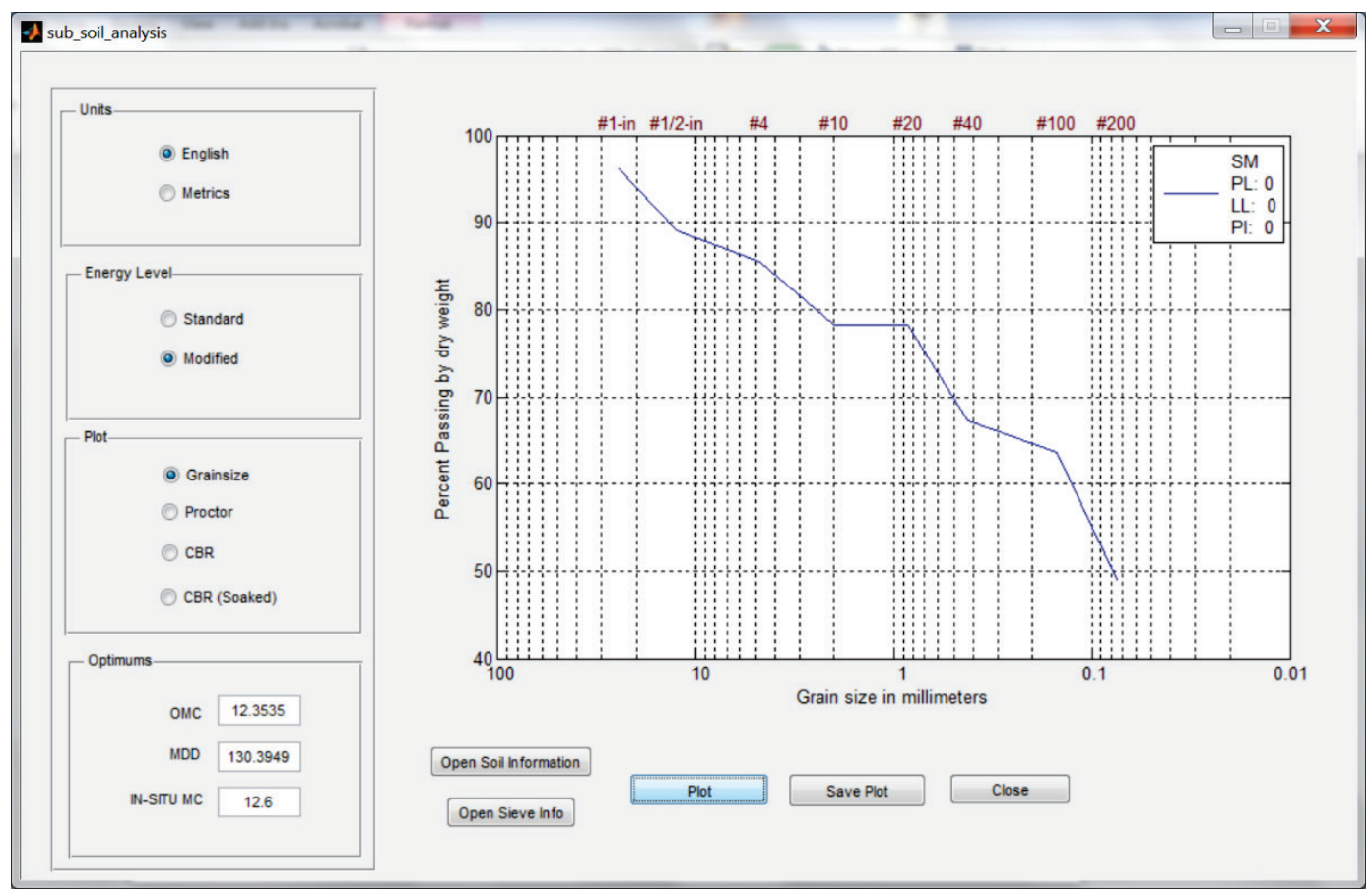


Figure 19. Data analysis window displaying modified proctor density curve.

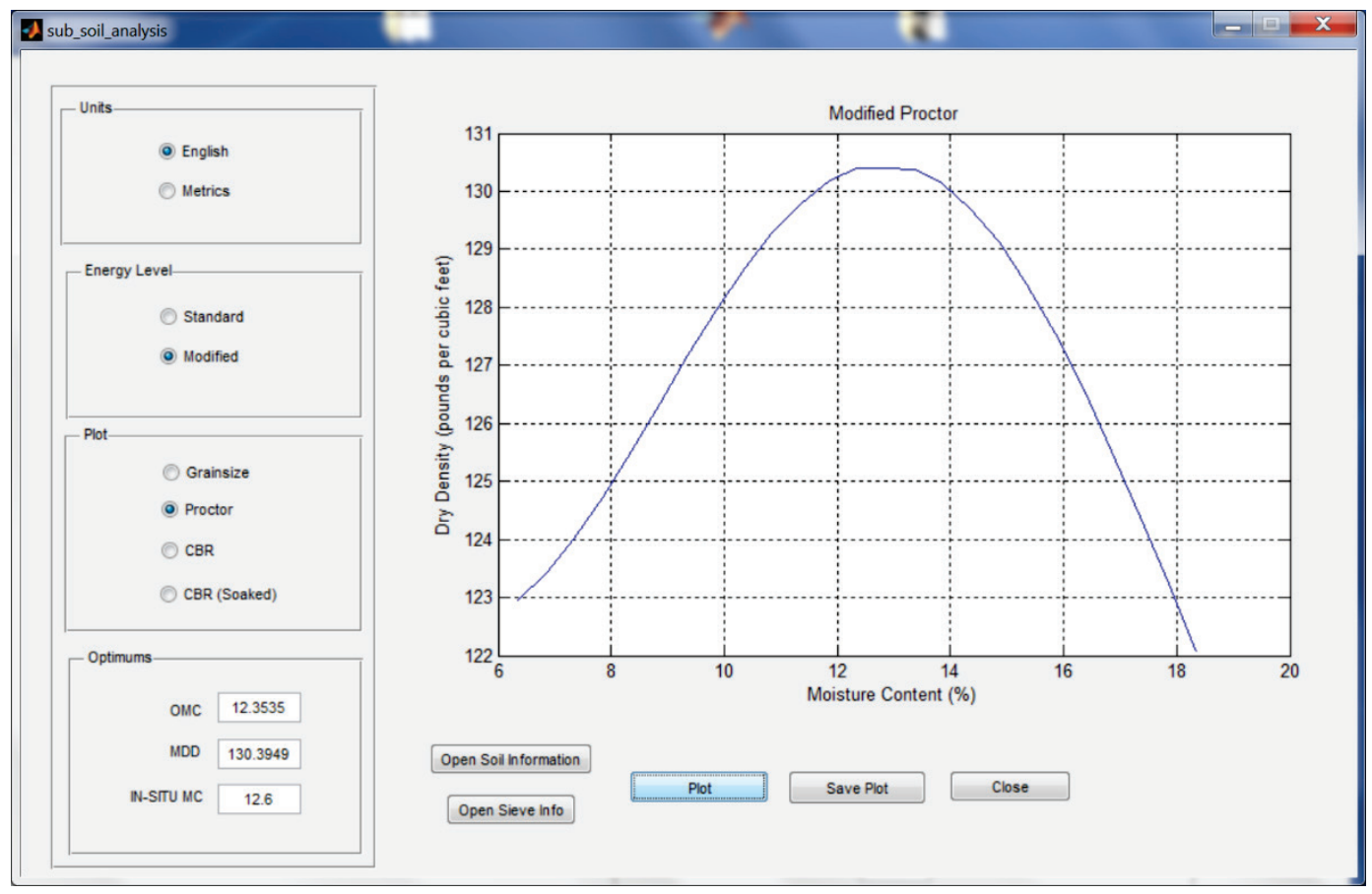

Figure 20. Data analysis window displaying modified proctor CBR curve.

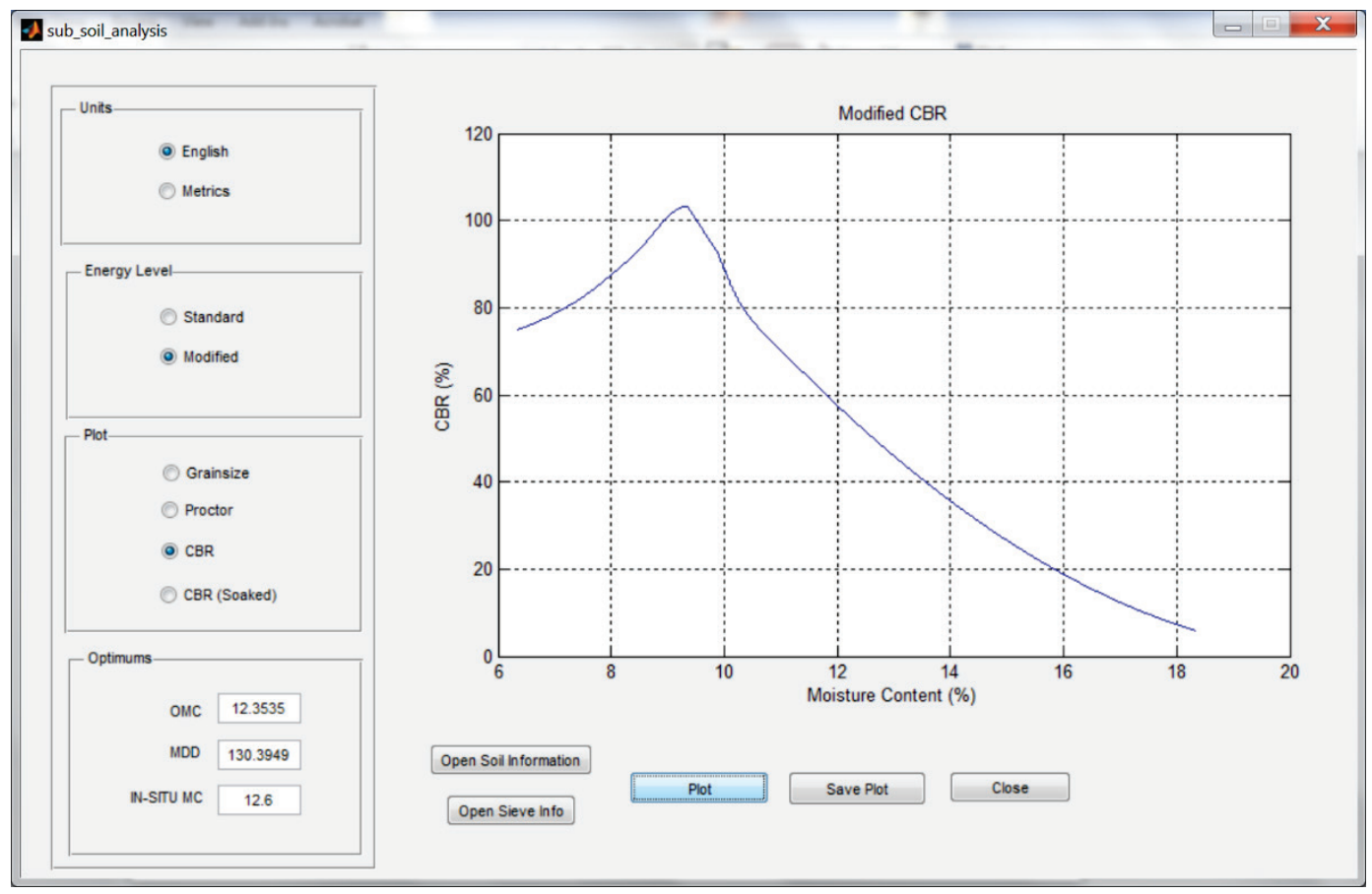




\section{Experimentation}

\subsection{Soils tested}

To determine the accuracy of the W-RSAK versus the D-RSAK technique, a series of 14 soils ranging from coarse grained to fine grained were selected (Table 3). Most of the soils tested had significant fine-grained material, as these soils represented the greatest limitation between past performances of the D-RSAK technique to the ASTM procedure. Maximum Dry Density (MDD) and Optimum Moisture Content (OMC) were determined from the standard proctor compaction effort (ASTM D698 2012).

Table 3. Summary of soil properties tested.

\begin{tabular}{|c|c|c|c|c|c|c|c|c|c|c|}
\hline \multirow{2}{*}{$\begin{array}{l}\text { Soil } \\
\text { ID }\end{array}$} & \multirow[b]{2}{*}{ Description } & \multicolumn{3}{|c|}{ Atterberg Limits } & \multicolumn{3}{|c|}{$\begin{array}{l}\text { Grain size } \\
\text { (percent by weight) }\end{array}$} & \multirow{2}{*}{$\begin{array}{l}\text { MDD } \\
\text { (pcf) }\end{array}$} & \multirow{2}{*}{$\begin{array}{c}\mathrm{OMC} \\
(\%)\end{array}$} & \multirow[b]{2}{*}{$\mathrm{G}_{\mathrm{s}}$} \\
\hline & & LL & $\mathrm{PL}$ & PI & Fines & Sand & Gravel & & & \\
\hline CL-1 & $\begin{array}{l}\text { Sandy Clay } \\
\text { (CL) }\end{array}$ & 27 & 13 & 14 & 56.9 & 42.1 & 1 & 119.5 & 12.0 & 2.67 \\
\hline CL-2 & $\begin{array}{l}\text { Sandy Clay } \\
\text { (CL) }\end{array}$ & 39 & 11 & 28 & 64.1 & 34.0 & 1.9 & 115.5 & 14.2 & 2.72 \\
\hline SC-1 & $\begin{array}{l}\text { Clayey Sand } \\
\text { (SC) }\end{array}$ & 31 & 12 & 19 & 40.0 & 55.0 & 5 & 122.3 & 10.9 & 2.71 \\
\hline $\mathrm{CH}-2$ & $\begin{array}{l}\text { Clay with sand } \\
(\mathrm{CH})\end{array}$ & 56 & 23 & 33 & 82.0 & 17.6 & 0.4 & 92.3 & 25.9 & 2.76 \\
\hline SC-2 & $\begin{array}{l}\text { Clayey Sand } \\
\text { (SC) }\end{array}$ & 25 & 14 & 11 & 32.1 & 66.0 & 1.9 & 122.8 & 11.3 & 2.69 \\
\hline $\mathrm{CH}-3$ & $\begin{array}{l}\text { Sandy Clay } \\
(\mathrm{CH})\end{array}$ & 36 & 14 & 22 & 64.9 & 32.4 & 2.7 & 108.9 & 14.8 & 2.71 \\
\hline CL-3 & $\begin{array}{l}\text { Sandy Clay } \\
\text { (CL) }\end{array}$ & 21 & 13 & 8 & 55.4 & 40.5 & 3.8 & 126.6 & 9.4 & 2.70 \\
\hline $\begin{array}{l}\mathrm{CH}- \\
\text { ERDC }\end{array}$ & Clay $(\mathrm{CH})$ & 73 & 24 & 49 & 95.1 & 4.9 & 0 & 85.7 & 24.6 & 2.76 \\
\hline $\mathrm{MH}$ & Silt $(\mathrm{MH})$ & 109 & 72 & 37 & 97.5 & 2.5 & 0 & 55.7 & 62.0 & 2.58 \\
\hline$M L$ & Silt (ML) & \multicolumn{3}{|c|}{ No Plasticity } & 87.8 & 11 & 1.2 & 109.5 & 15.8 & 2.75 \\
\hline SP & Sand (SP) & \multicolumn{3}{|c|}{ No Plasticity } & 3.1 & 92 & 4.9 & 109.7 & 1.9 & 2.67 \\
\hline SM & Sandy Silt (ML) & \multicolumn{3}{|c|}{ No Plasticity } & 50.3 & 47 & 2.7 & 121.8 & 10.0 & 2.71 \\
\hline $\begin{array}{l}\text { SP- } \\
\text { SC }\end{array}$ & $\begin{array}{l}\text { Sand with Clay } \\
\text { and Gravel (SP- } \\
\text { SC) }\end{array}$ & 23 & 13 & 10 & 8.0 & 50.7 & 41.3 & 128.8 & 8.0 & 2.68 \\
\hline Lime & Gravel (GP-GM) & 15 & 12 & 3 & 6 & 41 & 53 & 136.3 & 6.8 & 2.68 \\
\hline
\end{tabular}




\subsection{Experimental procedure}

For each soil type, nine soil samples were obtained for W-RSAK, D-RSAK, and ASTM-based testing according to the tests outlined in Table 4. Three replicate sieve analyses were performed on each platform to provide a robust data set for statistical evaluation. Atterberg limits conducted by the ERDC Materials Test Center are considered the reference standard for the expedient lab plastic limit tests conducted in the RSAK instances. Therefore, only six replicate plastic limit tests were conducted -- three each for the Dry and Wet procedures.

Table 4. Standard laboratory tests conducted for soil classification.

\begin{tabular}{|l|l|l|}
\hline Test Description & Standard Method & Properties Measured \\
\hline $\begin{array}{l}\text { Particle Size Analysis } \\
\text { (USCS Classification) }\end{array}$ & ASTM C 136 & $\begin{array}{l}\text { - \% Passing 1", 1/2", \#4, \#10, \#20, } \\
\# 40, \# 100 \text { and \#200 sieves }\end{array}$ \\
\hline $\begin{array}{l}\text { Standard Proctor } \\
\text { Compaction Effort }\end{array}$ & ASTM D 698 & $\begin{array}{l}\text { - Maximum Dry Density (MDD) } \\
\text { - Optimum Moisture Content (OMC) }\end{array}$ \\
\hline Atterberg Limits & ASTM D 4318 & $\begin{array}{l}\text { - Plastic Limit (PL) } \\
\text { - Liquid Limit (LL) } \\
\text { - Plasticity Index (PI) }\end{array}$ \\
\hline USCS Soils Classification & ASTM D 2487 & - Engineering classification \\
\hline
\end{tabular}

Testing of all the samples was carried out by a single technician who had limited experience conducting these types of soil tests, representing an inexperienced field soldier with basic training in the RSAK technique. With repetition, the technician became more comfortable and efficient with the test procedure, but data were evaluated during testing by the engineer to ensure no bias was obtained due to initial versus final testing.

The ASTM procedure included obtaining three representative samples of each soil (Figure 21) using an appropriate size fraction based on maximum particle size, which typically was much larger than the 500-g or less sample used for each RSAK test sample (Figure 21), then washing the soils in a deep \#200 sieve under constant water pressure and oven drying specimens (ASTM D2216 2010) to obtain moisture contents and prepare soil for sieving (Figure 23 and Figure 24). Sieving was conducted using 8-in.-diameter sieves and a mechanical shaker. These procedures were in contrast to the RSAK procedures, which used 500-g or less sample sizes, drying conducted with a burner, washing in a pan and/or pulverizing, and all sieving conducted with 5 -in.-diameter sieves that are manually shaken on a tabletop or by hand. A summary of sieve data collected from the three methodologies is presented in Appendix C, Table 9. 
Figure 21. Three replicates of limestone soil ready for washing for ASTM grain size determination.

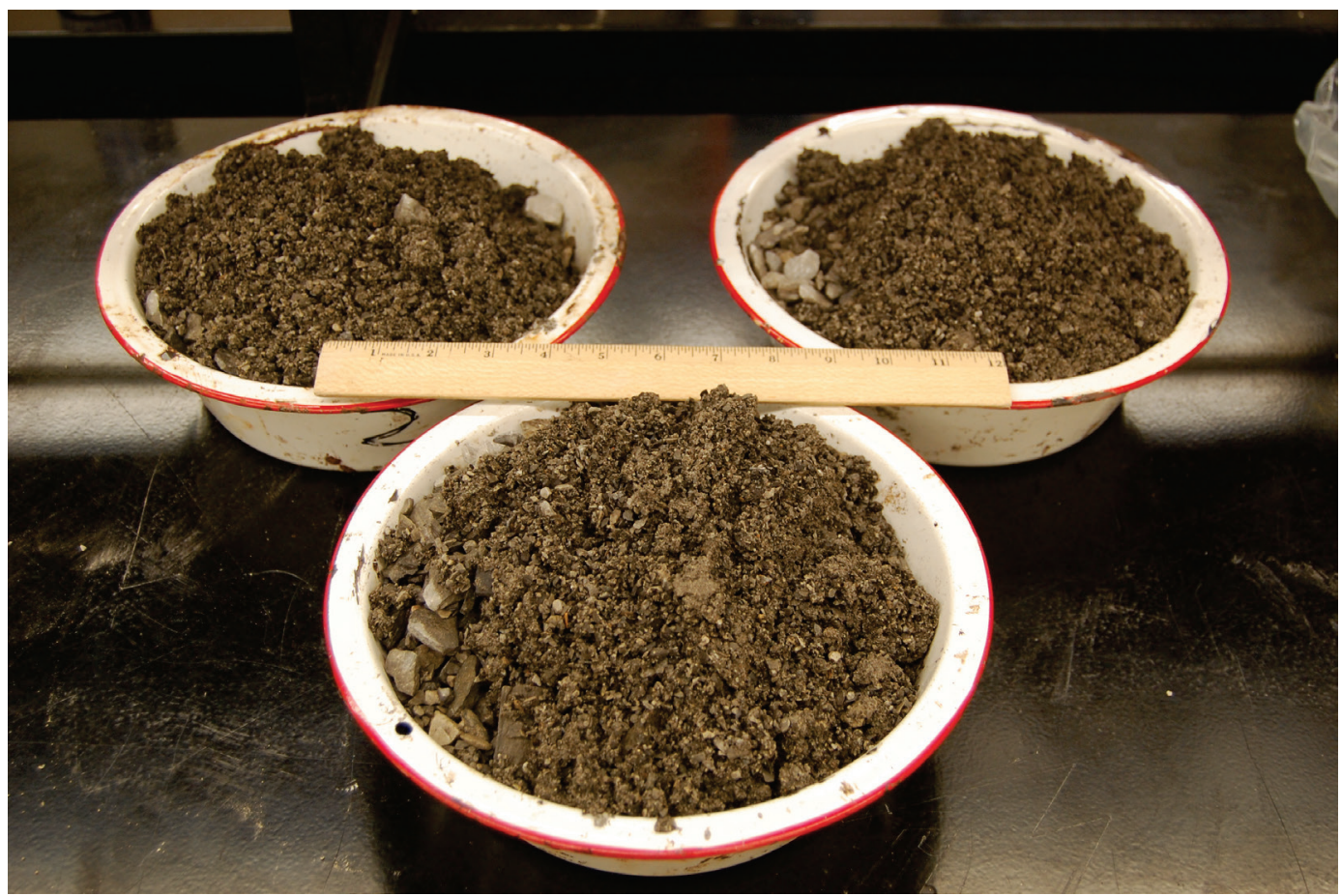

Figure 22. Clay gravel dried and after washing over \#200 sieve (note large ASTM sample size used versus a typical 500-g RSAK sample).

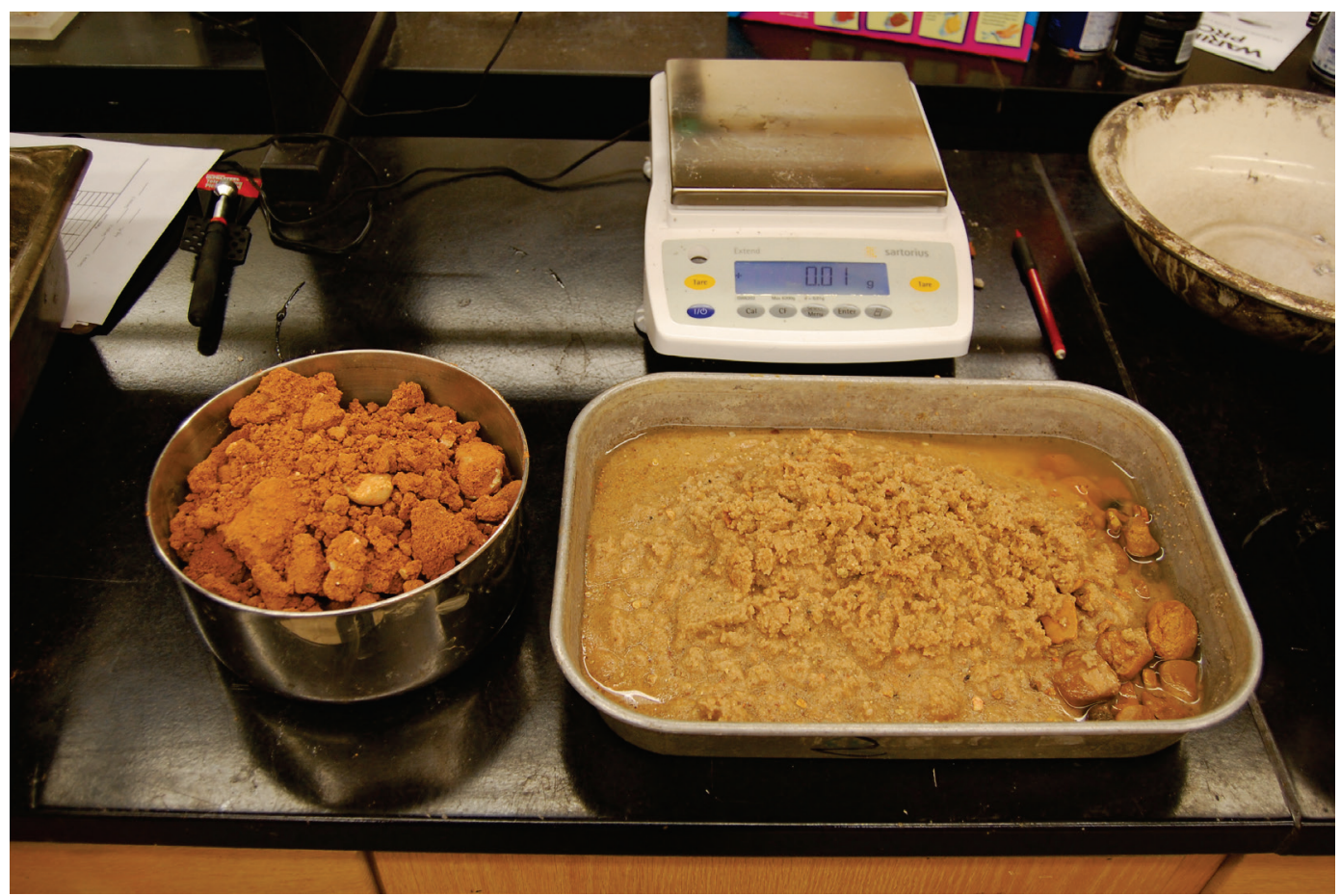


Figure 23. Washing fines in deep \#200 sieve for ASTM procedure.

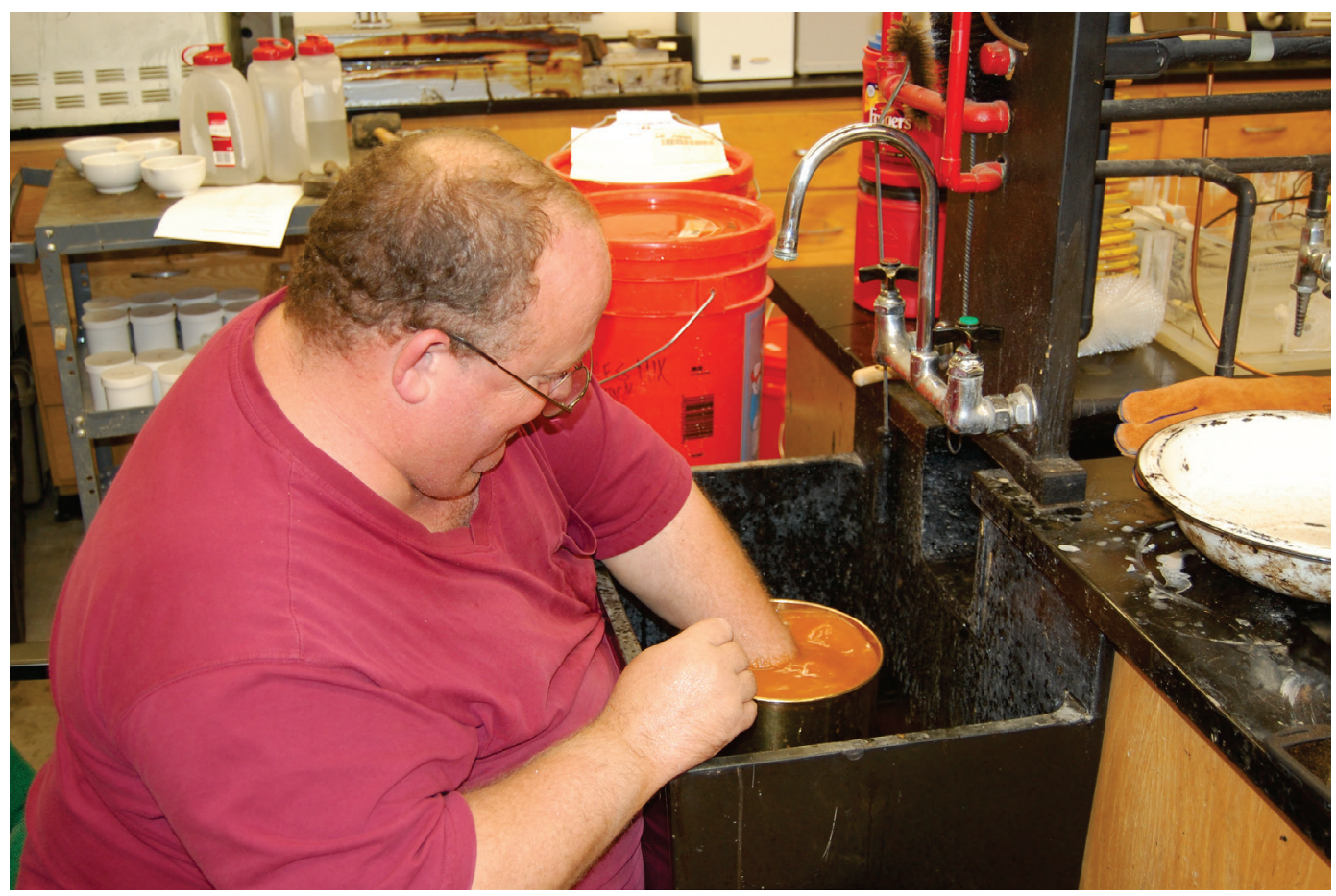

Figure 24. Oven drying limestone soil samples in large oven for at least $16 \mathrm{hr}$.

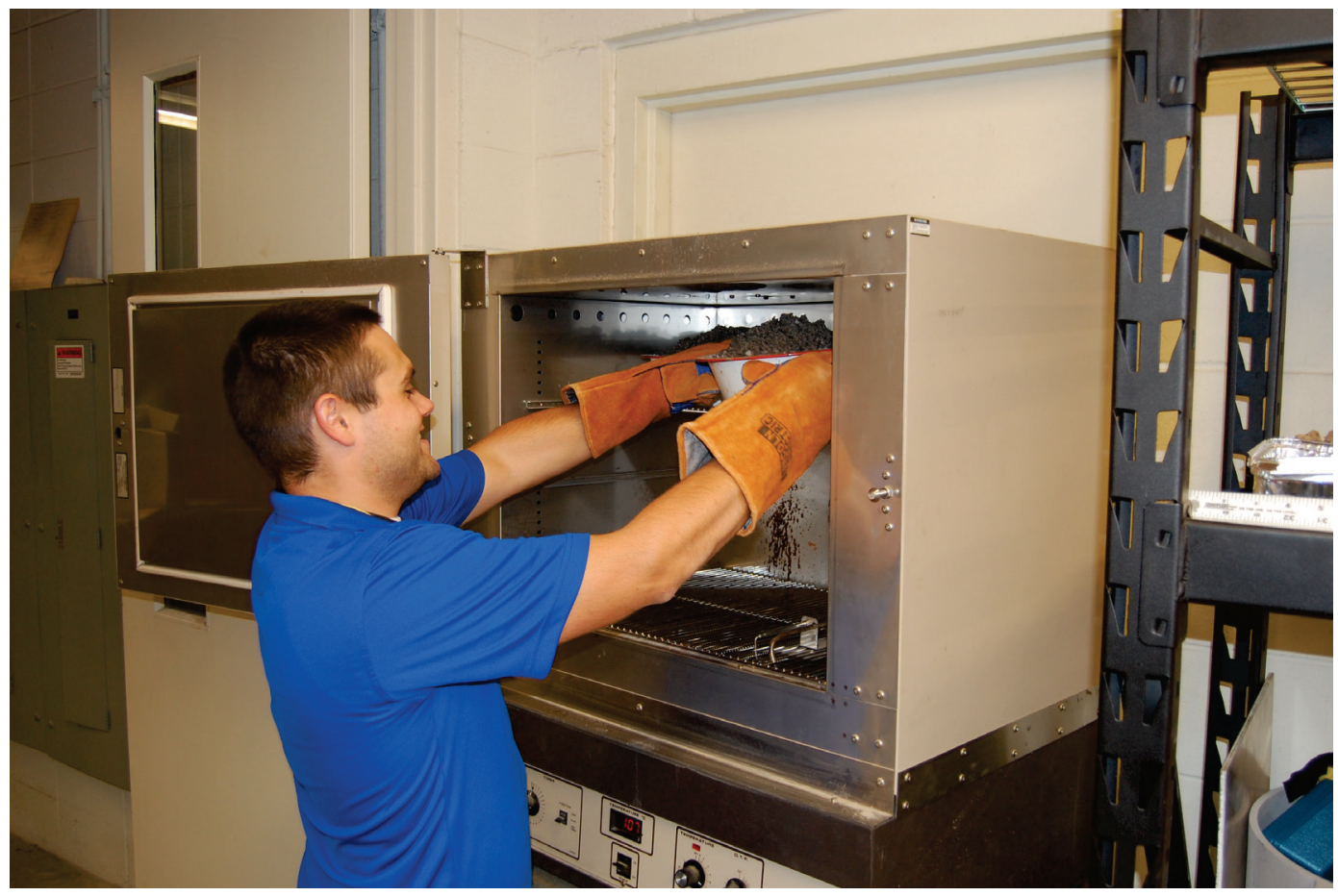


Adherence to ASTM procedures ensured that the best possible conditions were provided to obtain the gradation and classification; however, this study still exhibited differences in relation to the formal laboratory gradations shown in Appendix A. This might be explained due to sampling error or operator differential between technicians. Nonetheless, this demonstrates that even with careful soil preparation, sampling error can lead to gradation differences that can alter the eventual classification. 


\section{Data Analysis}

\subsection{Particle size distribution}

In determining the suitability of each technique to achieve the closest estimate of the ASTM grain size distribution and soil classification, the coefficient of determination, $\mathrm{R}^{2}$ (RSQ), was obtained for each sieve size across all 14 soils tested for both the dry- and wet-based procedures. Figure 25 illustrates that for sieves ranging from the \#40 and coarser (>0.42 $\mathrm{mm}$ ), the RSQ values are similar and high for each approach. This suggests that coarse soils sieve equally well using a variety of techniques. However, as soil size decreases below the $0.42-\mathrm{mm}$ threshold, there is a greater reduction in RSQ for the dry method than the wet, indicating increasing error compared to the ASTM method as summarized in Appendix C. The data suggest that the wet procedure produces a far better approximation of percent passing the smaller sieves than does the dry procedure and is able to be achieved in a much more reproducible fashion. This is primarily due to the inability to remove fine material stuck to larger, coarser aggregate and an inability to completely pulverize tightly bound clay material, which therefore behaves as fine sand.

Figure 25. Average Coefficient of Determination between ASTM and RSAK sieve methodologies by sieve opening size for all soils tested.

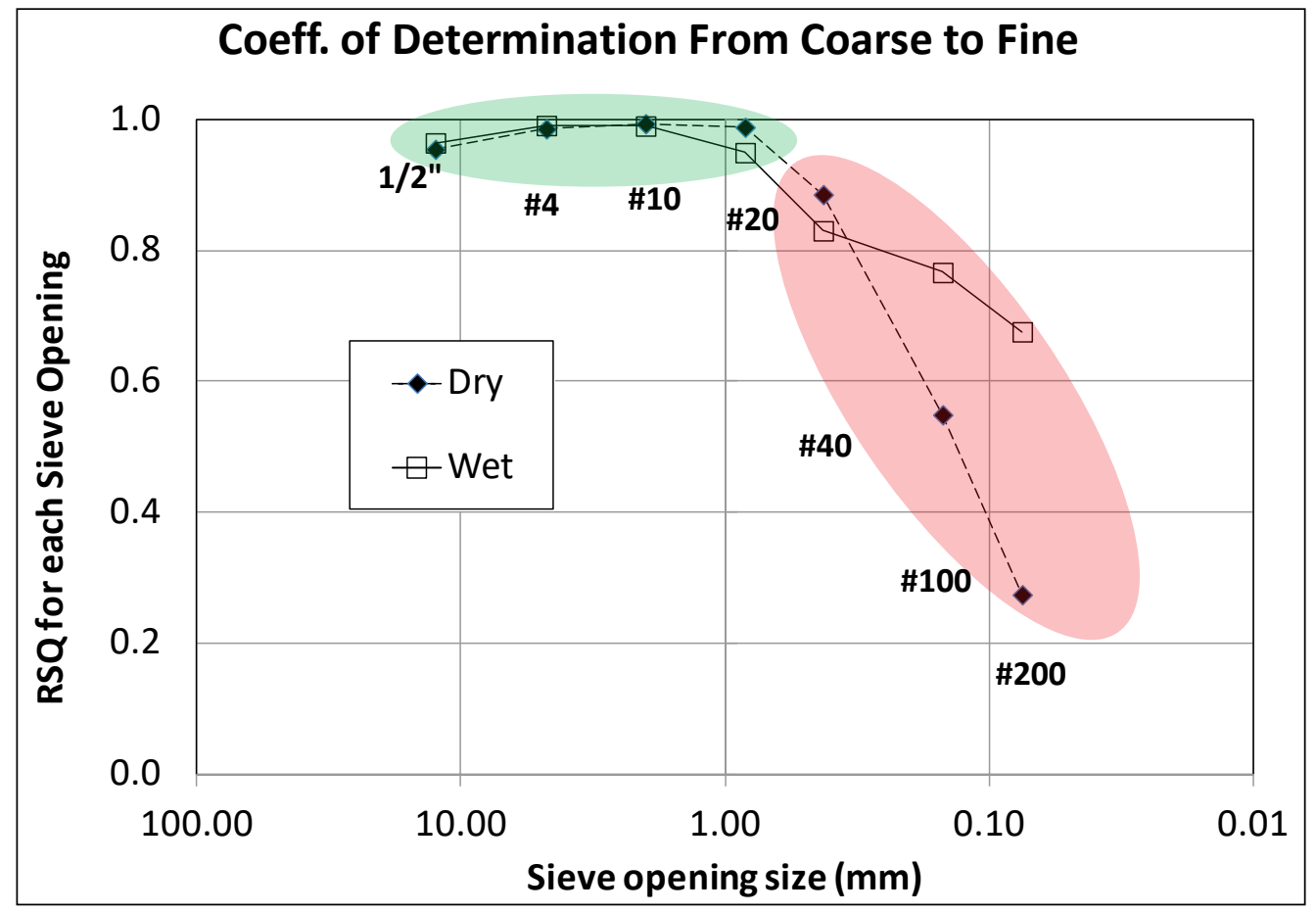




\subsection{Atterberg limits}

The plastic limit was determined by rewetting a portion of dried soil and rolling threads using the plastic limit roller. Table 5 shows the comparison between the laboratory Atterberg limits and the RSAK determination for the soils that exhibited plasticity. In the laboratory approach, plastic limit and liquid limit are determined independently. In the RSAK only the plastic limit is determined independently, and the liquid limit is predicted based on correlations dependent on the silt or clay textural classification. Since there is no difference in soil preparation between the dry and wet RSAK procedures, the average of all six independent plastic limit tests are presented in Table 5. Table 6 shows the accuracy of the RSAK approach when comparing either all six tests as independent data points to the laboratory values (Total) or the average of the six tests (Average) to the laboratory values. There is some variation between the two RSAK methods, but the variation is not a function of procedure, rather operator variability at time of testing. An RSQ of $94 \%$ for both the plastic limit and prediction of the liquid limit produced an $83 \%$ correlation to the plasticity index, which is the principal value for identifying soil classification. This suggests the RSAK approach is a good estimator of Atterberg limits when time constraints prevent use of the liquid limit.

Table 5. Atterberg limit comparison between laboratory and RSAK methods.

\begin{tabular}{|l|c|c|c|c|c|c|}
\hline \multirow{2}{*}{$\begin{array}{l}\text { Toil } \\
\text { Type }\end{array}$} & \multicolumn{3}{|c|}{ Laboratory } & \multicolumn{3}{c|}{ RSAK } \\
\hline CL-1 & 27 & $\mathrm{PL}$ & $\mathrm{Pl}$ & $\mathrm{LL}$ & $\mathrm{PL}$ & $\mathrm{PI}$ \\
\hline CL-2 & 39 & 13 & 14 & 24 & 13 & 12 \\
\hline SC-1 & 31 & 12 & 28 & 29 & 15 & 14 \\
\hline CH-2 & 56 & 23 & 33 & 59 & 26 & 33 \\
\hline SC-2 & 25 & 14 & 11 & 26 & 14 & 13 \\
\hline CH-3 & 36 & 14 & 22 & 31 & 16 & 15 \\
\hline CL-3 & 21 & 13 & 8 & 25 & 13 & 12 \\
\hline CH-ERDC & 73 & 24 & 49 & 79 & 32 & 46 \\
\hline
\end{tabular}

Table 6. RSQ summary from Atterberg limit comparison.

\begin{tabular}{|r|c|c|c|c|c|}
\hline \multicolumn{7}{|c|}{ RSQ for Atterberg Limits } \\
\hline & \multicolumn{2}{|c|}{ Wet-RSAK } & \multicolumn{2}{c|}{ Dry-RSAK } & All Data \\
\cline { 2 - 6 } & Total & Average & Total & Average & Average \\
\hline Plastic Limit & 0.874 & 0.900 & 0.888 & 0.939 & $\mathbf{0 . 9 3 5}$ \\
\hline Liquid Limit & 0.861 & 0.886 & 0.940 & 0.958 & $\mathbf{0 . 9 3 5}$ \\
\hline Plastcity Index & 0.759 & 0.781 & 0.832 & 0.852 & $\mathbf{0 . 8 2 6}$ \\
\hline
\end{tabular}




\subsection{Compaction indices}

Once the particle size distribution and Atterberg limit information is obtained from the field sample, the RSAK software estimates the optimum moisture content (OMC), the maximum dry density (MDD), and the associated moisture-density curves for that soil type at standard and modified proctor energy. In this experiment, the standard proctor energy compaction test (ASTM D698) was the basis for comparison between the RSAK output and the laboratory values shown in Table 7.

Table 7. Comparison of optimum moisture content and maximum dry density between laboratory and RSAK methods.

\begin{tabular}{|c|c|c|c|c|c|c|c|c|}
\hline \multirow{3}{*}{$\begin{array}{l}\text { Soil } \\
\text { Type }\end{array}$} & \multicolumn{4}{|c|}{ Maximum Dry Density } & \multicolumn{4}{|c|}{ Optimum Moisture Content } \\
\hline & \multirow[b]{2}{*}{ Laboratory } & \multicolumn{3}{|c|}{ Predicted } & \multirow[b]{2}{*}{ Laboratory } & \multicolumn{3}{|c|}{ Predicted } \\
\hline & & ASTM & Wet & Dry & & ASTM & Wet & Dry \\
\hline Sand & 109.2 & 116.4 & 116.3 & 116.8 & 9.8 & 10.8 & 10.7 & 10.4 \\
\hline SM & 121.8 & 124.4 & 123.1 & 120.3 & 10 & 12.9 & 12.8 & 10.7 \\
\hline SP-SC & 128.8 & 126.4 & 125.8 & 128.8 & 8 & 8.6 & 8.7 & 7.5 \\
\hline Lime & 135.9 & 136.1 & 136.3 & 136.6 & 5.2 & 5.3 & 6.8 & 5.1 \\
\hline SC-1 & 122.3 & 120.8 & 123.2 & 119.0 & 10.9 & 11.1 & 10.0 & 11.6 \\
\hline SC-2 & 122.8 & 118.5 & 118.8 & 116.5 & 11.3 & 11.7 & 11.5 & 12.3 \\
\hline $\mathrm{CH}$ (ERDC) & 85.7 & 94.0 & 98.4 & 95.7 & 24.6 & 24.3 & 22.3 & 23.0 \\
\hline $\mathrm{CH}-2$ & 92.3 & 101.2 & 102.1 & 100.2 & 25.9 & 20.7 & 20.0 & 20.6 \\
\hline $\mathrm{CH}-3$ & 108.9 & 116.3 & 115.6 & 113.8 & 14.8 & 13.3 & 13.3 & 13.9 \\
\hline $\mathrm{ML}$ & 109.5 & 124.7 & 121.1 & 116.8 & 15.8 & 17.0 & 15.5 & 13.7 \\
\hline CL-1 & 119.5 & 119.4 & 116.9 & 117.4 & 12 & 11.5 & 11.8 & 12.0 \\
\hline $\mathrm{CL}-2$ & 115.5 & 117.3 & 116.9 & 115.8 & 14.2 & 12.7 & 12.9 & 13.0 \\
\hline CL-3 & 126.6 & 122.3 & 120.4 & 120.3 & 9.4 & 10.2 & 10.7 & 10.7 \\
\hline Correlation & & 0.85 & 0.87 & 0.89 & & 0.92 & 0.94 & 0.95 \\
\hline
\end{tabular}

Using the regression analysis developed to predict MDD and OMC according to the guidance given in Berney and Wahl (2008), the appropriate sieve information from the ASTM, Dry RSAK method, and Wet RSAK method were input. The predicted MDD and OMC were calculated and compared to the laboratory results obtained from the standard proctor moisture-density curve. A coefficient of determination was calculated based on the 14 soil samples tested to compare the ability of the software and the influence that each sieve approach has on the overall prediction. It was found that little variation existed between approaches with RSQ values of the MDD varying between $85 \%$ and $89 \%$ and $92 \%$ to $95 \%$ for OMC. It is not obvious why the Dry-RSAK method exhibited the highest values and the ASTM the lowest, but for the particular soils tested, the error in transfer of particle gradations to a coarser mix influenced the calculation positively. It is not expected that this would be the case in all instances of the calculations and for all soils. Both the wet and dry RSAK 
approaches yielded almost identical RSQ, suggesting that the regression technique is applicable as an expedient estimate of the true moisturedensity curves.

\subsection{USCS classification}

While the Dry-RSAK method appears to show a slight advantage when determining $\mathrm{OMC}$ and MDD, a major consideration is its inability to properly obtain the soil classification from the grain size distribution. In Table 8, a comparison of the USCS classifications obtained from the laboratory the ASTM wash method and Wet and Dry RSAK methods shows that as the percentage of captured fines diminishes, the classification can change radically. For almost all soils tested with the D-RSAK, the classification falls between SP and SM, with only two of the clay samples having enough fines (5\% to $12 \%$ ) captured to reach the SP-SC category. The WRSAK performed much better, providing a clay classification for almost all soils with a laboratory clay classification. However, this technique was still unable to capture enough fines to reach a full $\mathrm{CH}$ and $\mathrm{CL}$ classification in most instances ( $>50 \%$ fines). The primary reason for the discrepancy is that the initial drying of the soil sample hardens small clay fractions into coarse granules that are difficult to disburse. The D-RSAK relies strictly on grinding and soils that are attached to truly coarse-grained materials cannot be ground away. The wash technique improves on this considerably by softening the hard granules, allowing them to be washed away; yet the heaviest clays still do not soften enough to disburse the clods. The ASTM and laboratory methods used water pressure and physical movement of the soil to wash the fines away; this led to a far better estimate of fines content, but is a technique that is often not available in the field. Subsequent investigations have shown that secondary grinding of the smaller sieved particles in the W-RSAK method can recover many of the granulated fines and provide a much better fines estimate than only washing can provide. 
Table 8. Comparison between USCS soil classifications between Laboratory, ASTM, and RSAK methods.

\begin{tabular}{|c|c|c|c|c|}
\hline \multirow{3}{*}{$\begin{array}{l}\text { Soil } \\
\text { Type }\end{array}$} & \multicolumn{4}{|c|}{ Classification } \\
\hline & \multirow[b]{2}{*}{ Laboratory } & \multicolumn{3}{|c|}{ Predicted } \\
\hline & & ASTM & Wet & Dry \\
\hline Sand & SP & SW-SM & SW & SW \\
\hline SM & $\mathrm{ML}$ & $\mathrm{ML}$ & SM & SM \\
\hline SP-SC & SP-SC & SP-SC & SC & SP \\
\hline Lime & GP-GM & SP-SM & SP-SM & SP \\
\hline SC-1 & SC & SC & $\mathrm{SC}$ & SP \\
\hline SC-2 & SC & $\mathrm{SC}$ & $\mathrm{SC}$ & SP \\
\hline $\mathrm{CH}$ (ERDC) & $\mathrm{CH}$ & $\mathrm{CH}$ & SC & SP \\
\hline $\mathrm{CH}-2$ & $\mathrm{CH}$ & $\mathrm{CH}$ & SC & SP \\
\hline $\mathrm{CH}-3$ & $\mathrm{CH}$ & $\mathrm{CL}$ & SC & SP \\
\hline $\mathrm{ML}$ & $\mathrm{ML}$ & $\mathrm{ML}$ & $\mathrm{ML}$ & SM \\
\hline CL-1 & $\mathrm{CL}$ & SC & SC & SP-SC \\
\hline CL-2 & $\mathrm{CL}$ & $\mathrm{CL}$ & $\mathrm{CL}$ & $\mathrm{SP}$ \\
\hline CL-3 & $\mathrm{CL}$ & $\mathrm{CL}$ & $\mathrm{SC}$ & SP-SC \\
\hline
\end{tabular}

The importance of obtaining the correct USCS classification with the RSAK software is that a proper shape and expanse of the compaction curve is dependent on this input variable. Even if the OMC and MDD are appropriately determined, if the wrong curve shape is chosen, then the user runs the risk of incorrectly estimating an appropriate moisture and compaction range to guide the construction process. This consideration demonstrates the primary limitation of the dry-RSAK method when dealing with cohesive soil types. For non-cohesive or low plasticity soils, the methodology works well but breaks down when dealing with medium plasticity soils. 


\section{Conclusions and Recommendations}

\subsection{Conclusions}

The wet-based RSAK was developed to provide a systematic means to furnish accurate grain size information and an ASTM-based USCS classification. Based off of the original ERDC designed RSAK using a drying and pulverizing methodology to reduce a field sample to a grain size fraction suitable for sieving, the wet-based RSAK uses a wash technique to eliminate fines and provide a better estimate of the fine-grained fraction of soil samples. Based off of series grain size experiments conducted on 14 soils of varying USCS classifications, the W-RSAK improved upon the dry RSAK's ability to capture fines content and was able to correctly identify the fines classification and overall classification of the soil far better than the dry RSAK. All of this was accomplished using a set of field equipment less than half the cube volume of the prior RSAK method and a stovepowered drying technique that enables the wet-RSAK to be completely self-contained in the field. An optional hot-plate drying technique can be employed with moisture content results equal to that of the traditional oven-dried technique.

\subsection{Recommendations}

For measurement of expeditionary soils, the use of the CALDERA expedient soil test and the wet-RSAK technology provides a thorough examination of the soil. With a few hours of training, soldiers can be prepared to provide soil classifications and engineering assessments of local materials in a matter of minutes. The data obtained from these tests provide insight to the analyst on soil properties and behavior useful in both forensic and construction analysis.

\subsection{Areas for future study}

In looking at the successes and limitations of the RSAK, several areas are available to improve both accuracy and deployment capabilities. The following outline the primary areas of concern for future research.

\subsubsection{Expedient liquid limit test}

Past research has been unable to identify a liquid limit test that can be performed in a compressed time frame on in-situ soil material. Any future 
research that can overcome this obstacle will provide a great benefit to the accuracy of the RSAK as error collected during prediction of the liquid limit carries through to errors in classification, in OMC and MDD prediction and strength prediction. Further, the liquid limit prediction requires the user to be familiar with the soil's texture, which may not be a simple task for a user who has had little contact with soil. This has been an enduring problem with the RSAK and one that is sorely needed to provide a complete suite of tests that adequately approximate ASTM methodologies and no longer necessitating familiarity with soil texture prior to use.

\subsubsection{Reduction in kit volume}

Due to the expeditionary nature of the RSAK, any reduction in cube volume is a desirable outcome of future research. As mobile military units are forced to carry greater amounts of equipment, making systems smaller and lighter enables adoption and deployment of new equipment to be more feasible. Custom-made sieves, a smaller heating device, smaller balance, and customized packaging all can make the system lighter and more portable. When every military service is presented the RSAK, the first question asked is always, "Can it be made smaller?" The W-RSAK is the answer to NGIC for the CALDERA program and an even smaller kit is on request by Air Force Special Operations Command. 


\section{References}

American Society for Testing and Materials (ASTM) International. 2006. Standard test method for sieve analysis of fine and coarse aggregates. Designation C 136. West Conshohocken, PA: American Society for Testing and Materials International.

. 2007. Standard test method for particle-size analysis of soils. Designation D 422-63. West Conshohocken, PA: American Society for Testing and Materials International.

2010. Standard test methods for laboratory determination of water (moisture) content of soil and rock by mass. Designation D 2216-10. West Conshohocken, PA: American Society for Testing and Materials International.

2010. Standard test methods for liquid limit, plastic limit, and plasticity index of soils. Designation D 4318. West Conshohocken, PA: American Society for Testing and Materials International.

2011. Standard practice for classification of soils for engineering purposes (unified soil classification system). Designation D 2487 West Conshohocken, PA: American Society for Testing and Materials International.

. 2012. Standard test methods for laboratory compaction characteristics of soil using standard effort. Designation D 698. West Conshohocken, PA: American Society for Testing and Materials International.

2004. Standard test method for materials finer than 75-um (No. 200) sieve in mineral aggregates by washing. Designation C 117-04. West Conshohocken, PA: American Society for Testing and Materials International.

2016. Standard Test Method for CBR (California Bearing Ratio) of LaboratoryCompacted Soils. Designation D1883-16. West Conshohocken, PA: American Society for Testing and Materials International.

. 2006. Standard Practice for Description and Identification of Soils (VisualManual Procedure). Designation D 2488-06. West Conshohocken, PA: American Society for Testing and Materials International.

Anderton, G. L., E. S. Berney IV, T. A. Mann, J. K. Newman, E. A. Baylot, D. K. Miller, and Q. Mason. 2008. Joint Rapid Airfield Construction (JRAC) 2007 technology demonstration. ERDC/GSL TR-08-17. Vicksburg MS: U.S. Army Engineer Research and Development Center.

Berney IV, E. S. and Wahl, R.E. 2008. A rapid soils analysis kit. ERDC/GSL TR-o8-3. Vicksburg, MS: U.S. Army Engineer Research and Development Center.

Berney, E. S., M. Mejías-Santiago, and J. D. Kyzar. 2013. Non-nuclear alternatives to monitoring moisture-density response in soils. ERDC/GSL TR-13-6. Vicksburg MS: U.S. Army Engineer Research and Development Center. 
Berney, E. S., Mejías-Santiago, M., and M. D. Norris. 2016. Validation testing of nonnuclear alternatives to measuring soil density. ERDC/GSL TR-16-28. Vicksburg MS: U.S. Army Engineer Research and Development Center.

Berney IV, E. S., J. D. Kyzar and L. O. Oyelami. 2011. Device comparison for determining field soil moisture content. ERDC/GSL TR-11-42. Vicksburg, MS: U.S. Army Engineer Research and Development Center.

Department of the Army. 2015. Materials Testing. Army Technical Manual TM 3-34.43. Ft. Leonardwood, MO.

Ehrgott, J. Jr., D. Rickman, J. Payne, W. Myers, Jr., C. Thomas, M. Adley, J. Windham, E. Berney, T. Waddell, T. C. Pratt, D. P. Danko, R. L. Talbott, Jr., W. McNeal, Jr., and C. W. Crowder. 2016. An introduction to the CALDERA forensic crater analysis program. ERDC TR-16-9. Vicksburg MS: U.S. Army Engineer Research and Development Center.

Ehrgott, J. Jr. 2011. Influence of soil properties on the above ground blast environment from a near-surface detonation. ERDC/GSL TR-11-28. Vicksburg MS: U.S. Army Engineer Research and Development Center.

Irwin, L. H. 2011. Elementary soil testing for gravel roads. Transportation Research Board Webinar. http://onlinepubs.trb.org/onlinepubs/webinars/111109.pdf

Paige-Green, P. 2011. The South African gravel roads test kit. Transportation Research Board Webinar. http://onlinepubs.trb.org/onlinepubs/webinars/111109.pdf

Troxler Electronic Laboratories, Inc. 2007. Application brief: Troxler Model 3430 Roadreader ${ }^{\mathrm{TM}}$ nuclear moisture density gauge. Station, TX: Texas Department of Transportation.

Windham, J. E., J. Q. Ehrgott, Jr., D. D. Rickman, J. E. Payne, W. S. Myers, E. S. Berney IV, T. C. Pratt, C. D. Thomas, Z. K. Crosby, and L. S. Duckworth. 2015. CALDERA: Postblast crater data collection and analysis. 4th Edition Guidebook. Vicksburg, MS: U.S. Army Engineer Research and Development Center. 


\section{Appendix A: Expanded Expedient Soil Classification}

The expedient soil classification system developed for the CALDERA program is a simplified method to distill the USCS system into a set of three basic categories each with two variants: Coarse = Gravel or Sand, Intermediate $=$ Intermediate Gravel or Intermediate Sand, and Fine $=$ Silt or Clay (Figure 26) (Ehrgott et al. 2016). This basic visual and textural classification system modeled after the Army Materials Testing Manual (TM 3.34-3, 2015) enables a rapid means to assign a soil classification that can characterize soil behavior during IED blast conditions. To make this procedure compatible with a USCS classification, a simple dissection of the grain size can lead the user to subdivide each of the general colored categories in Figure 26 into either a poorly or well-graded coarse soil (RED); a mixture with silt or clay (BLUE); or a high or low plasticity clay (GREEN). Figure 27 and Figure 28 illustrate this process using a color reference back to the original 6-soil classification at the conclusion of flowchart path. This provides 12 base USCS classifications including GW, GP, GM, GC, SW, SP, SC, SM, ML, MH, CL, and CH.

Figure 26. Simplified soil classification chart for CALDERA.

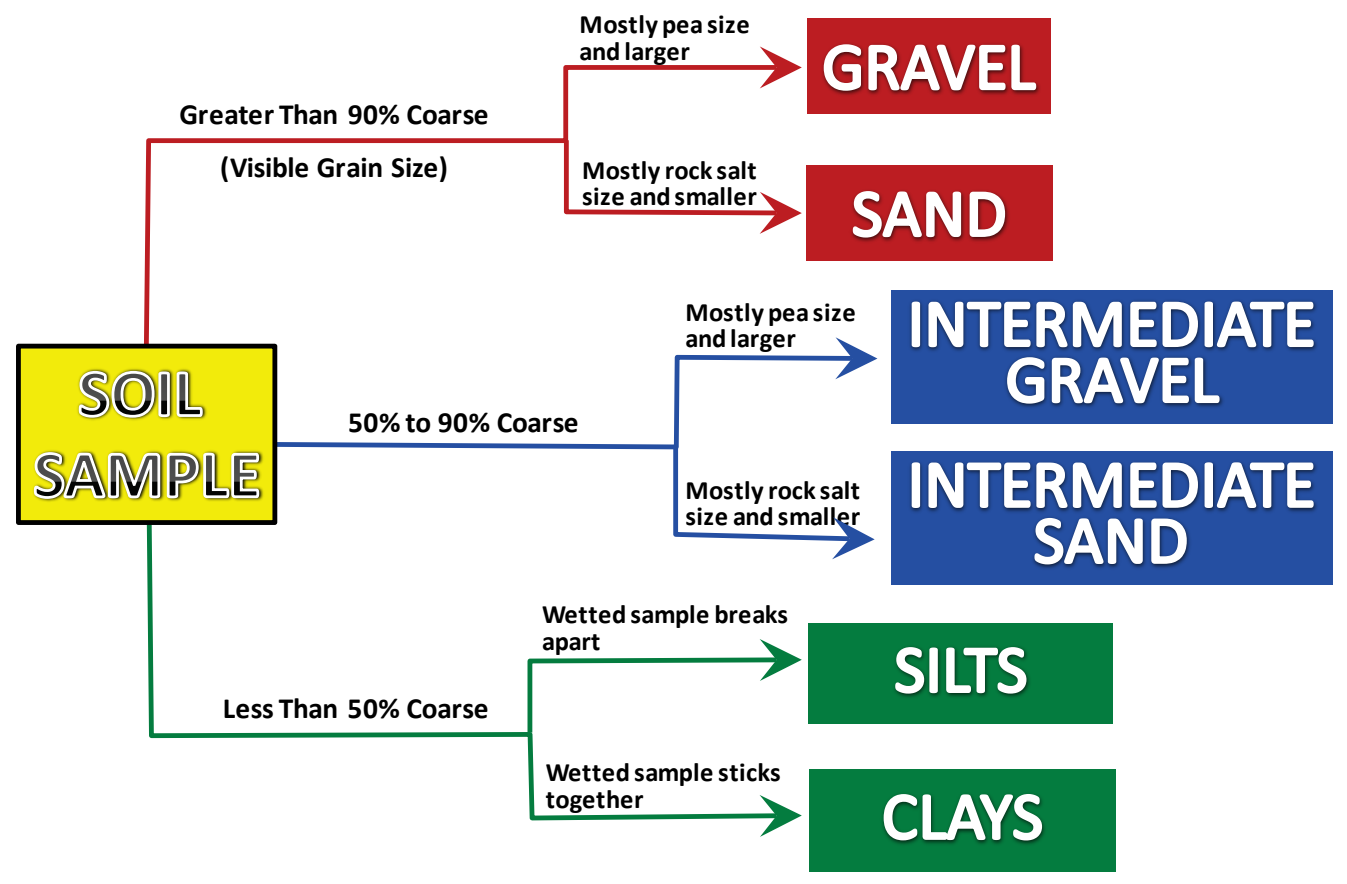


Figure 27. USCS classification breakdown for coarse-grained soils.

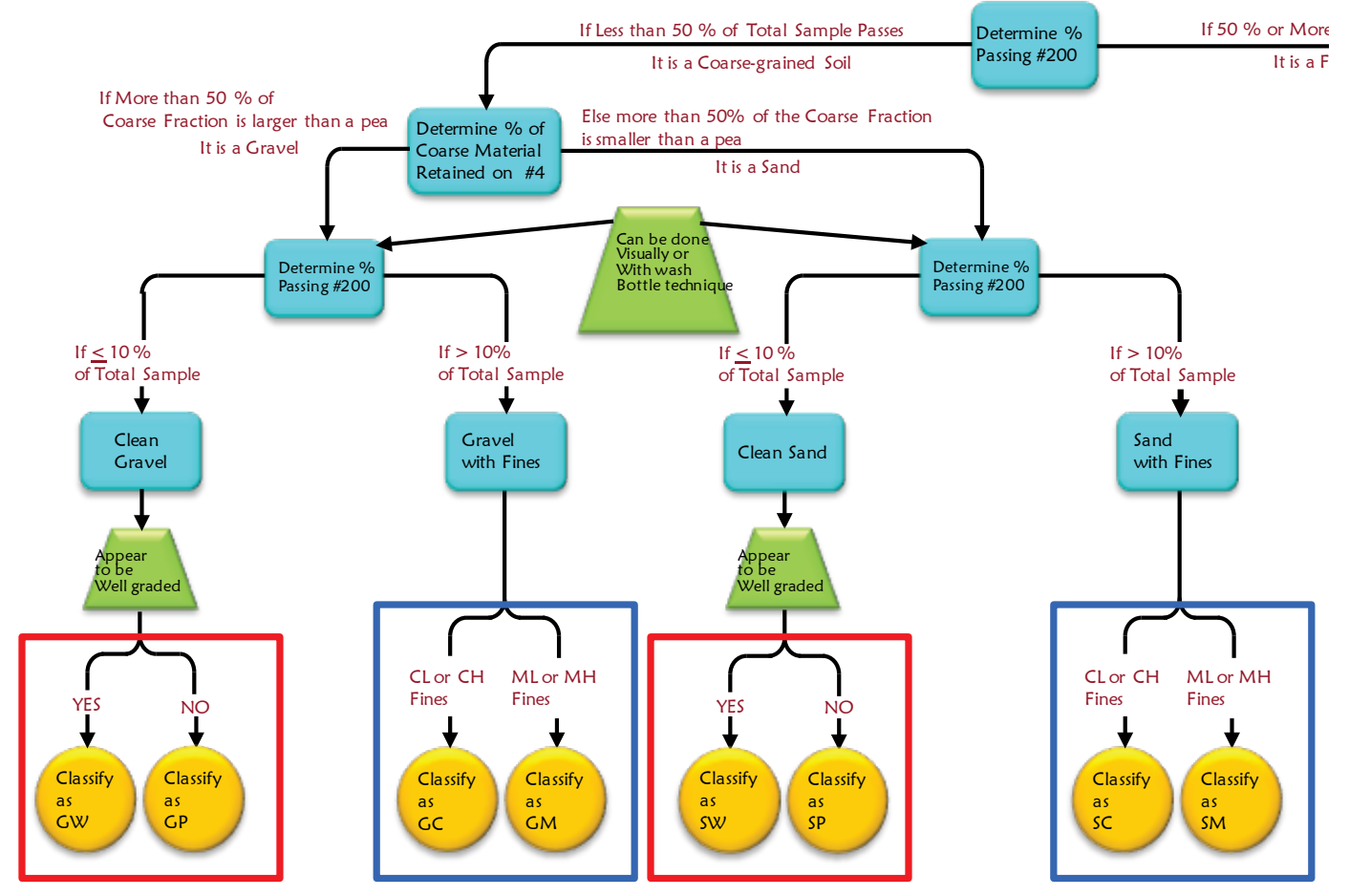


Figure 28. USCS classification breakdown for fine-grained soils based on textural analysis.

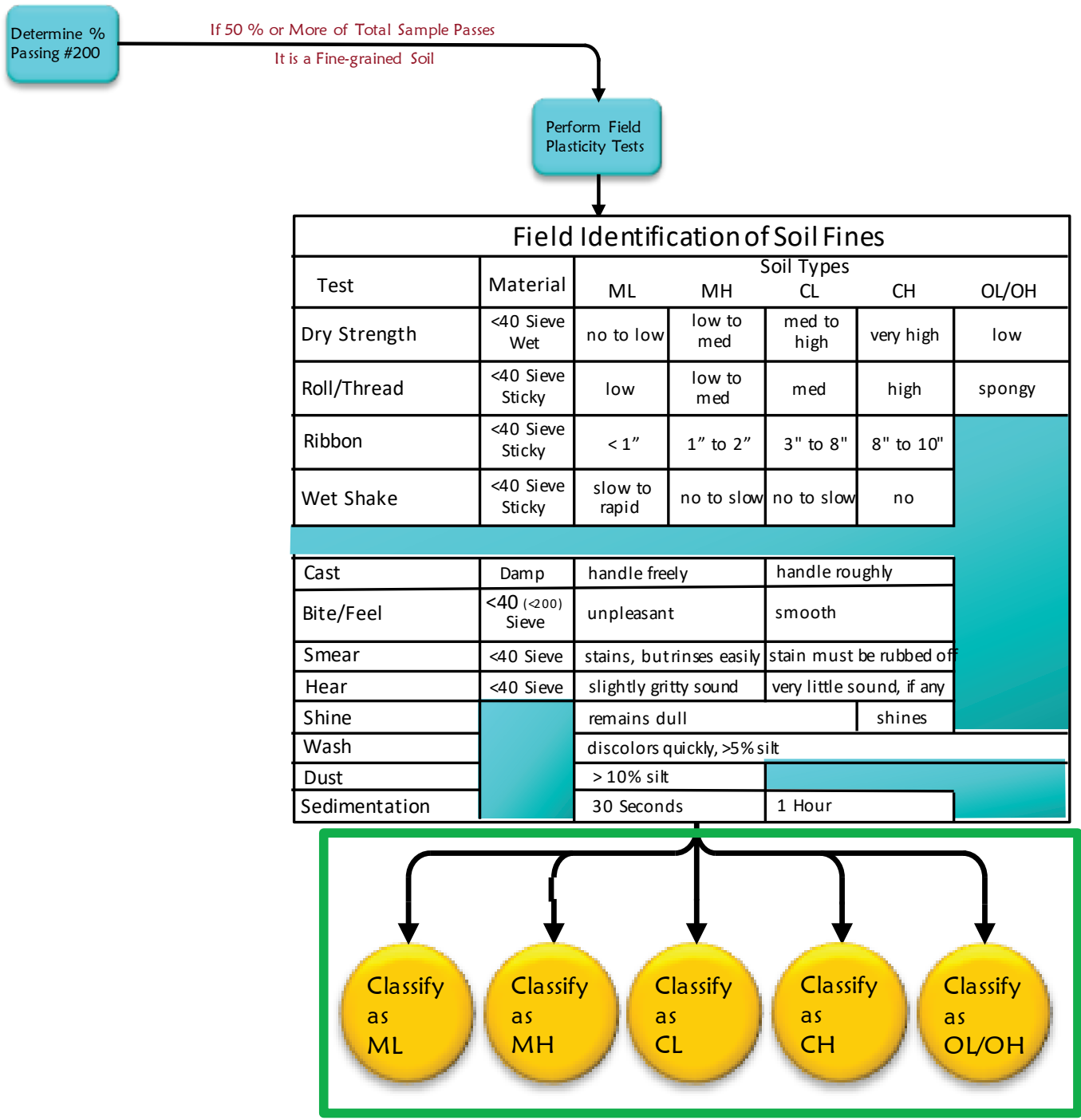




\section{Appendix B: Soil Characterization Data}

\section{B.1 CL-1}

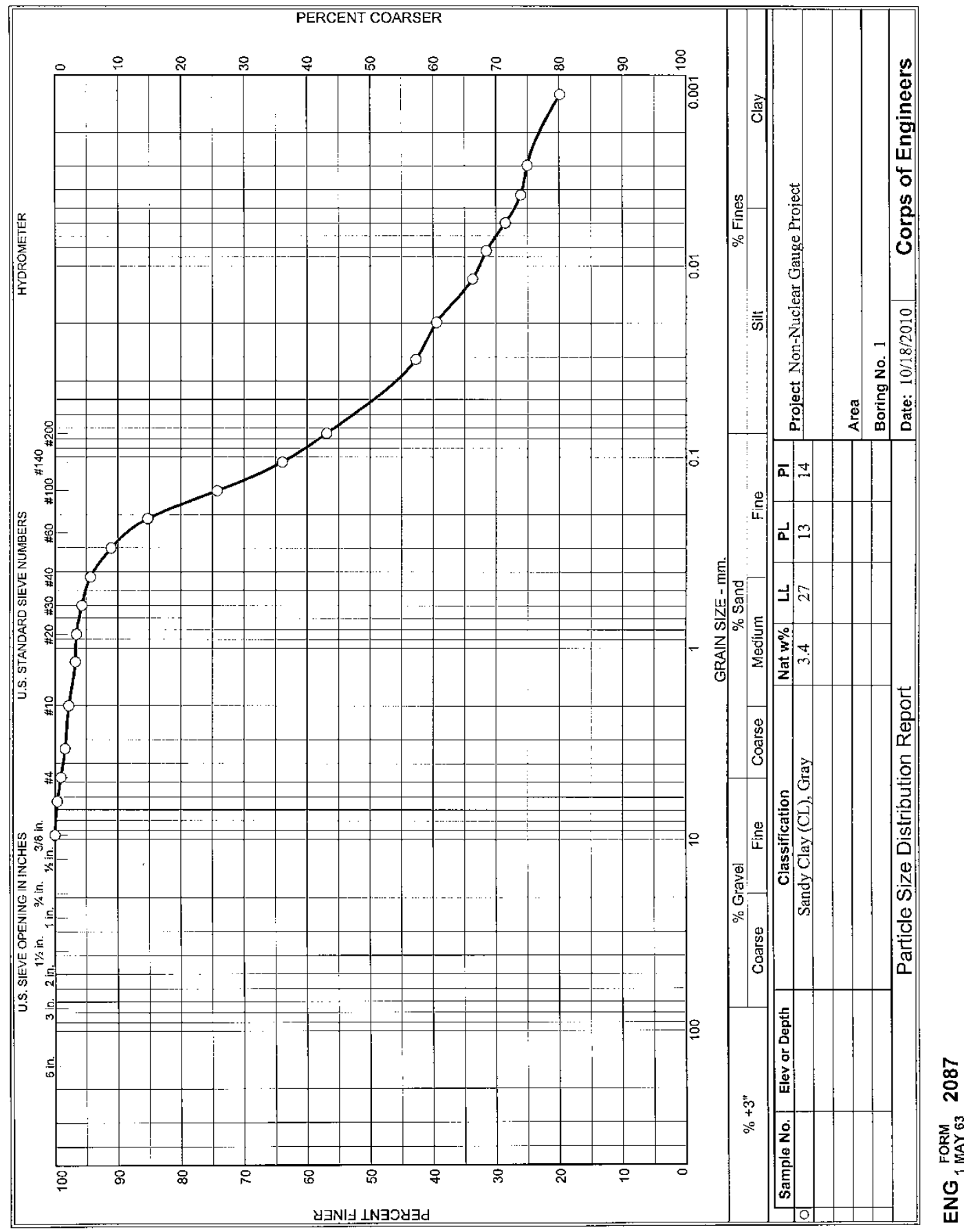




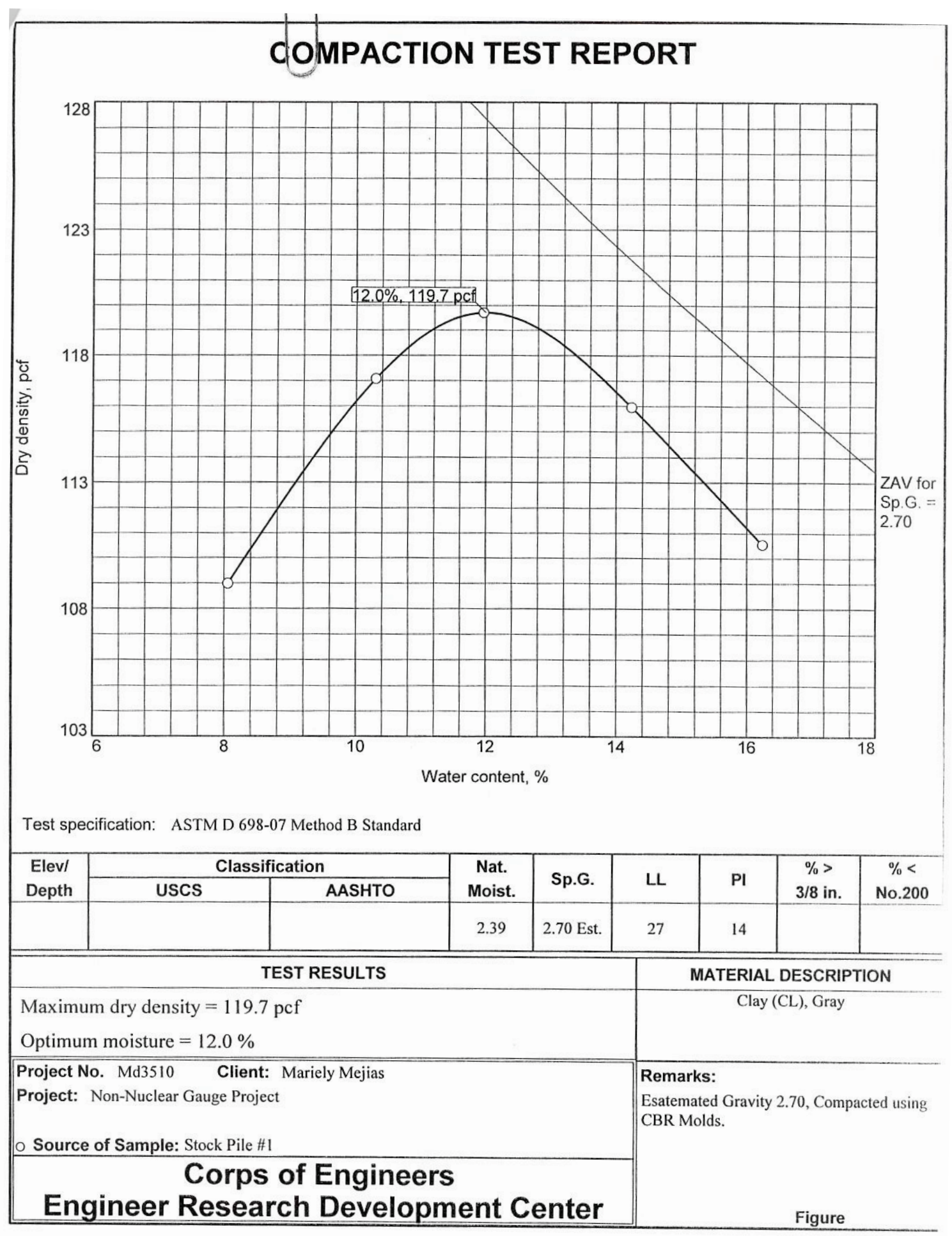

Tested By: CEC 
WORK ORDER NO. MD1812

\section{SPECIFIC GRAVITY OF SOILS \\ ASTM D 854 \\ FLASK SET \# 1}

Project: Non-Nuclear Gauge

Date: $\quad 4 / 18 / 12$

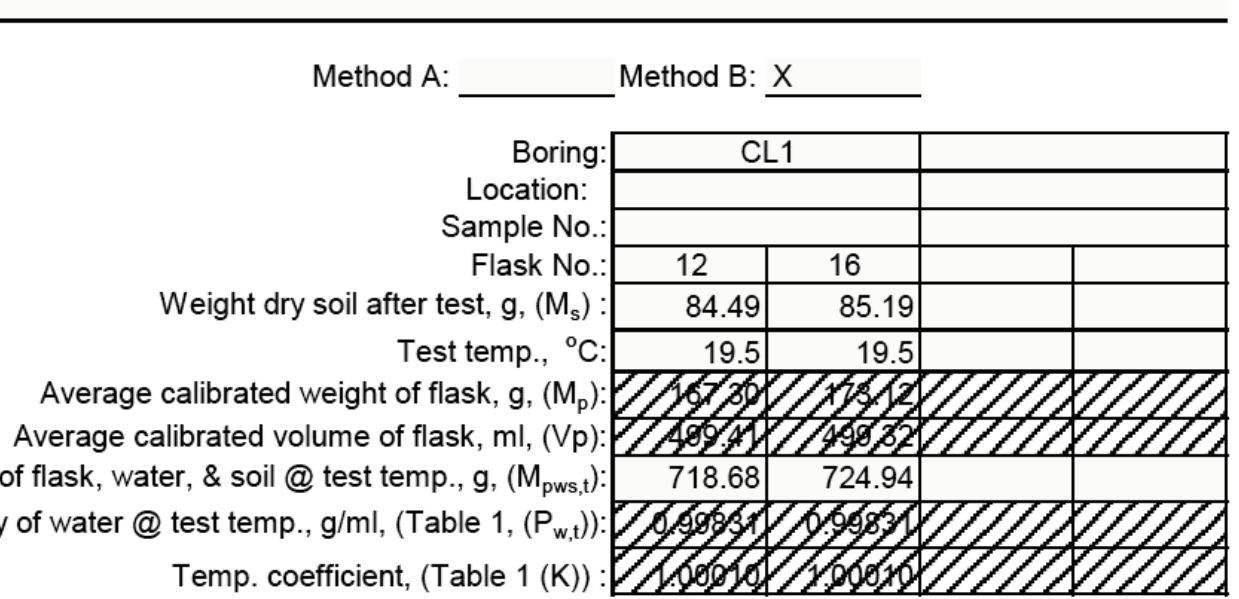

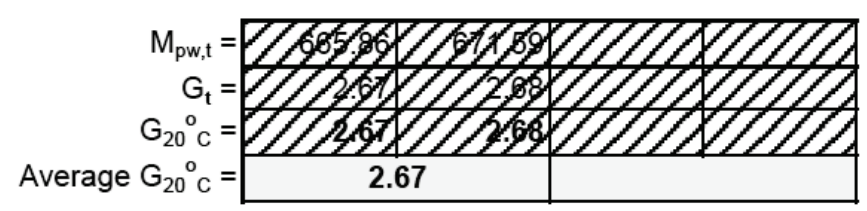

Formulas: Weight of flask \& water @ test temp., $g=M_{p w, t}=M_{p}+\left(V_{p} X P_{w, t}\right)$

Specific gravity of soil @ test temp. = Gt $=M_{s} /\left(M_{p w, t}-\left(M_{p w s, t}-M_{s}\right)\right)$

Specific gravity of soil @ $20^{\circ} \mathrm{C}=\mathrm{KX} \mathrm{G}_{\mathrm{t}}$

Visual Classification: Clay (CL), Brown

Percent passing No. 4 sieve: $\frac{100}{10}$

Was any soil or material excluded from the specimen? $\quad$ Yes $\quad$ No $X$ Description of soil or material excluded:

Remarks:

Technician: AT

Computed by:

Checked by:

LRC 


\section{B.2 CL-2}

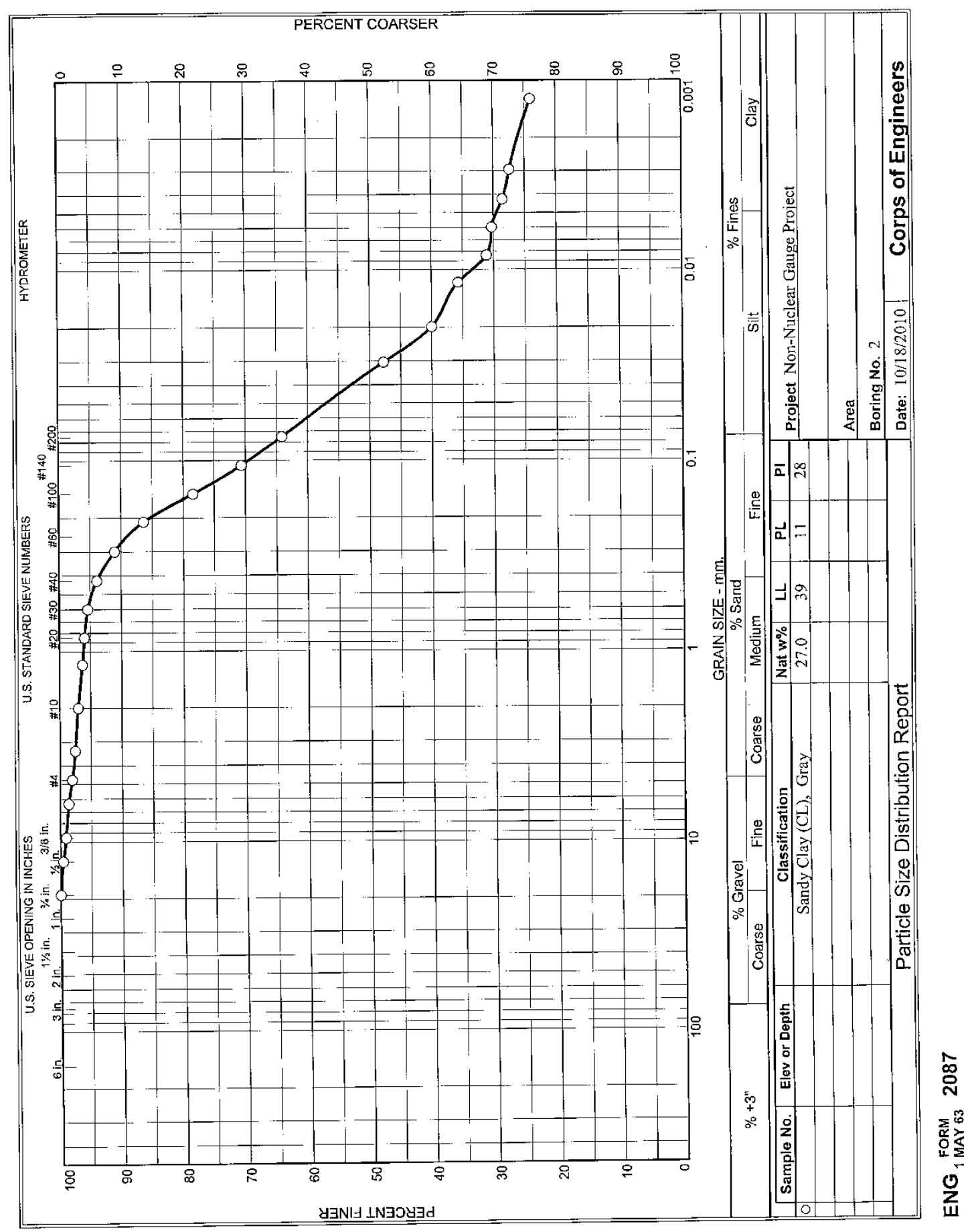




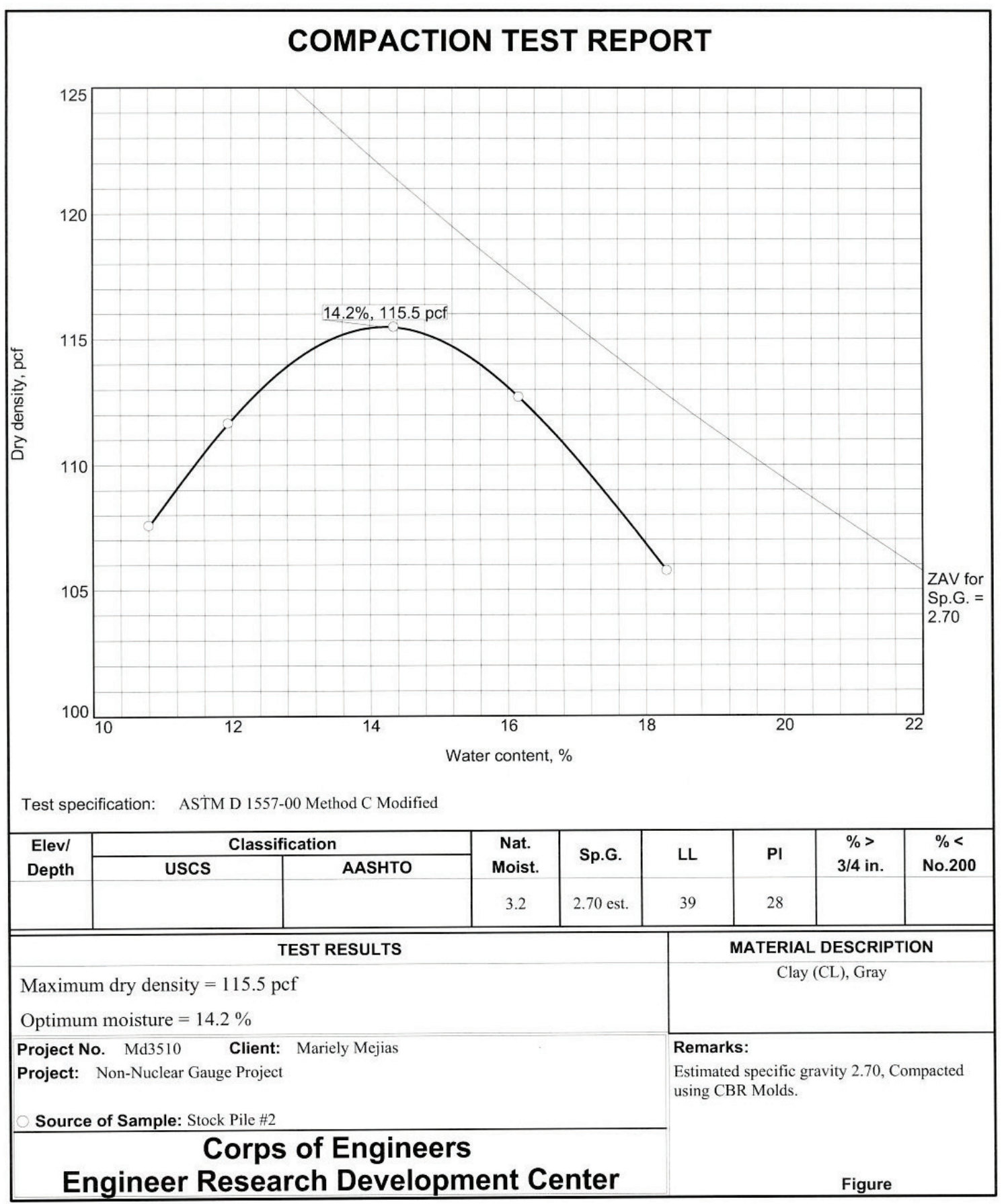

Tested By: CEC

Checked By: LRC 


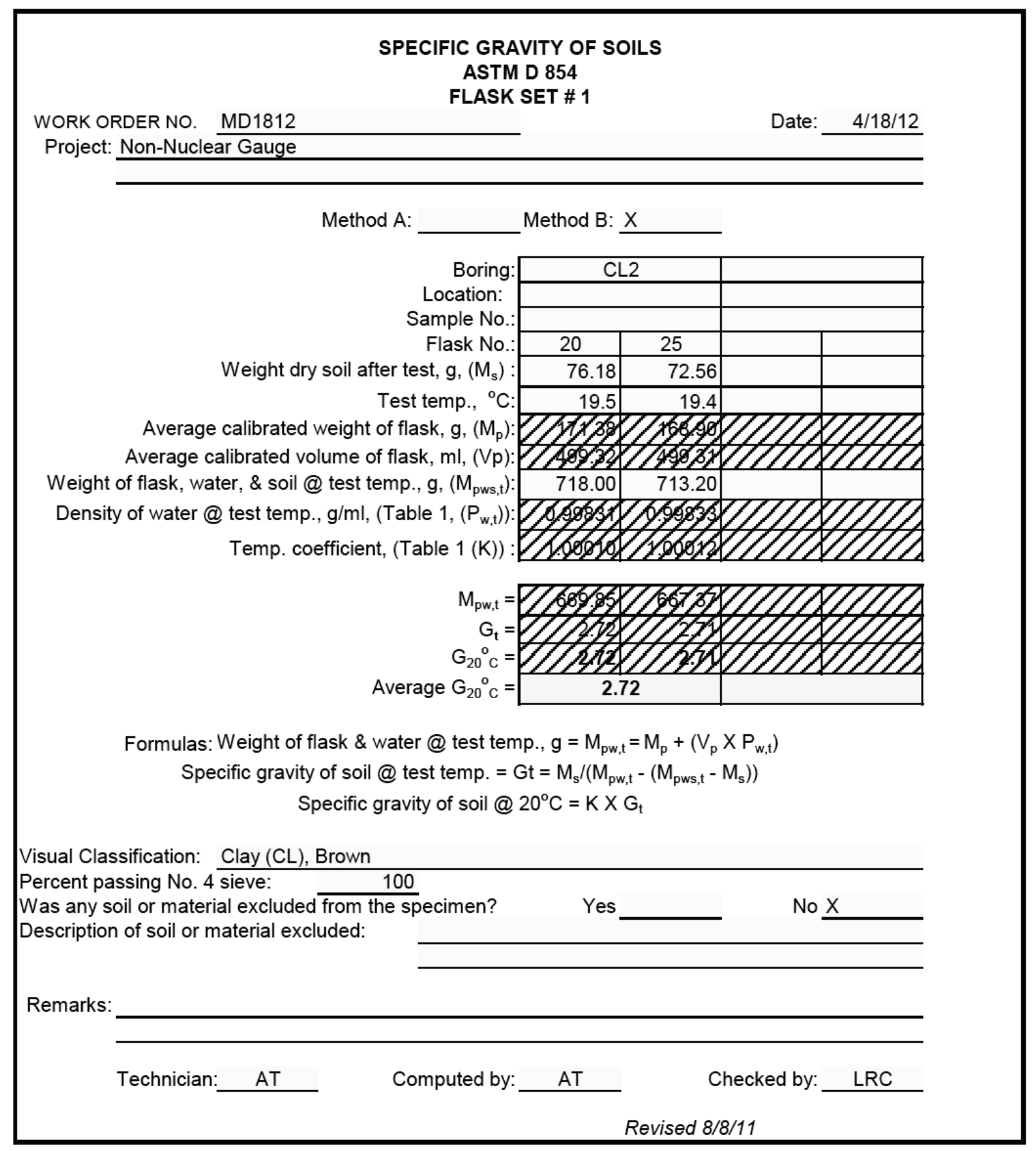




\section{B.3 SC-1}

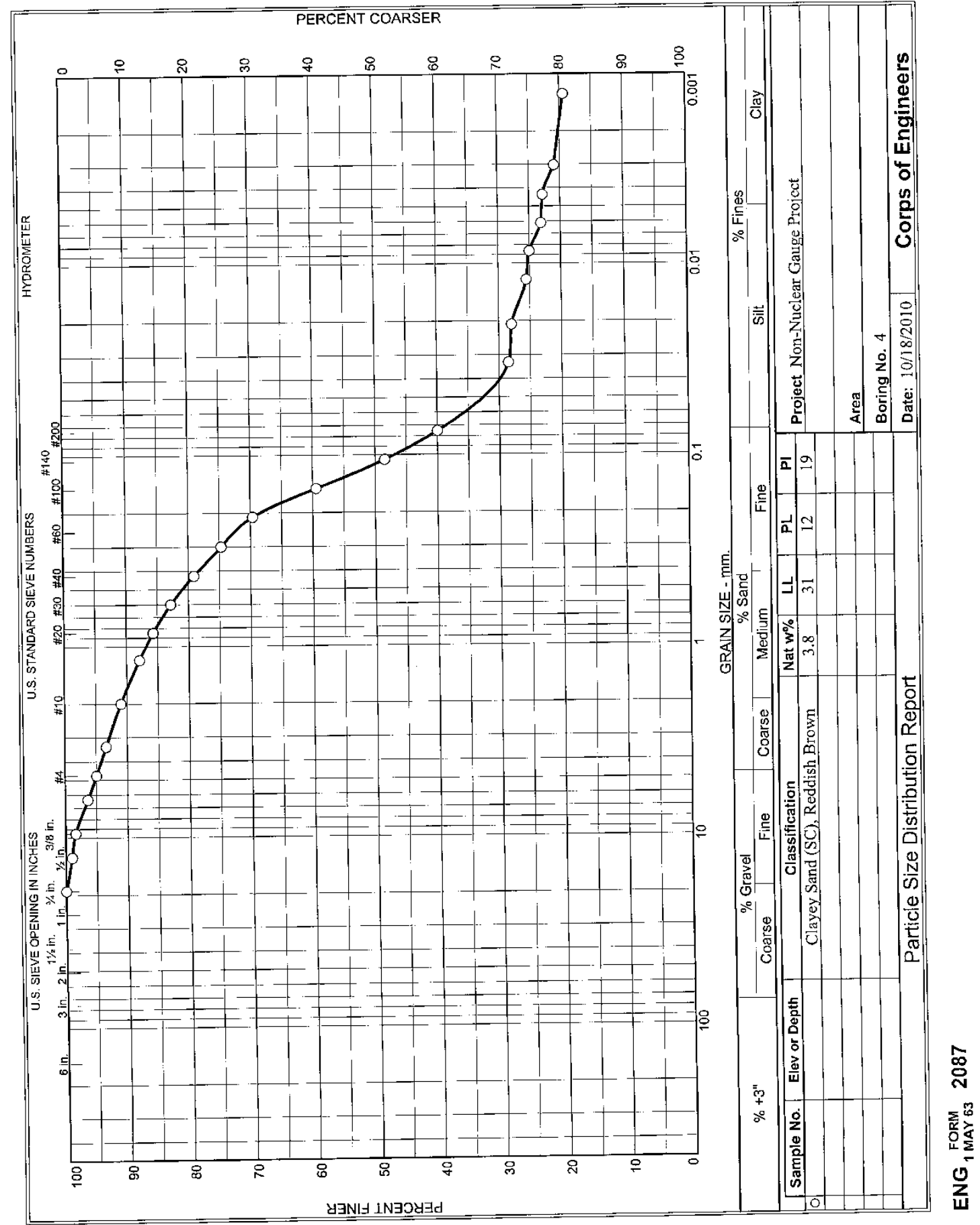




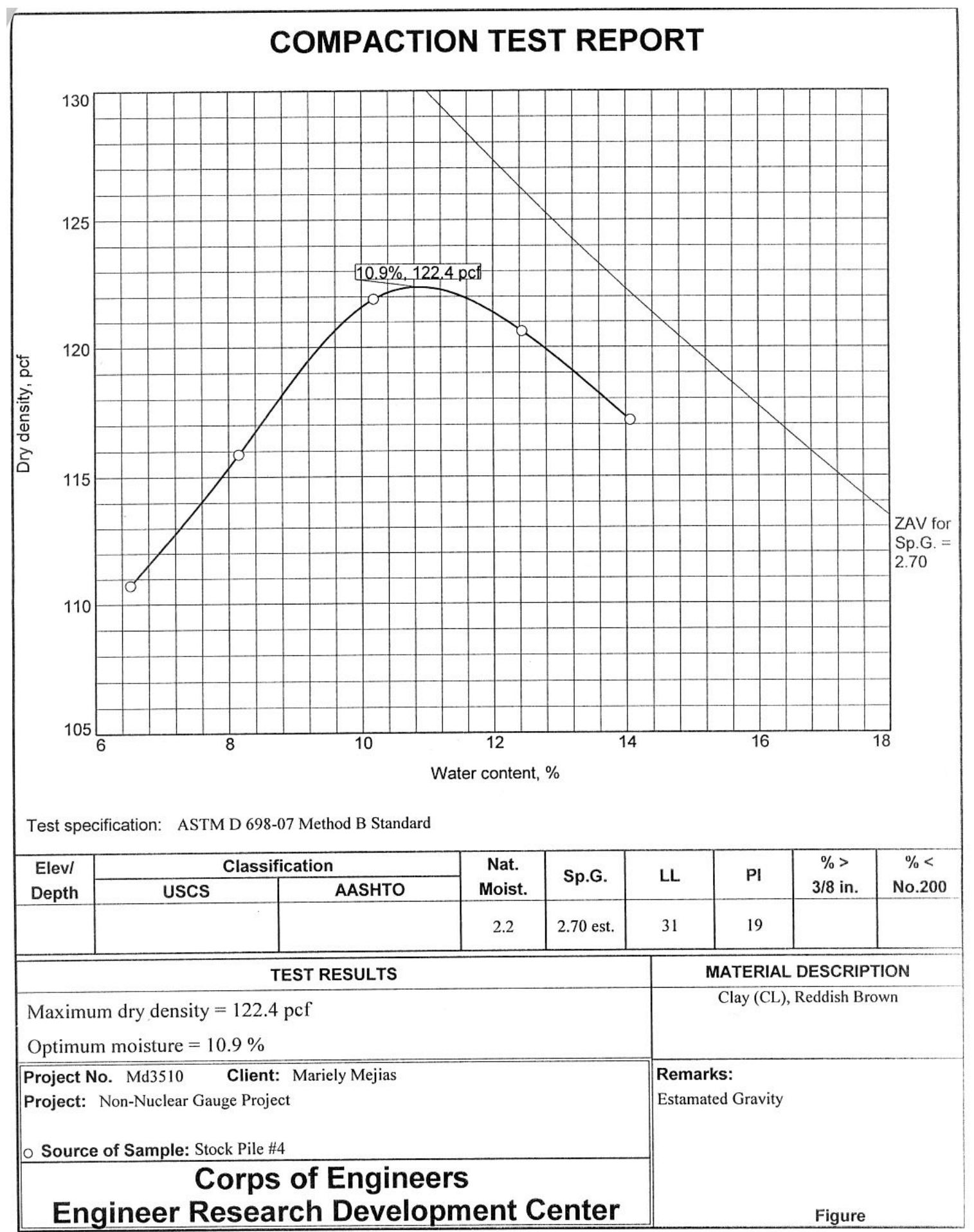

Tested By: CEC 


\section{SPECIFIC GRAVITY OF SOILS \\ ASTM D 854 \\ FLASK SET \# 2}

WORK ORDER NO. MD1812

Project: Non-Nuclear Gauge

Date: $\quad 04 / 18 / 12$

Method A: Method B: $\underline{X}$

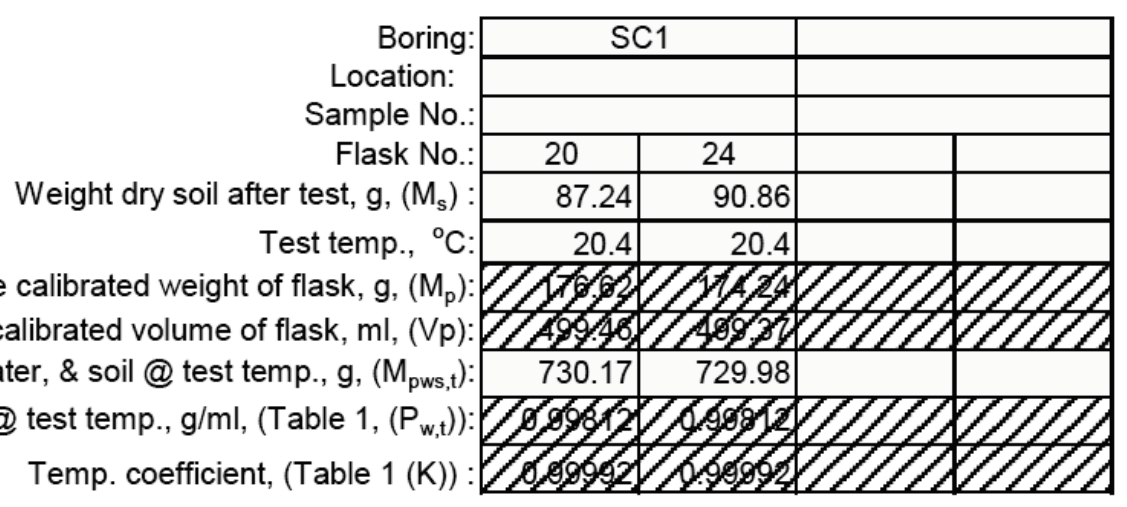

Average calibrated weight of flask,

Average calibrated volume of flask, $\mathrm{ml},(\mathrm{Vp})$ : Weight of flask, water, \& soil @ test temp., g, $\left(\mathrm{M}_{\mathrm{pws}, \mathrm{t}}\right)$ :

Density of water @ test temp., g/ml, (Table 1, $\left(P_{w, t}\right)$.

Temp. coefficient, (Table $1(\mathrm{~K}))$

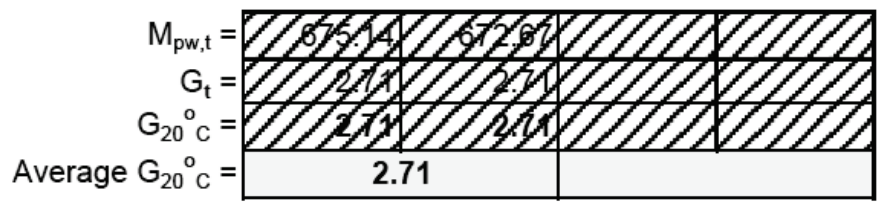

Formulas: Weight of flask \& water @ test temp., $g=M_{p w, t}=M_{p}+\left(V_{p} X P_{w, t}\right)$

Specific gravity of soil @ test temp. $=G t=M_{s} /\left(M_{p w, t}-\left(M_{p w s, t}-M_{s}\right)\right)$

Specific gravity of soil @ $20^{\circ} \mathrm{C}=\mathrm{KX} \mathrm{G}_{\mathrm{t}}$

Visual Classification: Clayey Sand (SC), Reddish Brown

Percent passing No. 4 sieve: $\frac{100}{10}$

Was any soil or material excluded from the specimen? $\quad$ Yes _ No $\mathrm{X}$ Description of soil or material excluded:

Remarks:

Technician: AT

Computed by:

AT

Checked by: LRC 


\section{B.4 CH-2}

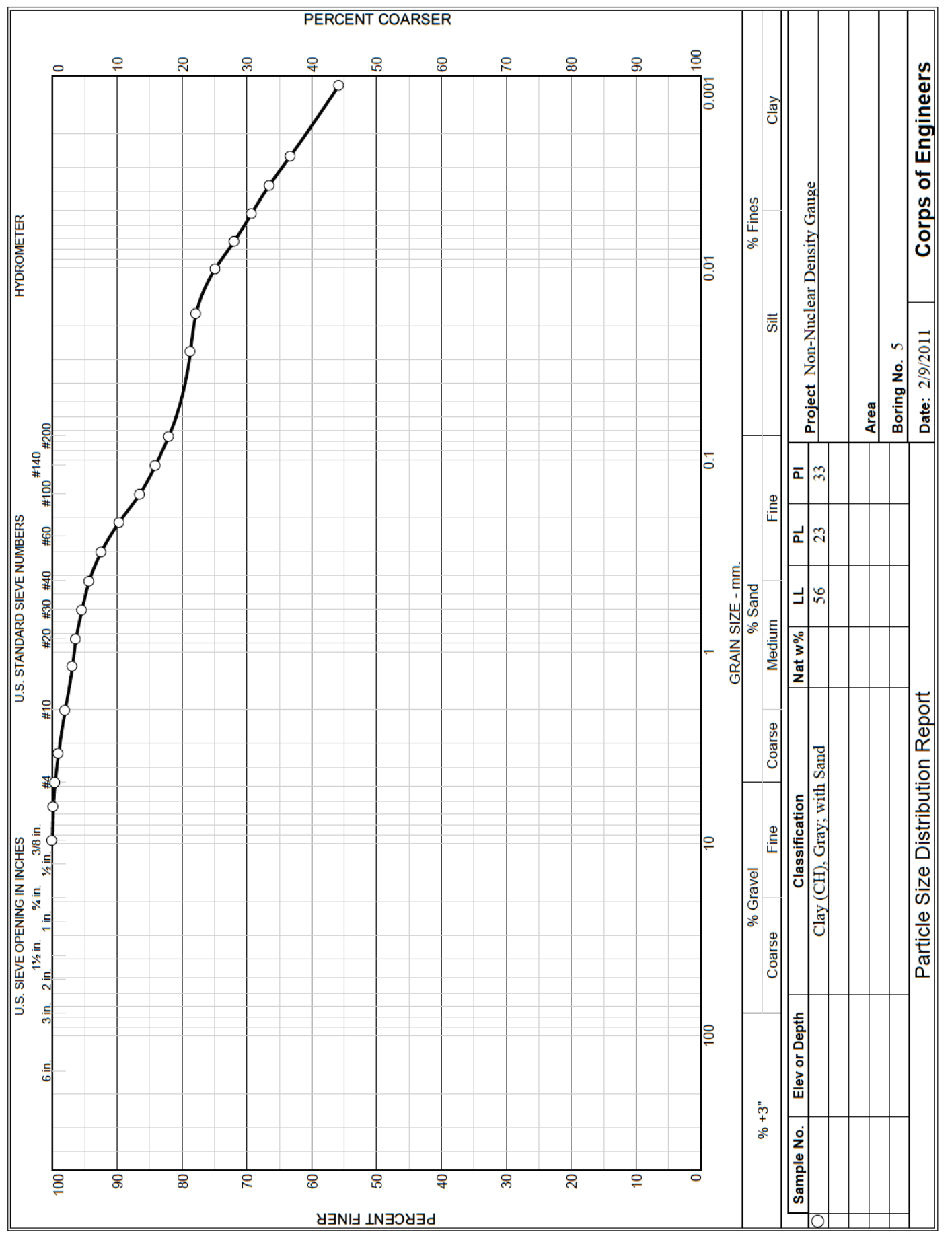

总 


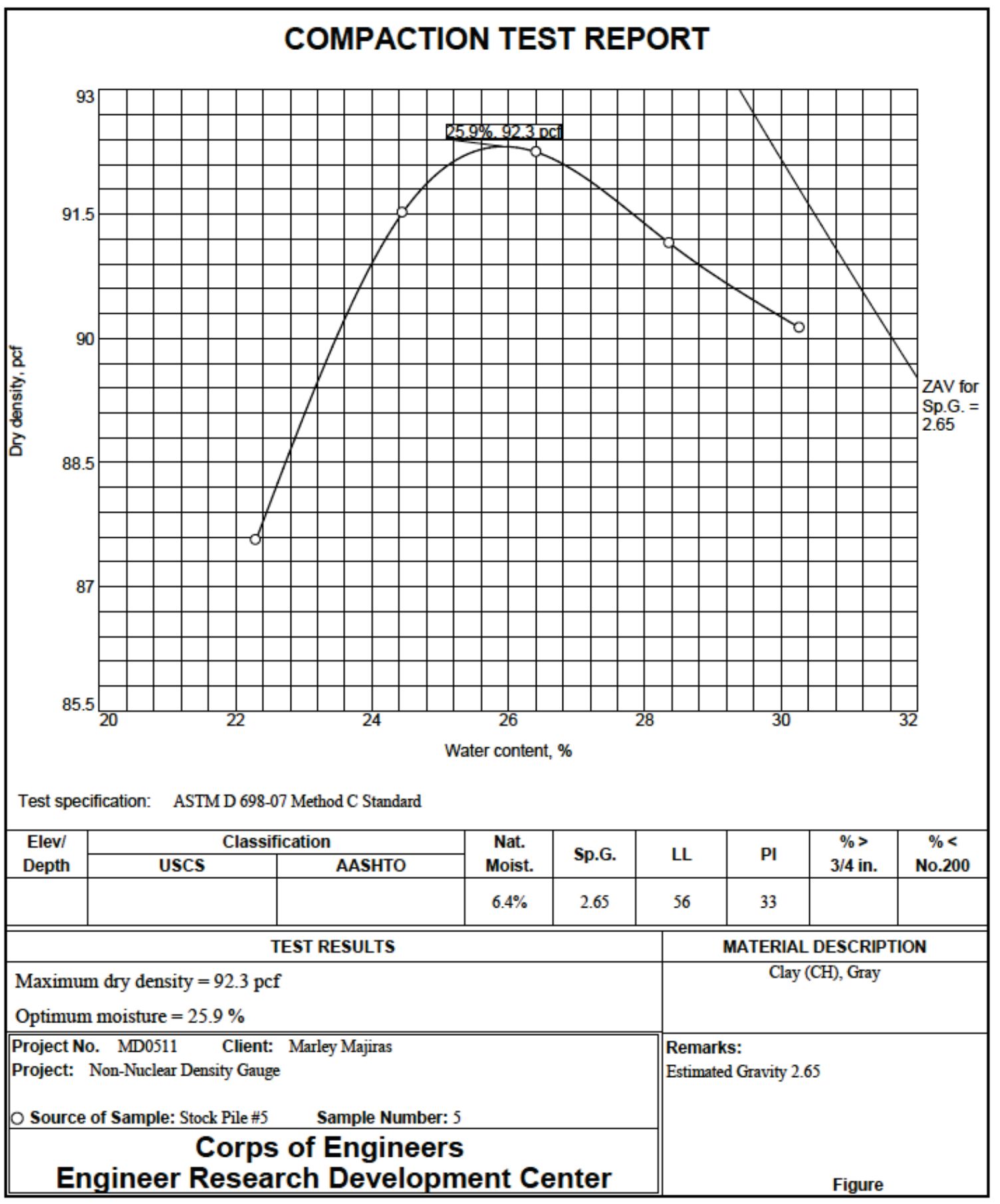

Tested By: CEC

Checked By: LRC 


\section{SPECIFIC GRAVITY OF SOILS \\ ASTM D 854 \\ FLASK SET \# 1}

WORK ORDER NO. MD1812

Project: Non-Nuclear Gauge

Date: $\quad 4 / 18 / 12$

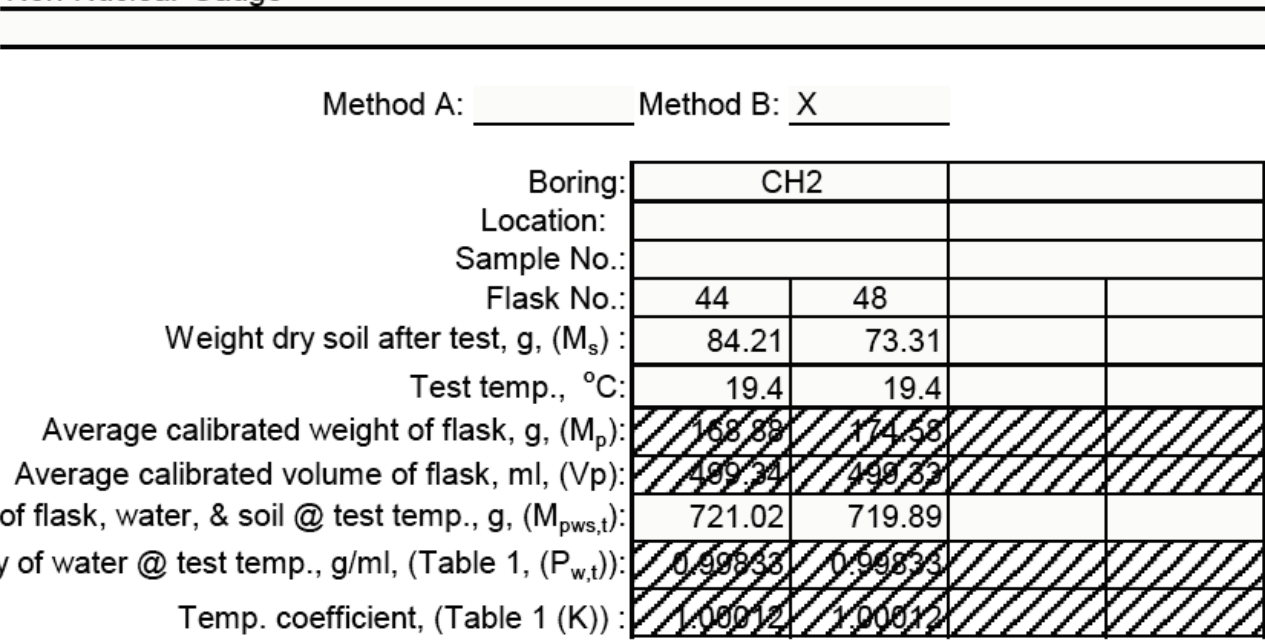

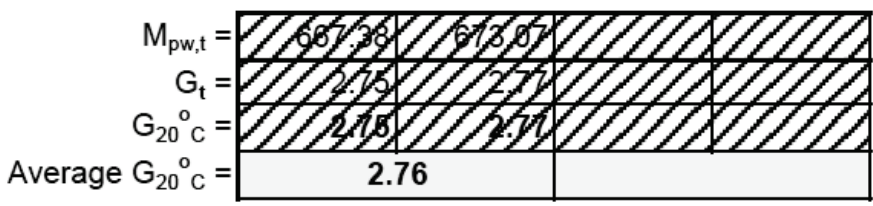

Formulas: Weight of flask \& water @ test temp., $g=M_{p w, t}=M_{p}+\left(V_{p} X P_{w, t}\right)$

Specific gravity of soil @ test temp. $=G t=M_{s} /\left(M_{p w, t}-\left(M_{p w s, t}-M_{s}\right)\right)$

Specific gravity of soil @ $20^{\circ} \mathrm{C}=\mathrm{KX} \mathrm{G}_{\mathrm{t}}$

Visual Classification: Clay (CH), Gray

Percent passing No. 4 sieve: 100

Was any soil or material excluded from the specimen? Yes __ No

Description of soil or material excluded:

Remarks:

Technician: AT Computed by:




\section{B.5 SC-2}

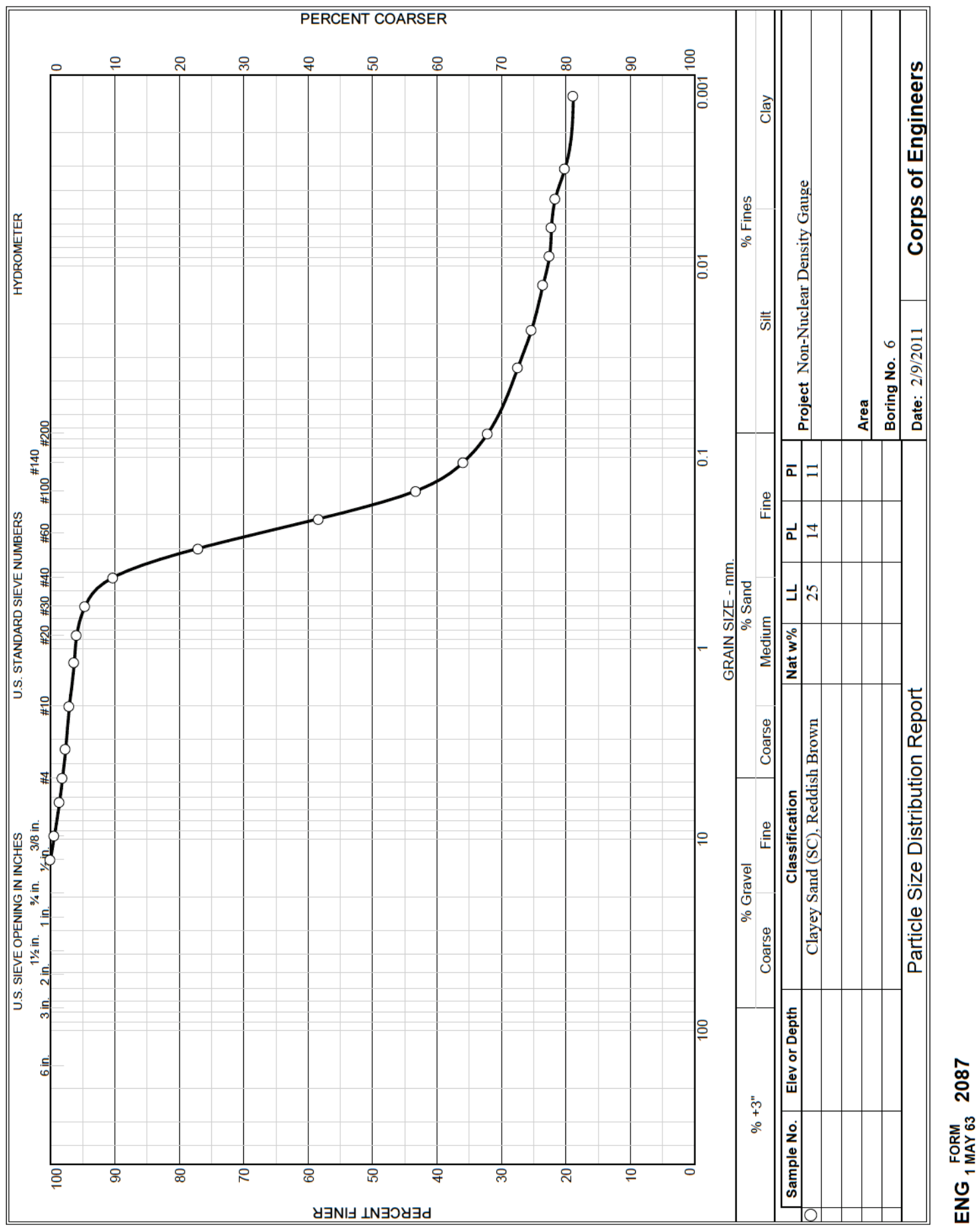




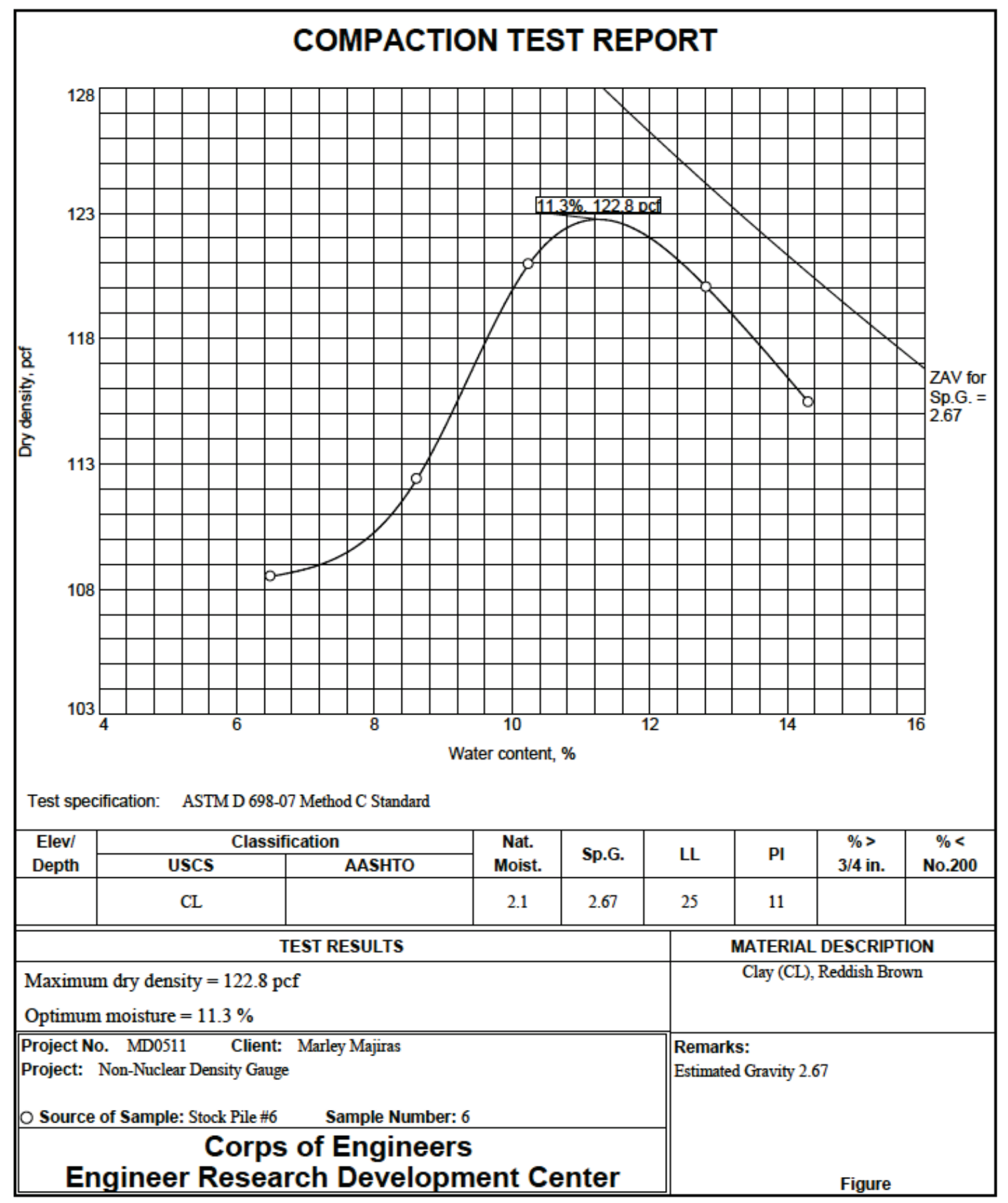

Tested By: CECILDD

Checked By: LRC 


\section{SPECIFIC GRAVITY OF SOILS \\ ASTM D 854 \\ FLASK SET \# 2}

WORK ORDER NO. MD1812

Project: Non-Nuclear Gauge

Date: $\quad 04 / 18 / 12$
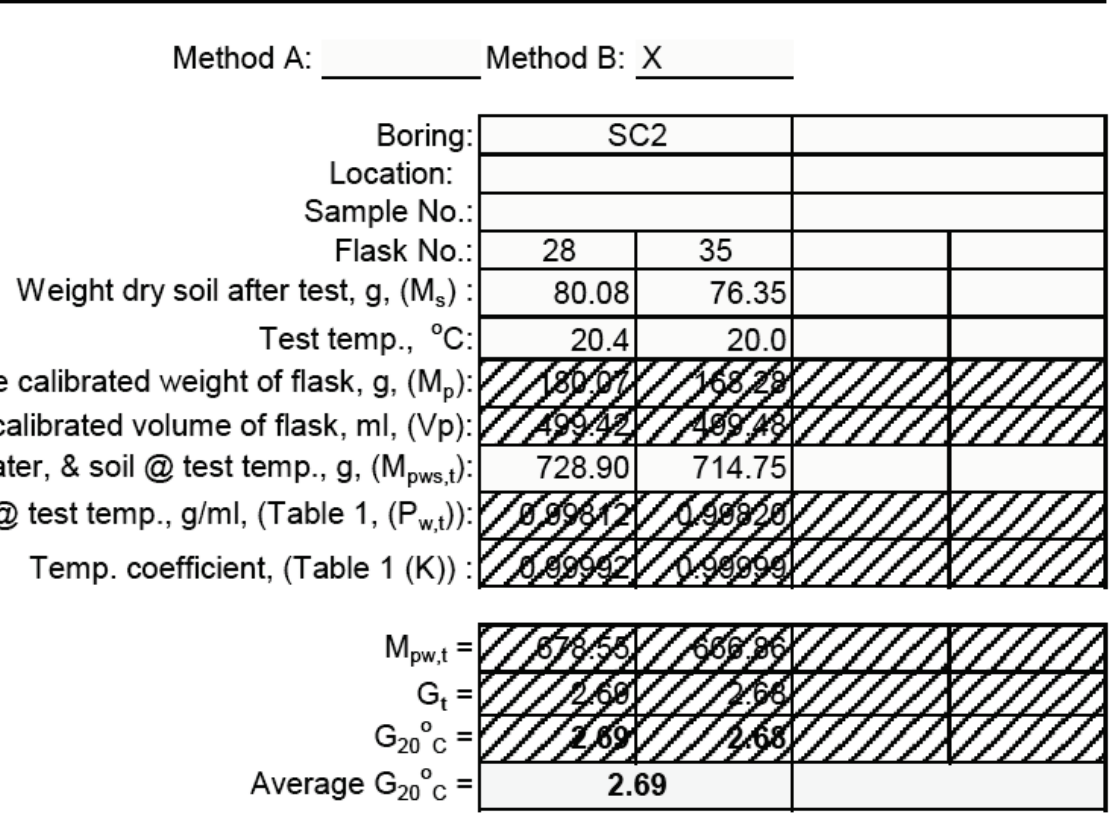

Formulas: Weight of flask \& water @ test temp., $g=M_{p w, t}=M_{p}+\left(V_{p} X P_{w, t}\right)$

Specific gravity of soil @ test temp. $=G t=M_{s} /\left(M_{p w, t}-\left(M_{p w s, t}-M_{s}\right)\right)$

Specific gravity of soil @ $20^{\circ} \mathrm{C}=\mathrm{KX} \mathrm{G}_{\mathrm{t}}$

Visual Classification: Clayey Sand (SC), Reddish Brown

Percent passing No. 4 sieve: $\frac{100}{10}$

Was any soil or material excluded from the specimen?

Description of soil or material excluded:

Yes

No $\underline{X}$

Average calib

Weight of flask, water, \& soil @ test temp., g, $\left(\mathrm{M}_{\mathrm{pws}, \mathrm{t}}\right)$

Density of water @ test temp., g/ml, (Table 1, $\left(P_{w, t}\right)$

Temp. coefficient, (Table $1(\mathrm{~K})$ )

Remarks:

Technician: AT

Computed by:

AT

Checked by:

LRC 


\section{B.6 CH-3}

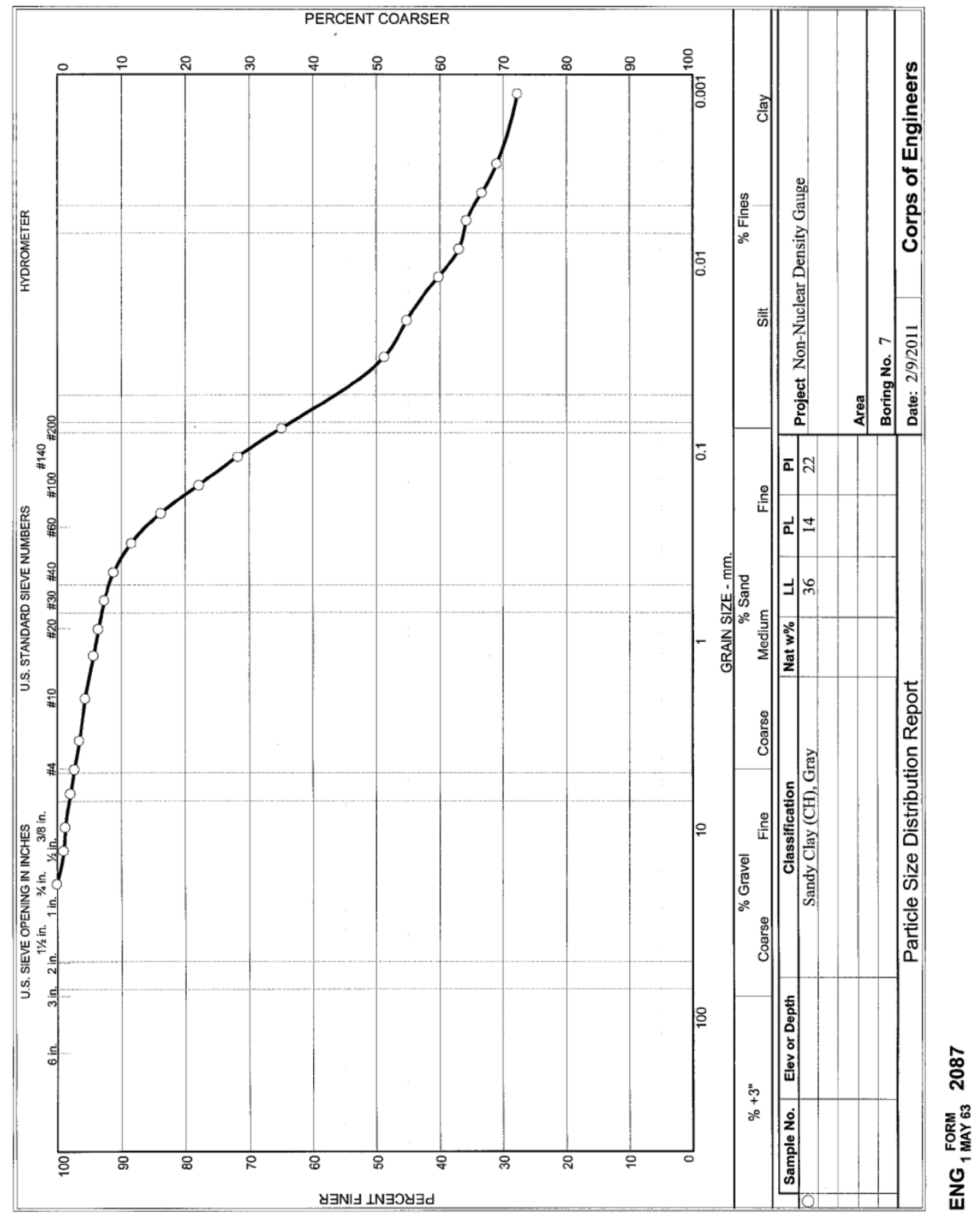




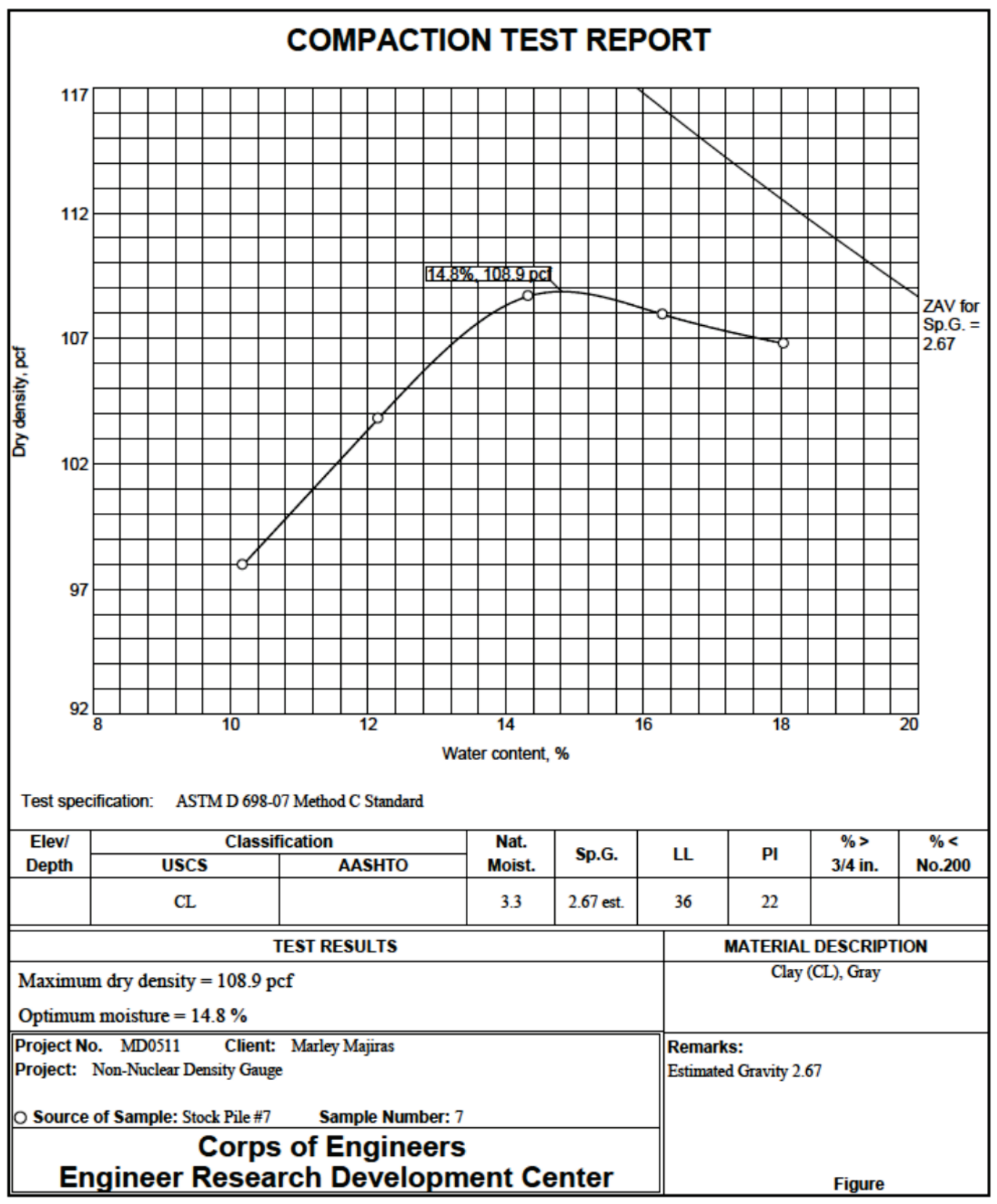

Tested By: CECLLDD

Checked By: LRC 


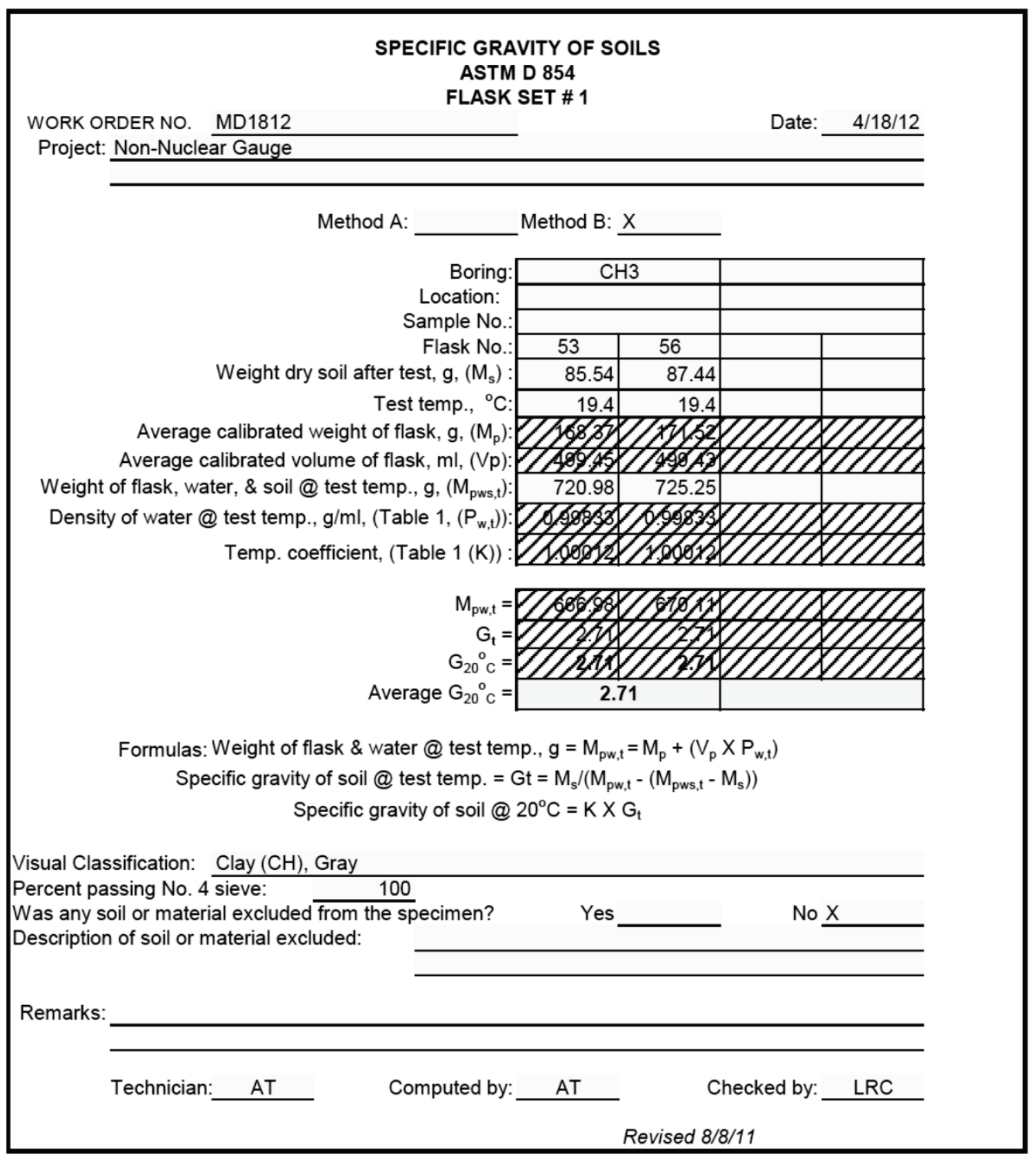




\section{B.7 CL-3}

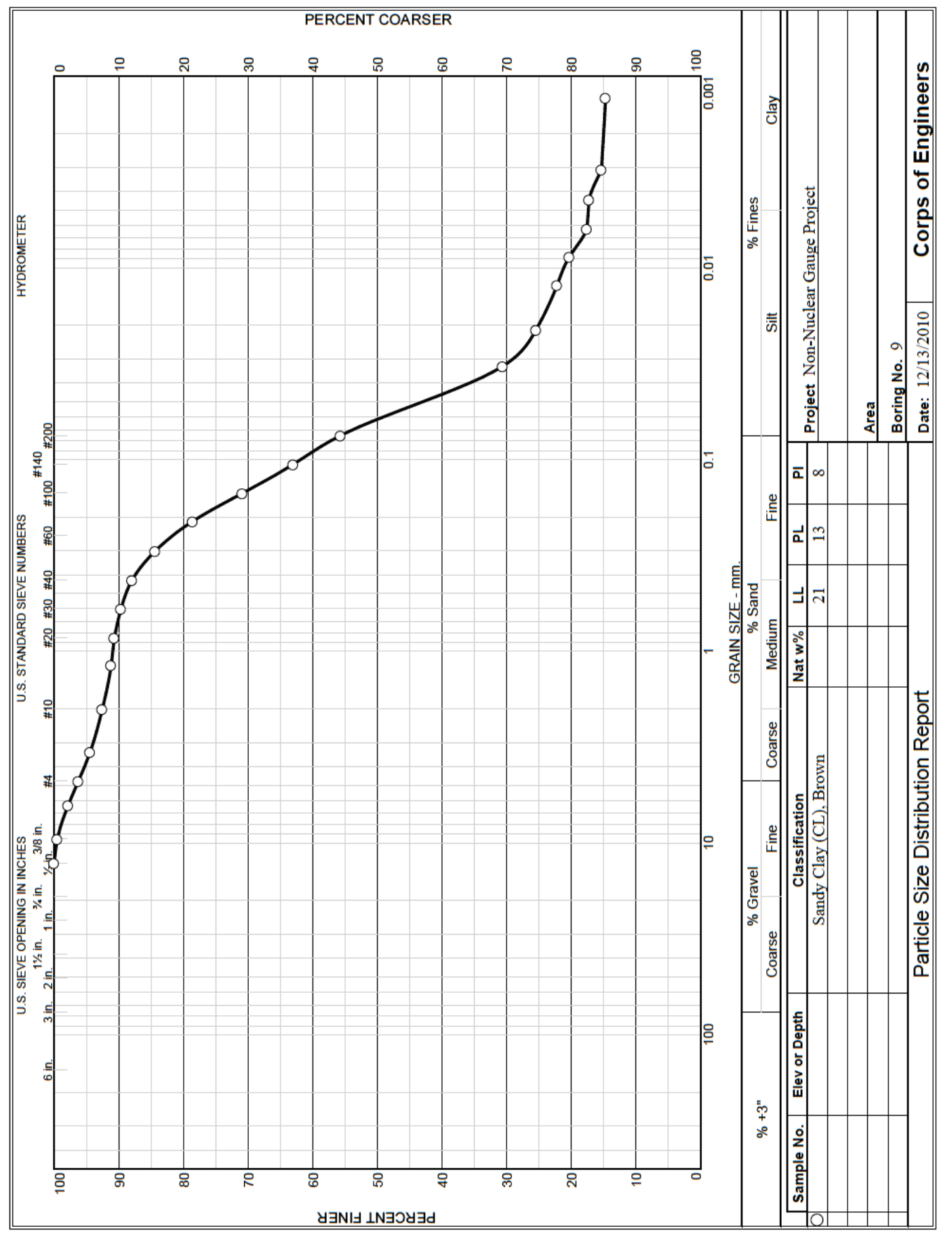

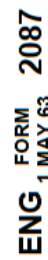




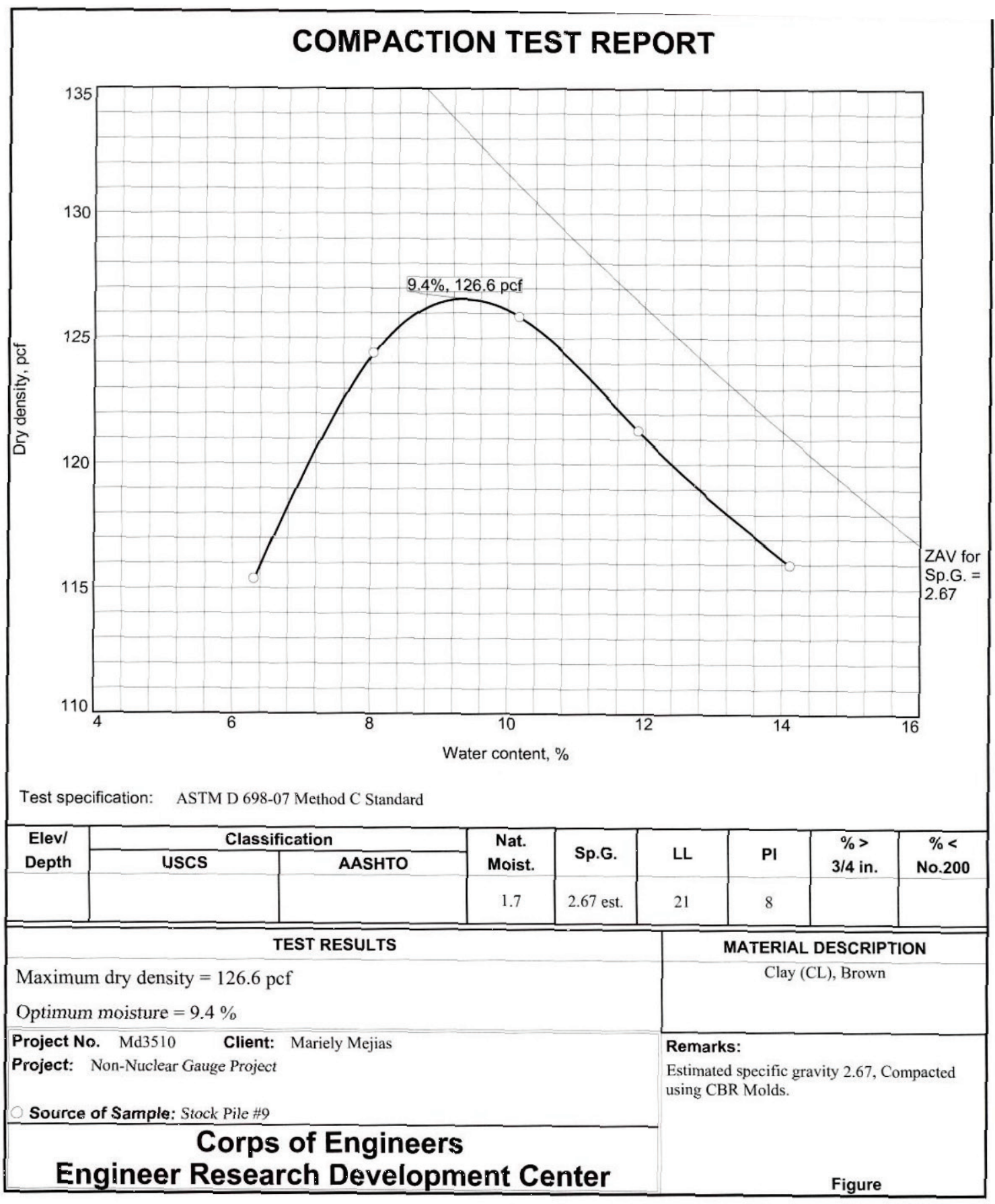

Tested By: CEC

Checked By: LRC 


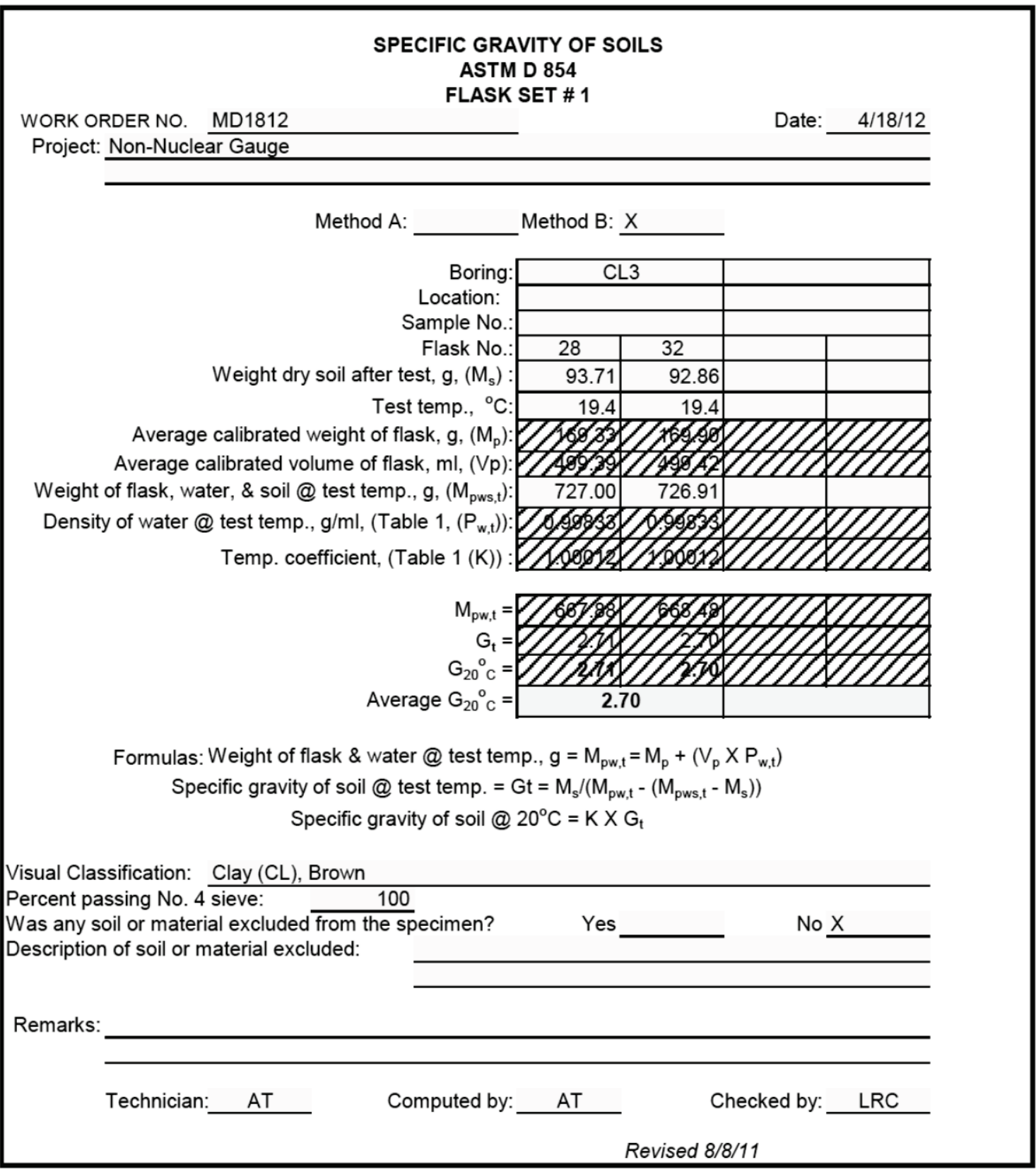




\section{B.8 CH-ERDC}

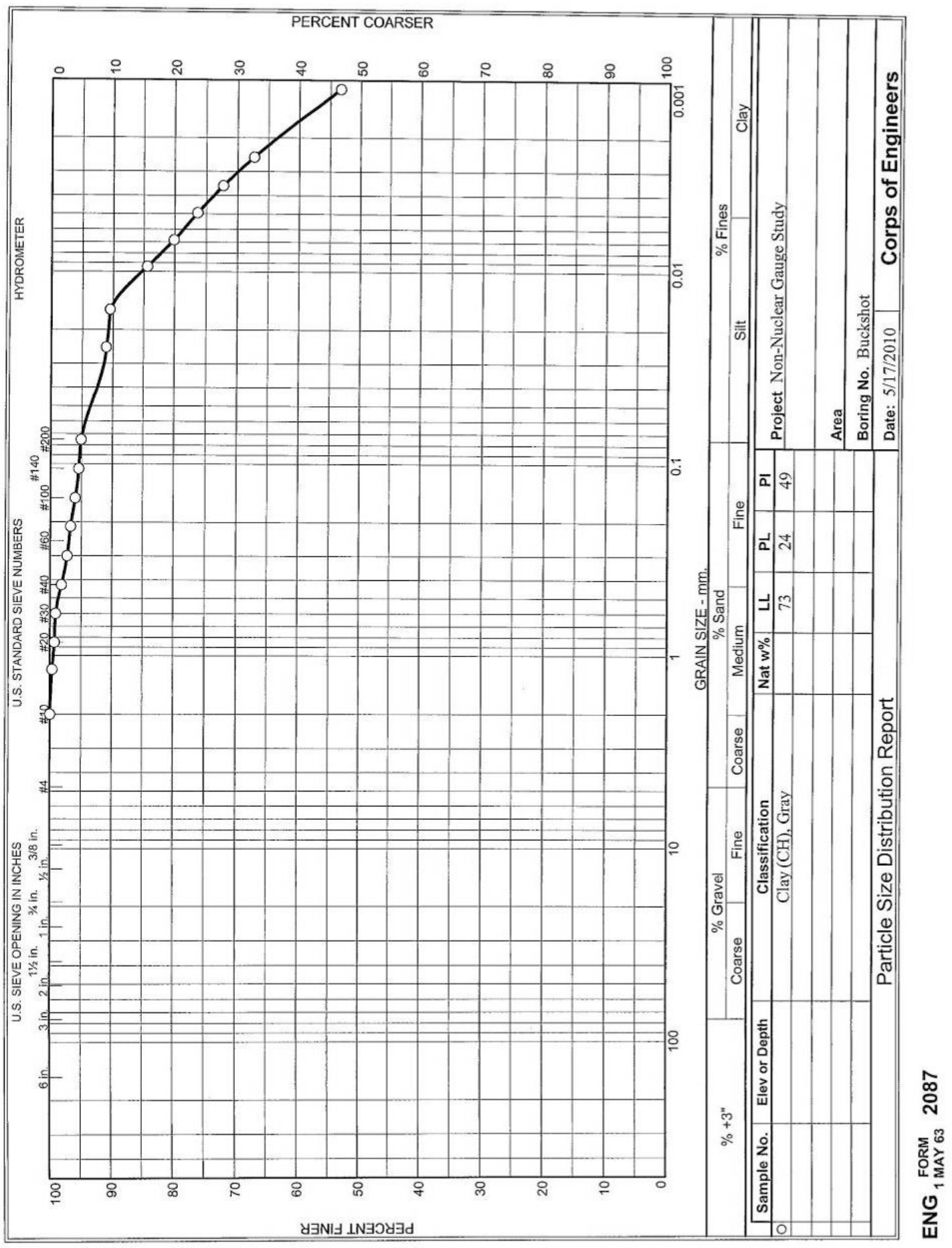




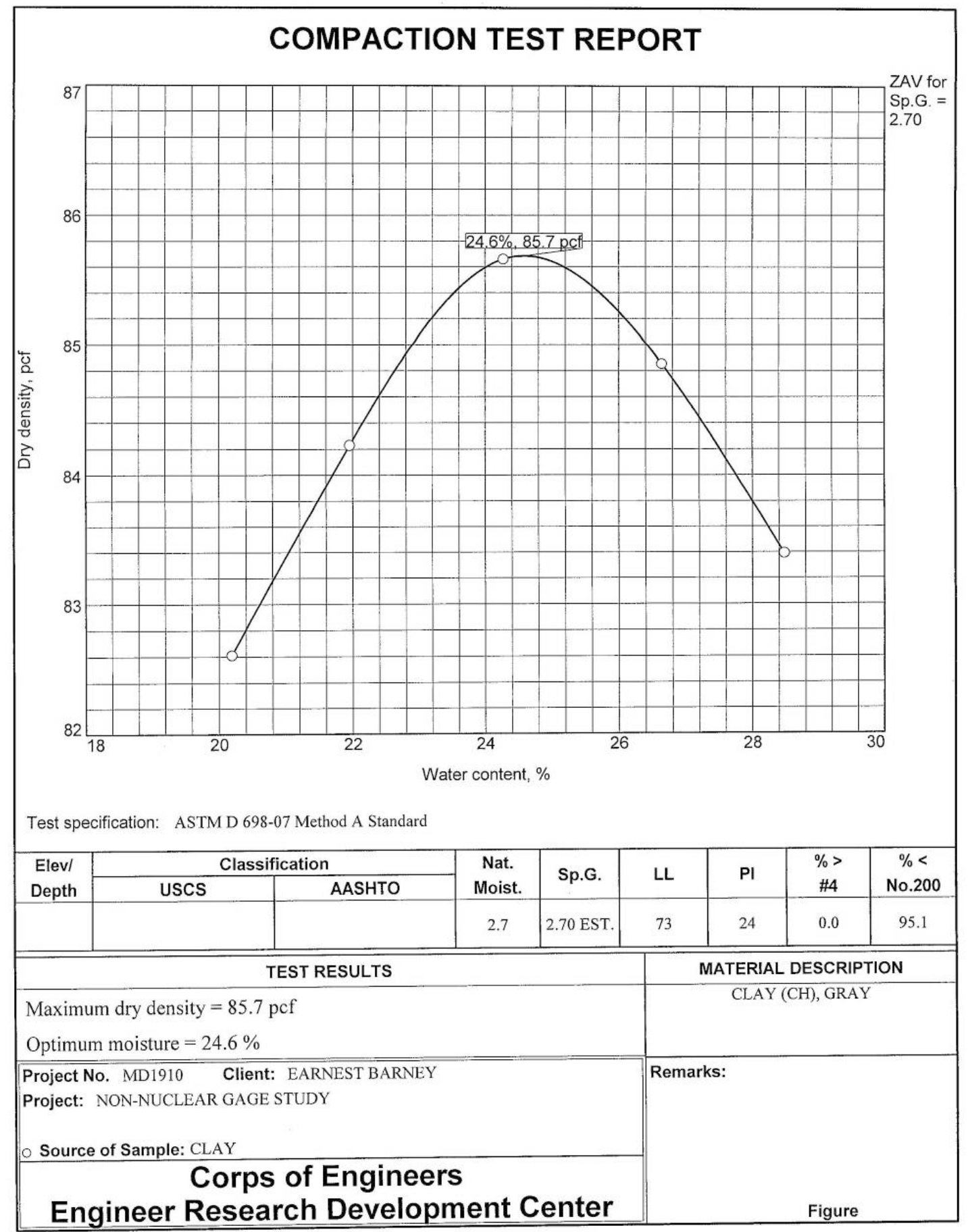

Tested By: CEC 


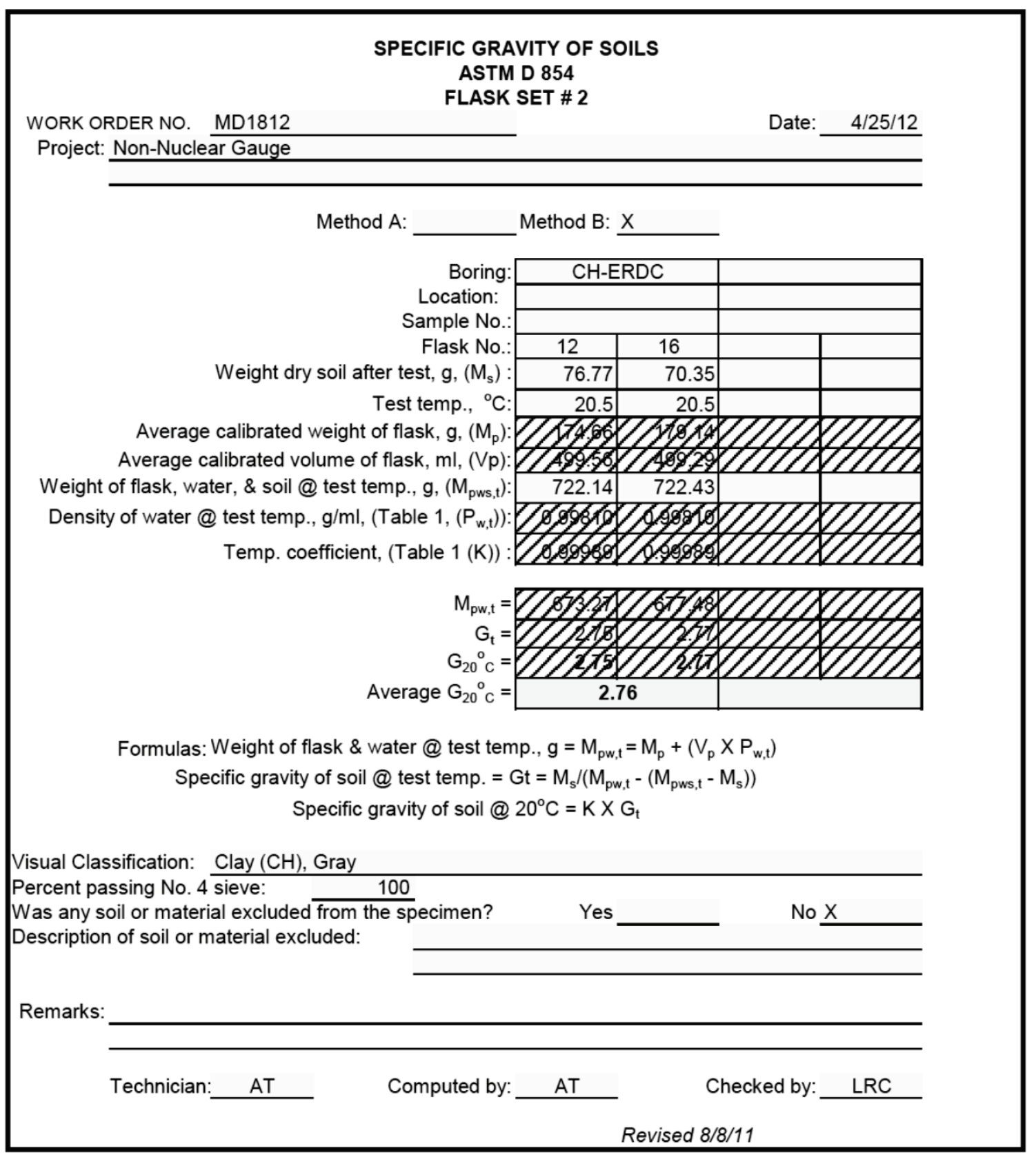




\section{B.9 MH}

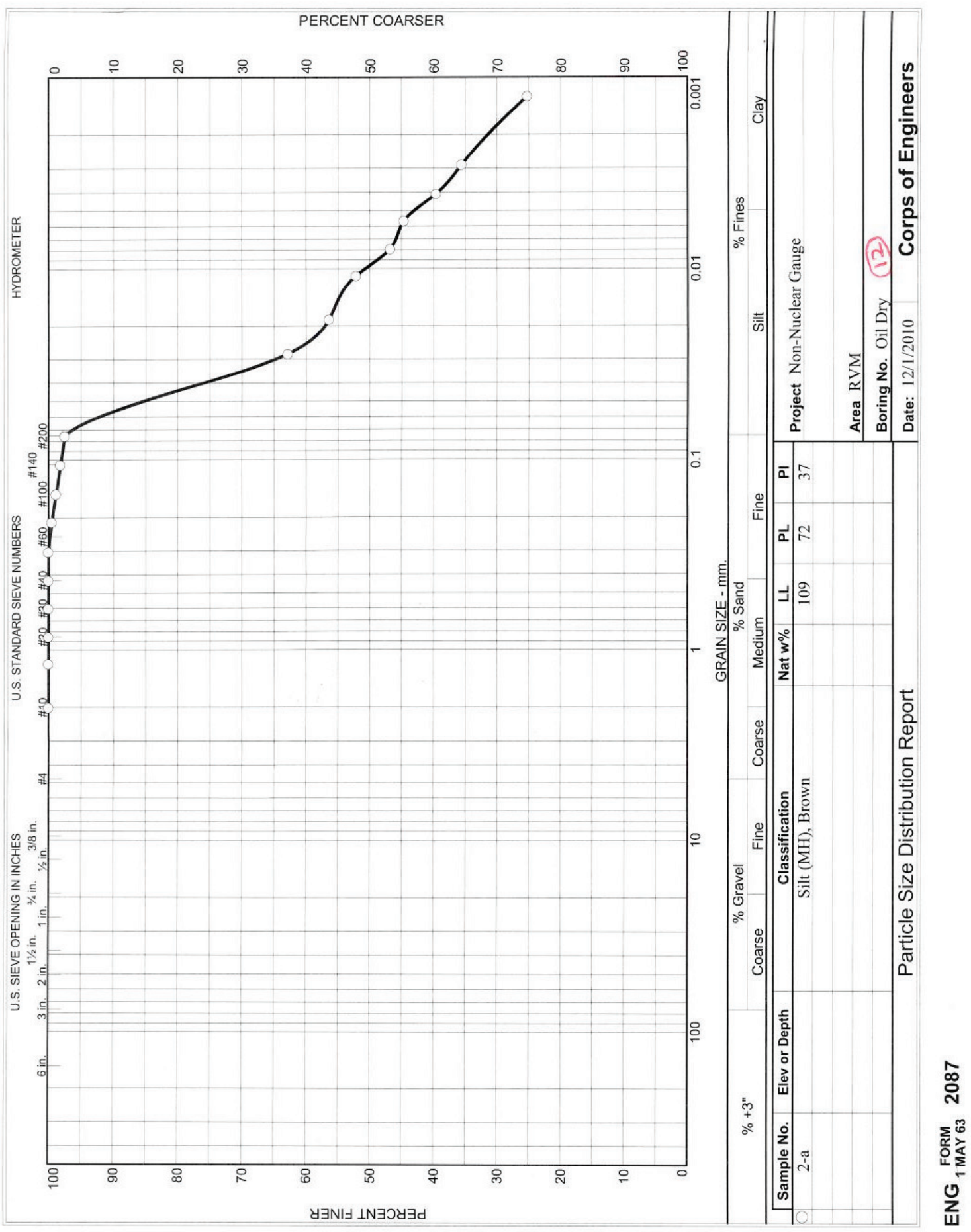




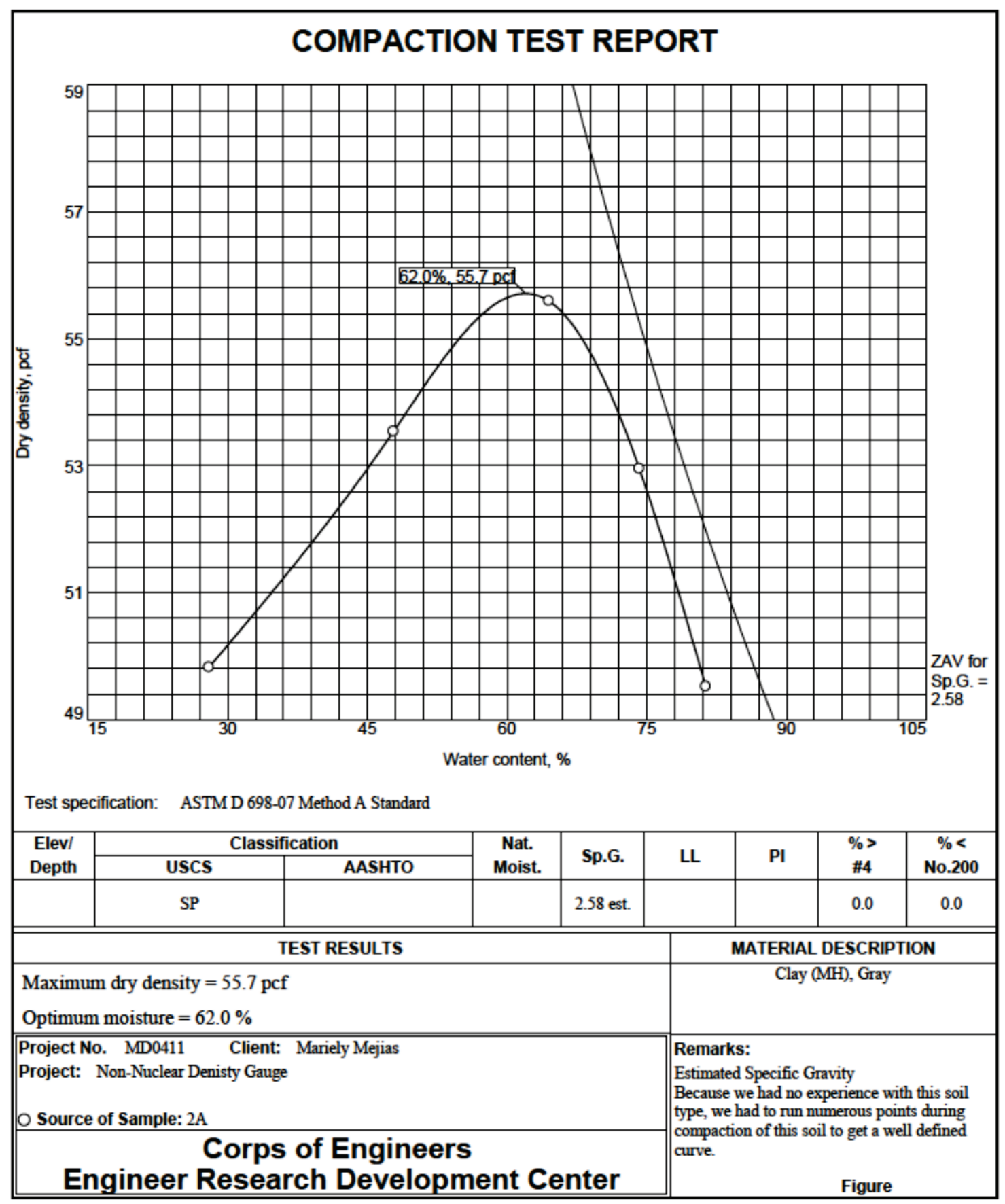

Tested By: CEC

Checked By: LRC 


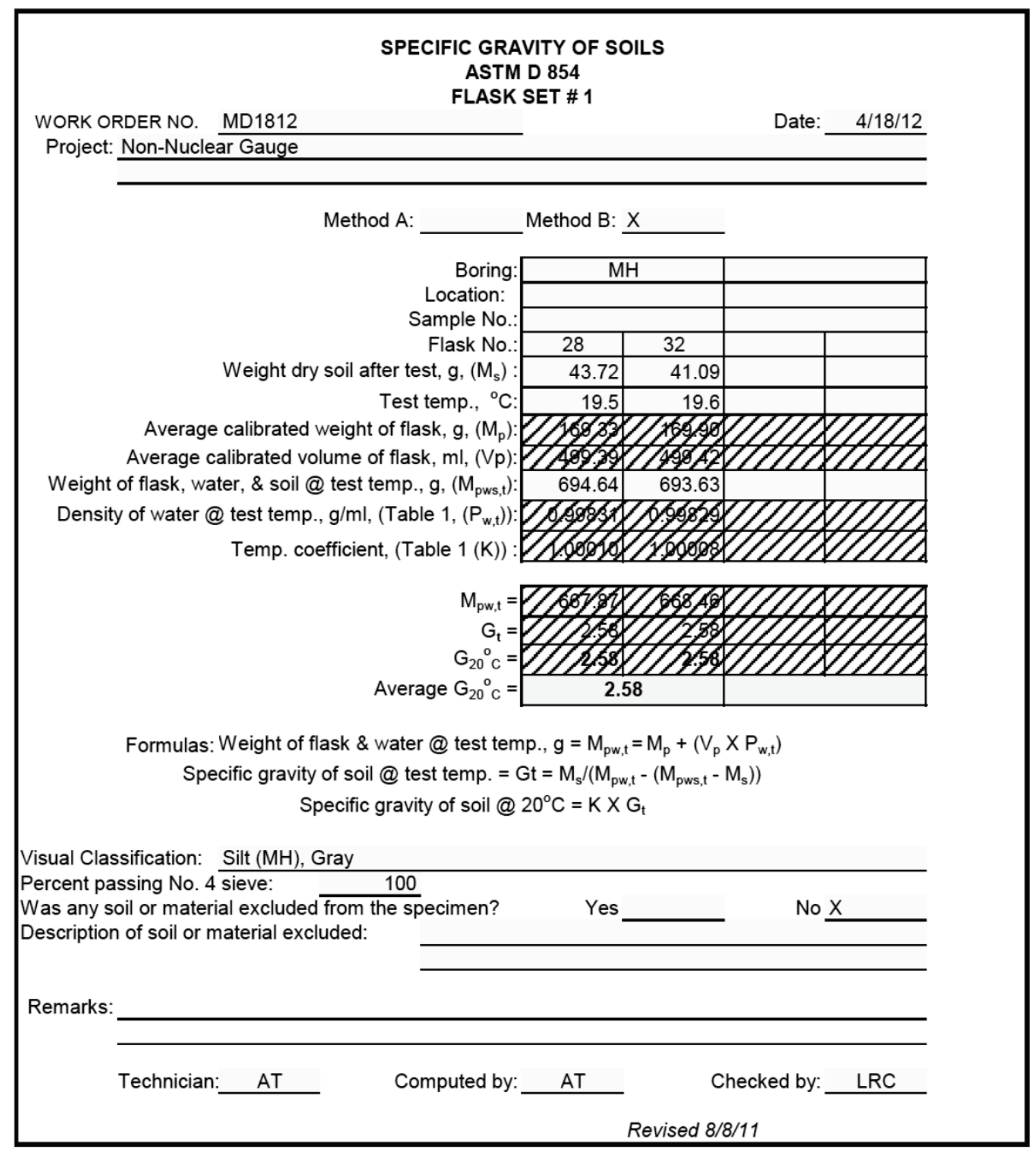




\section{B.10 ML}

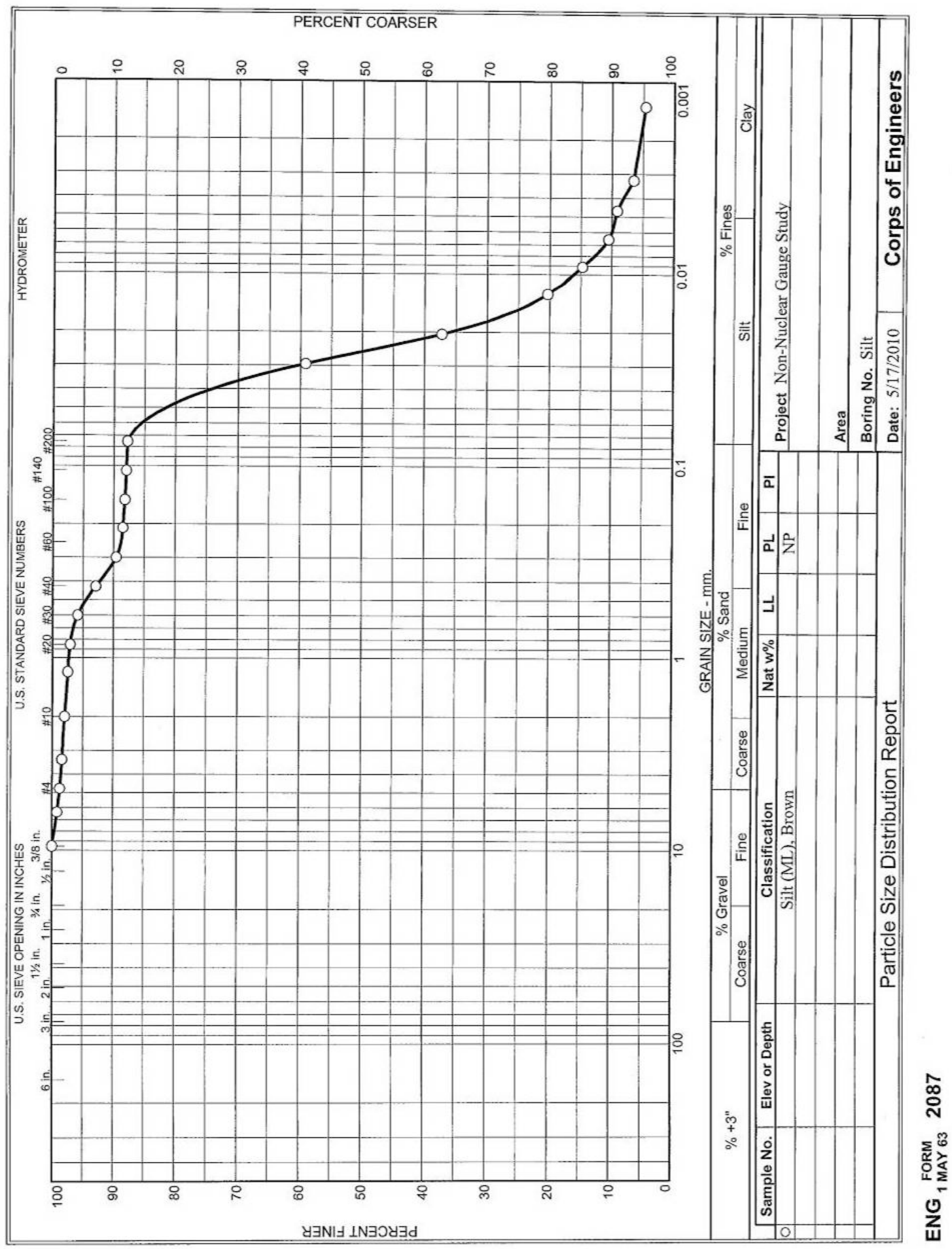




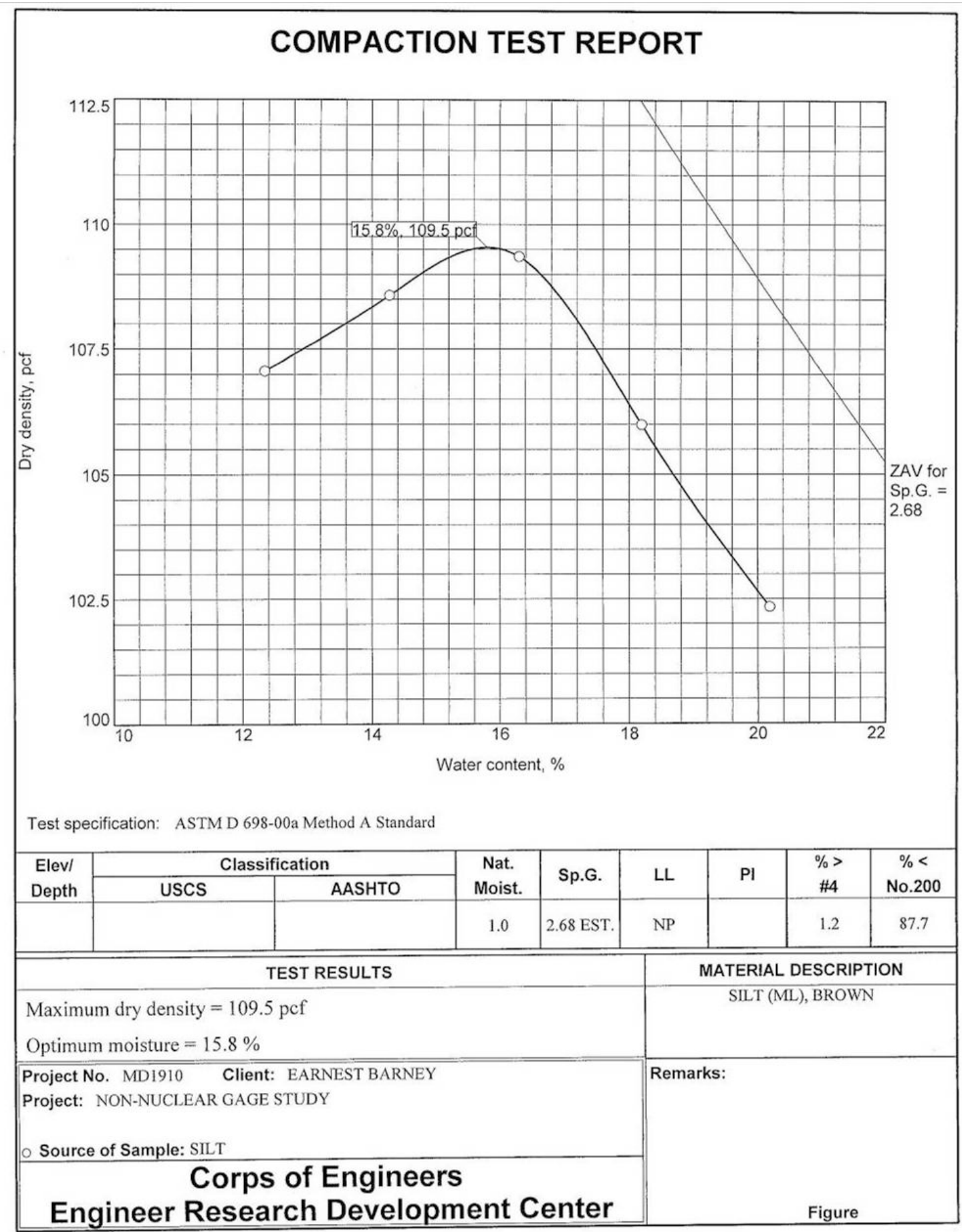

Tested By: CEC 


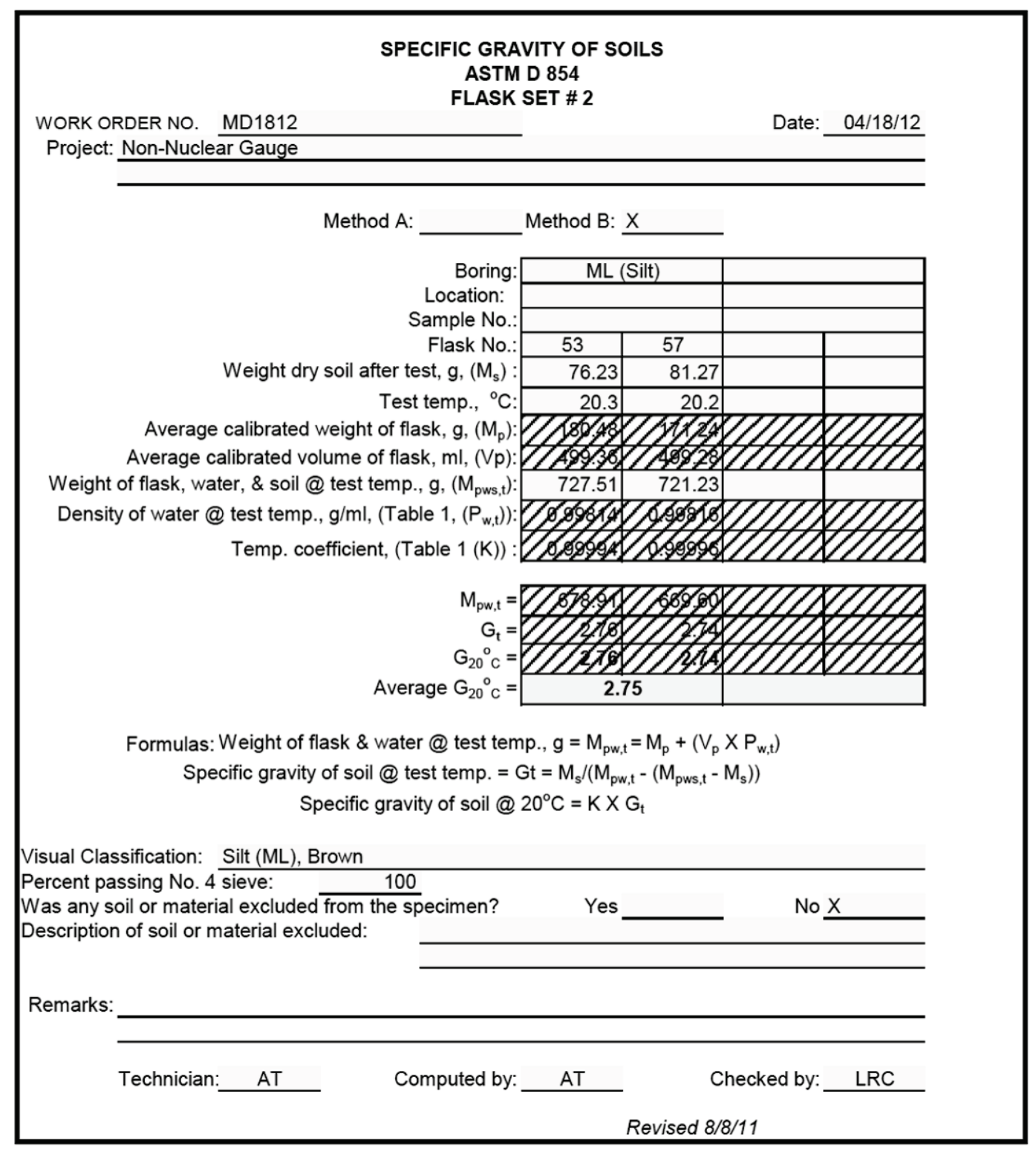




\section{B.11 SP}

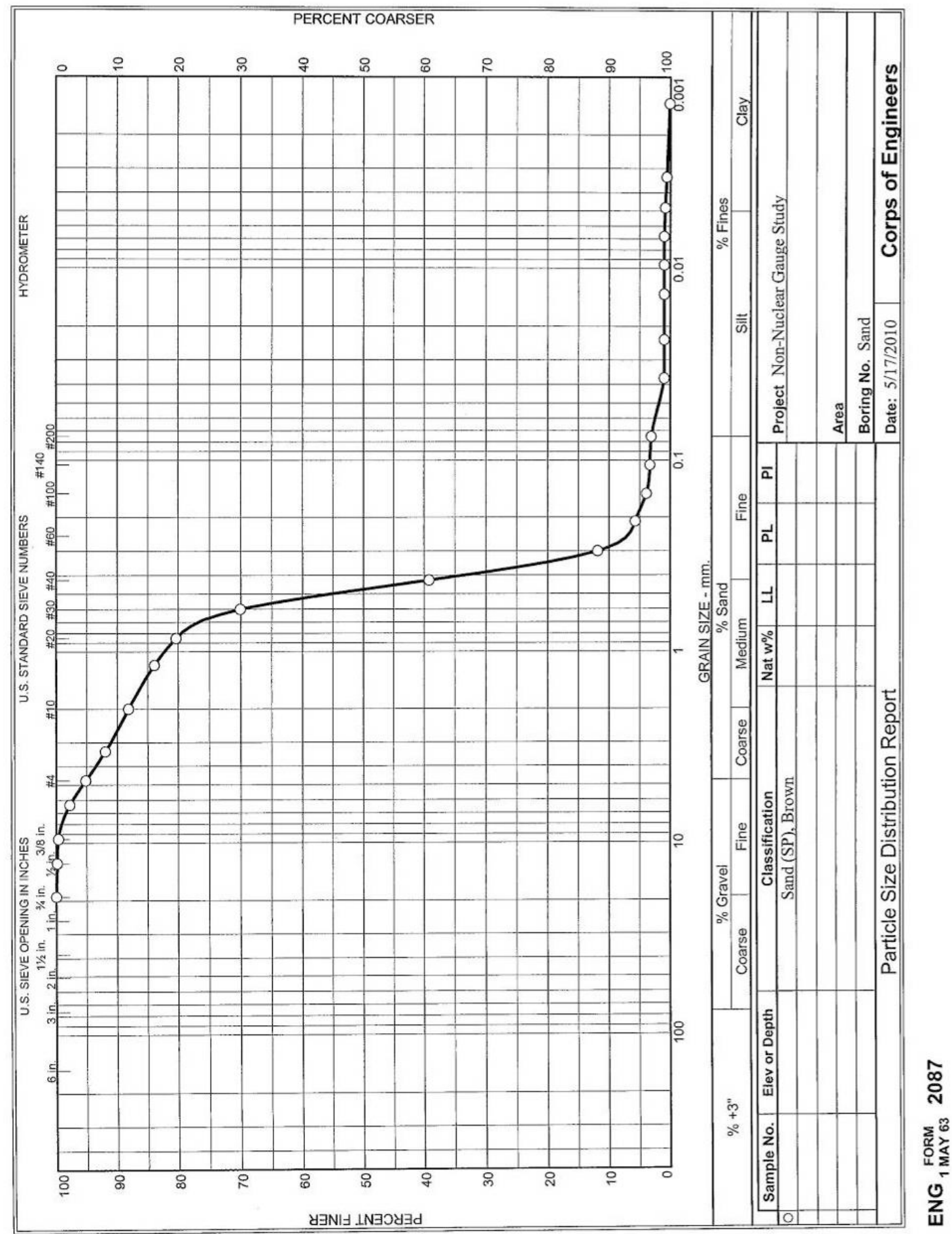




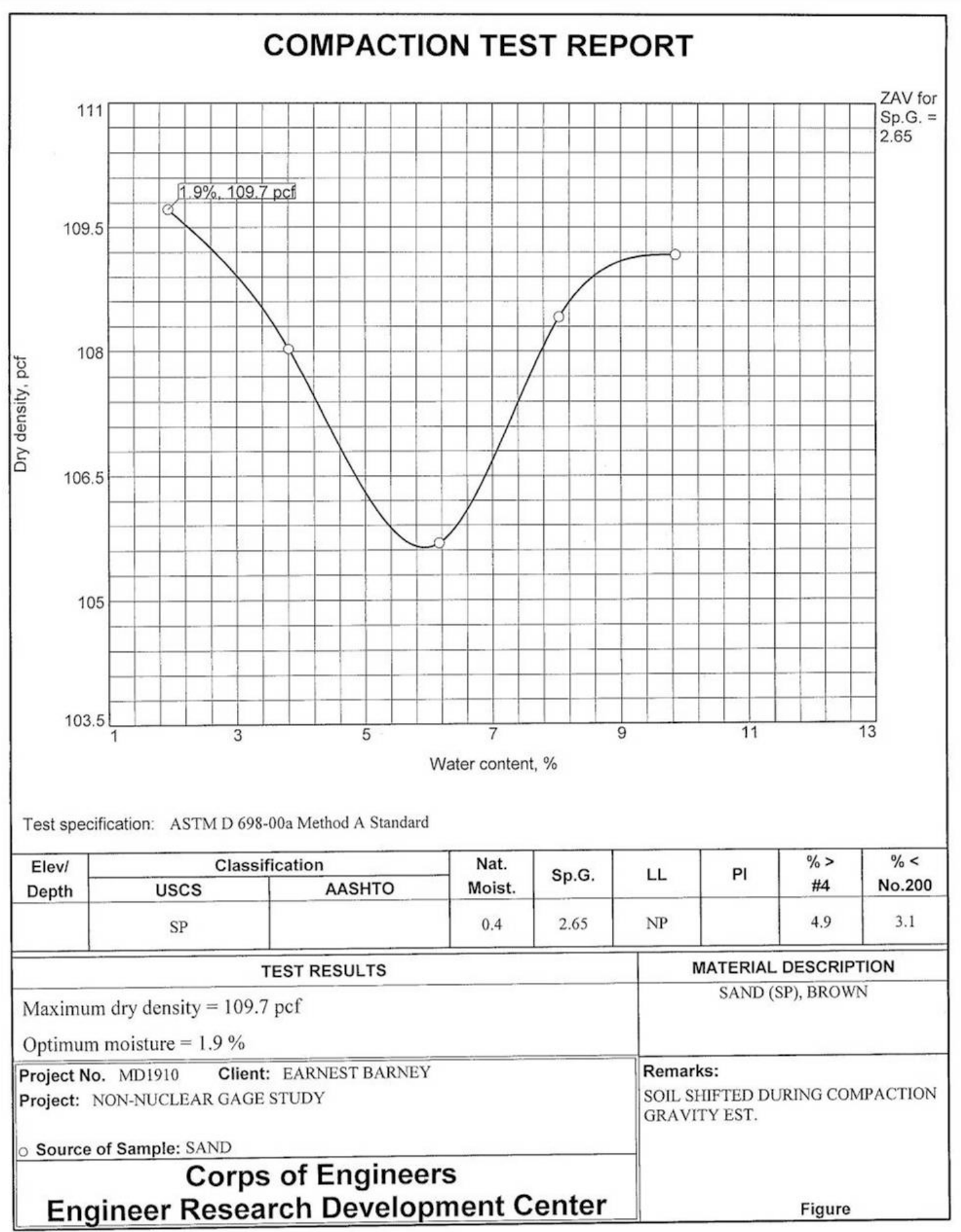

Tested By: CEC 


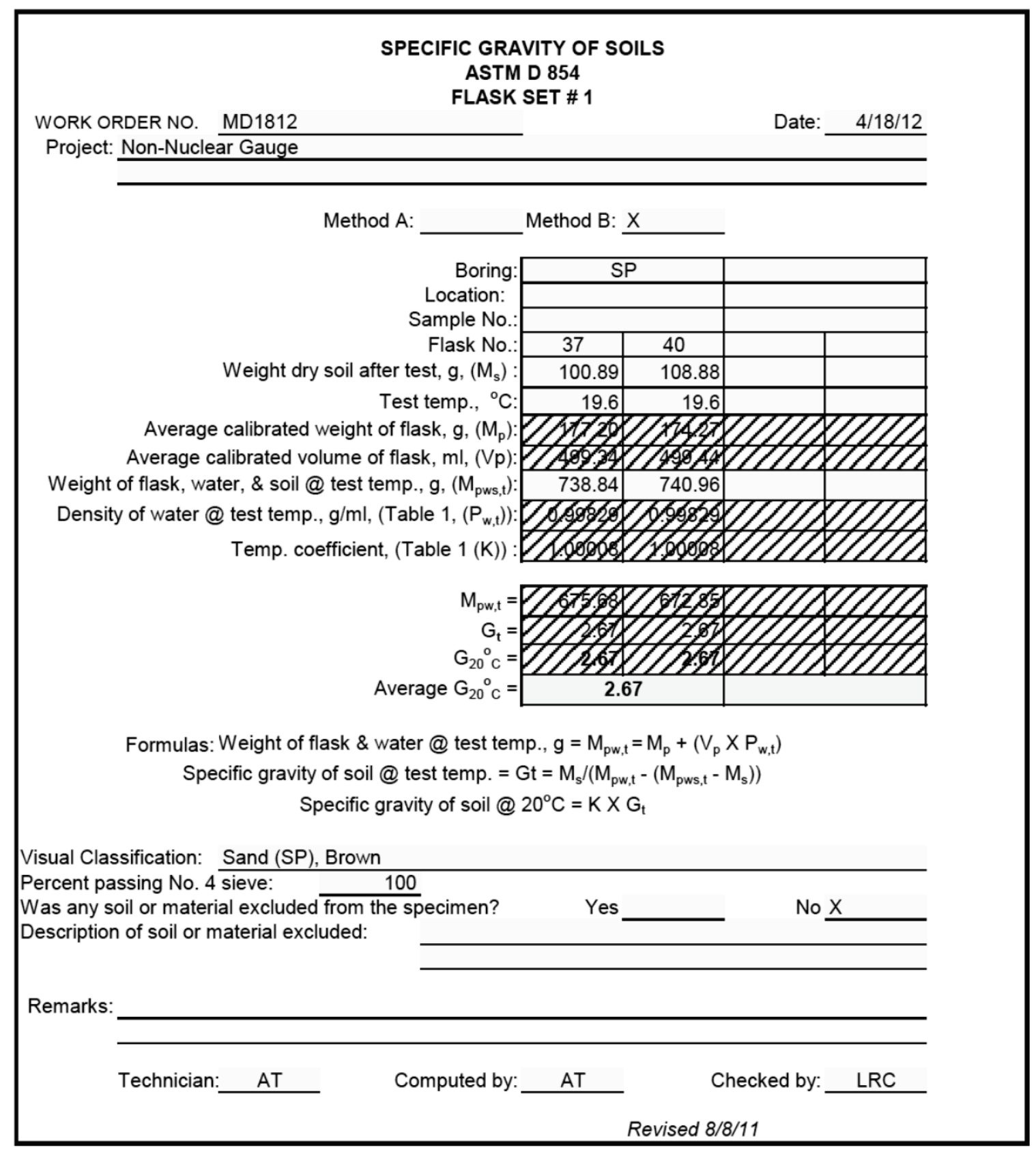




\section{B.12 SM}

Note: This soil was classified as Sandy-Silt (ML) by the MTC.

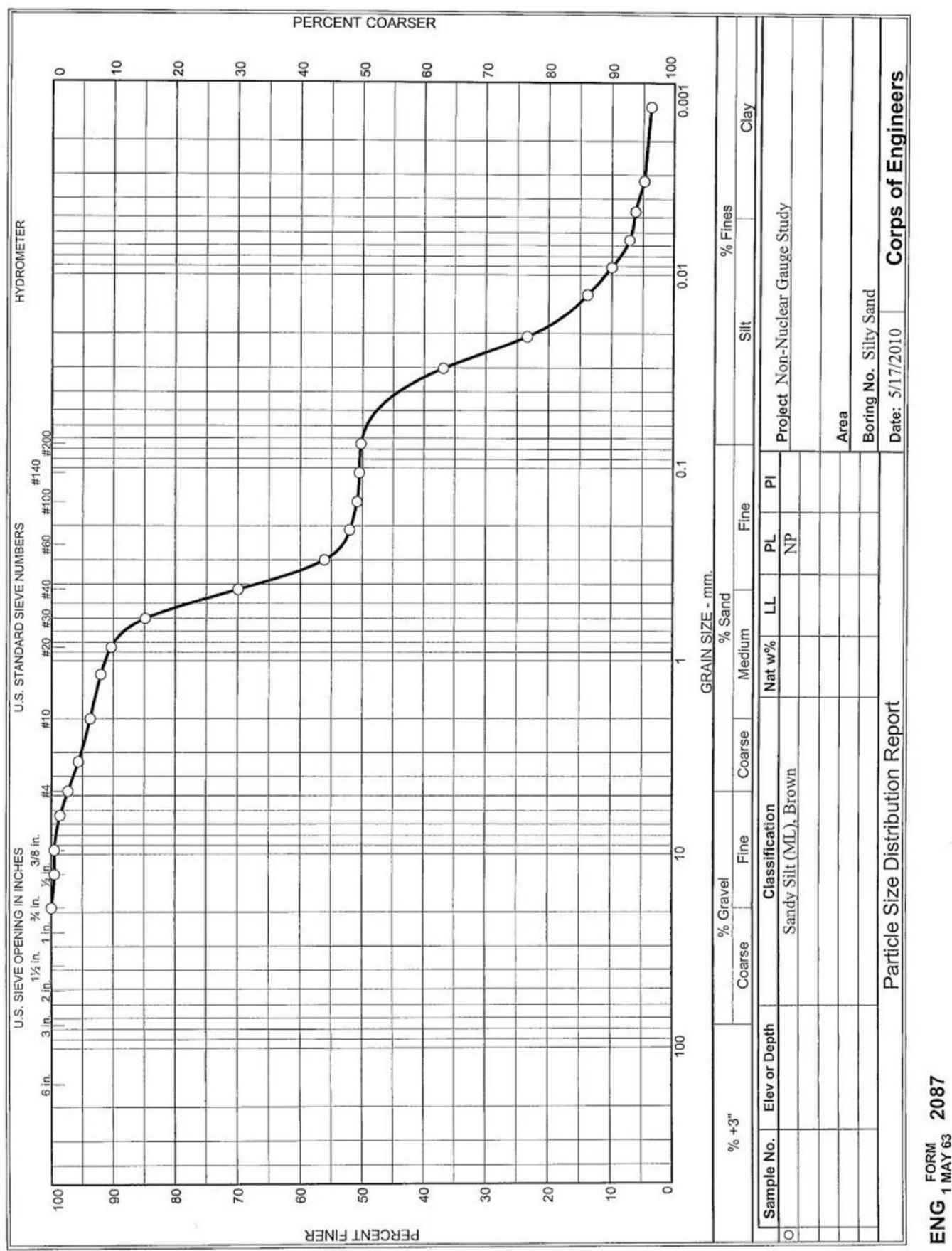




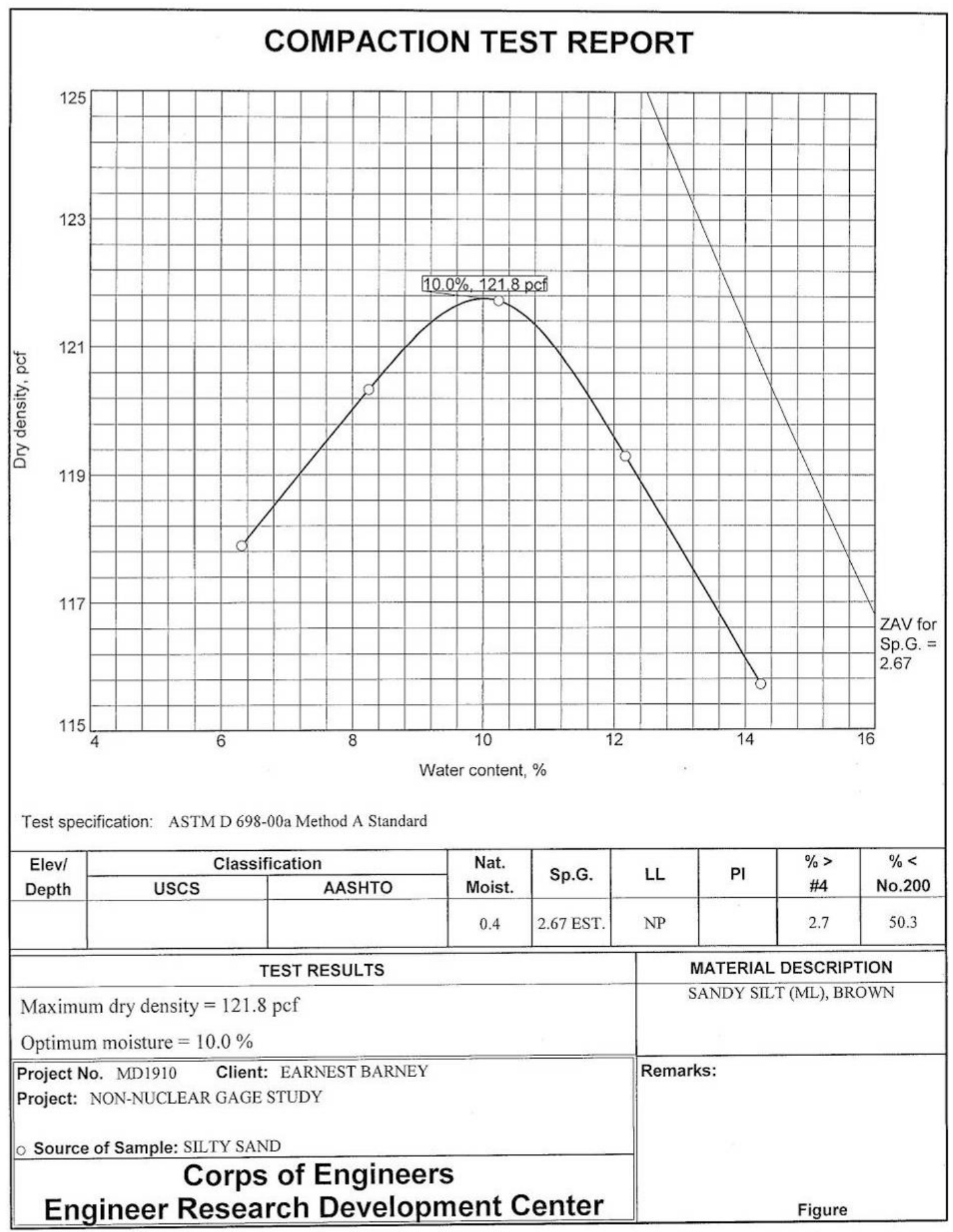

Tested By: CEC 


\section{SPECIFIC GRAVITY OF SOILS \\ ASTM D 854 \\ FLASK SET \# 1}

WORK ORDER NO. MD1812

Project: Non-Nuclear Gauge

Date: $\quad 4 / 18 / 12$

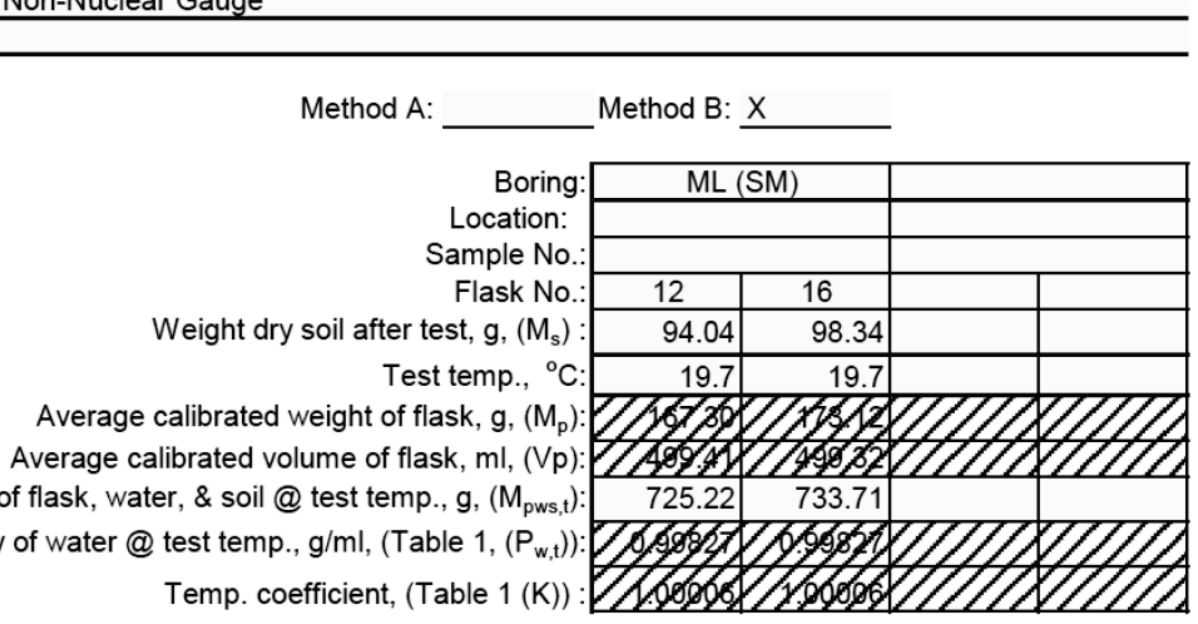

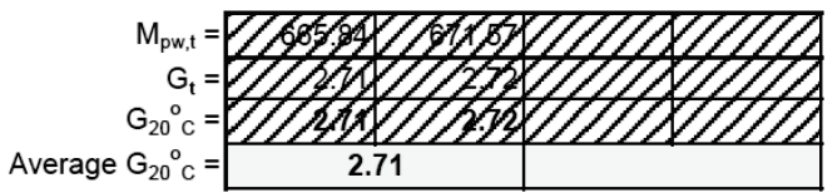

Formulas: Weight of flask \& water @ test temp., $g=M_{p w, t}=M_{p}+\left(V_{p} X P_{w, t}\right)$

Specific gravity of soil @ test temp. $=G t=M_{s} /\left(M_{p w, t}-\left(M_{p w s, t}-M_{s}\right)\right)$

Specific gravity of soil @ $20^{\circ} \mathrm{C}=\mathrm{KX} \mathrm{G}_{\mathrm{t}}$

Visual Classification: Silty Sand (SM), Brown

Percent passing No. 4 sieve: $\quad 100$

Was any soil or material excluded from the specimen?

Description of soil or material excluded:

Yes

No $\underline{X}$

$\longrightarrow$

Remarks:

Technician: AT

Computed by:

AT

Checked by:

LRC 


\section{B.13 SP-SC}

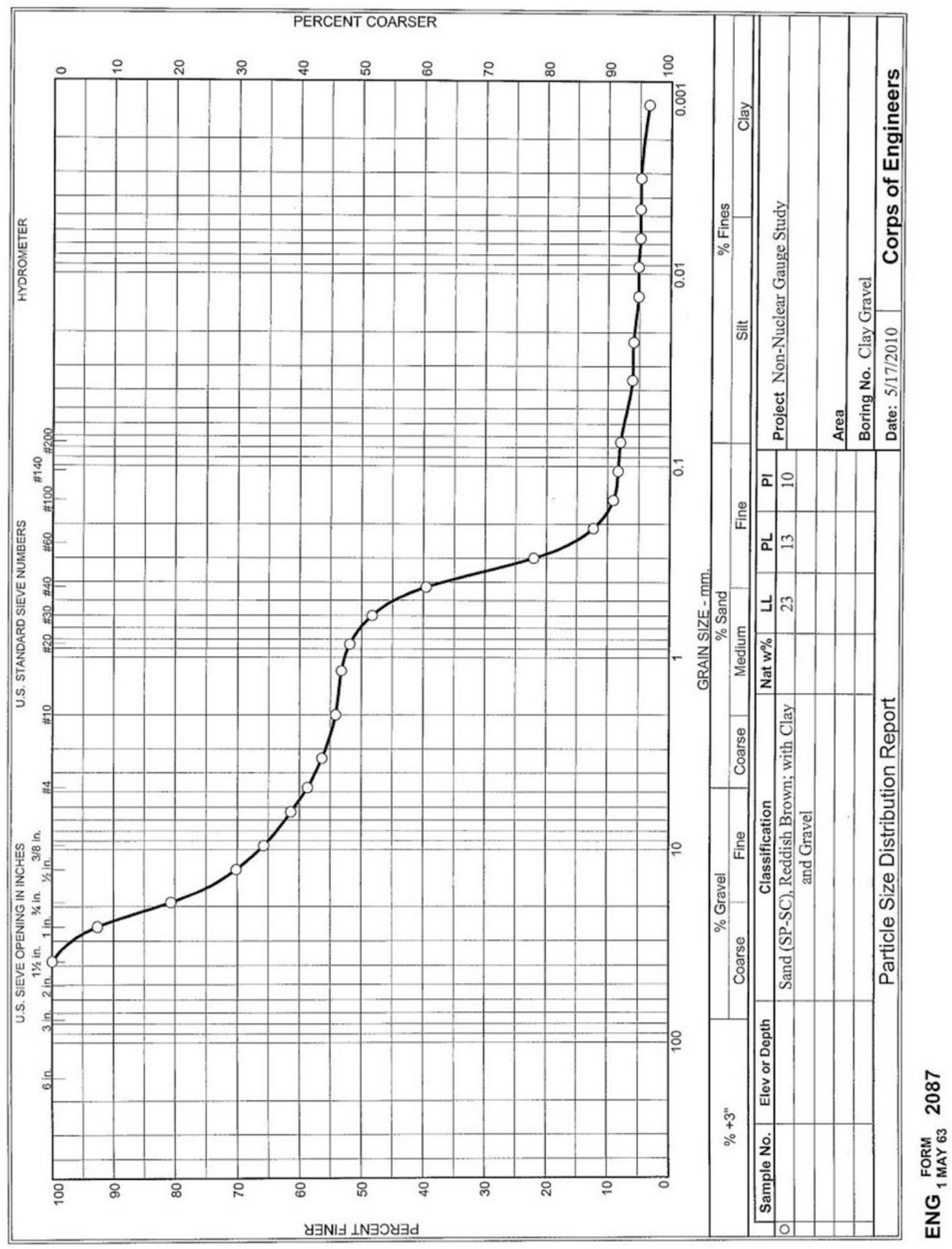




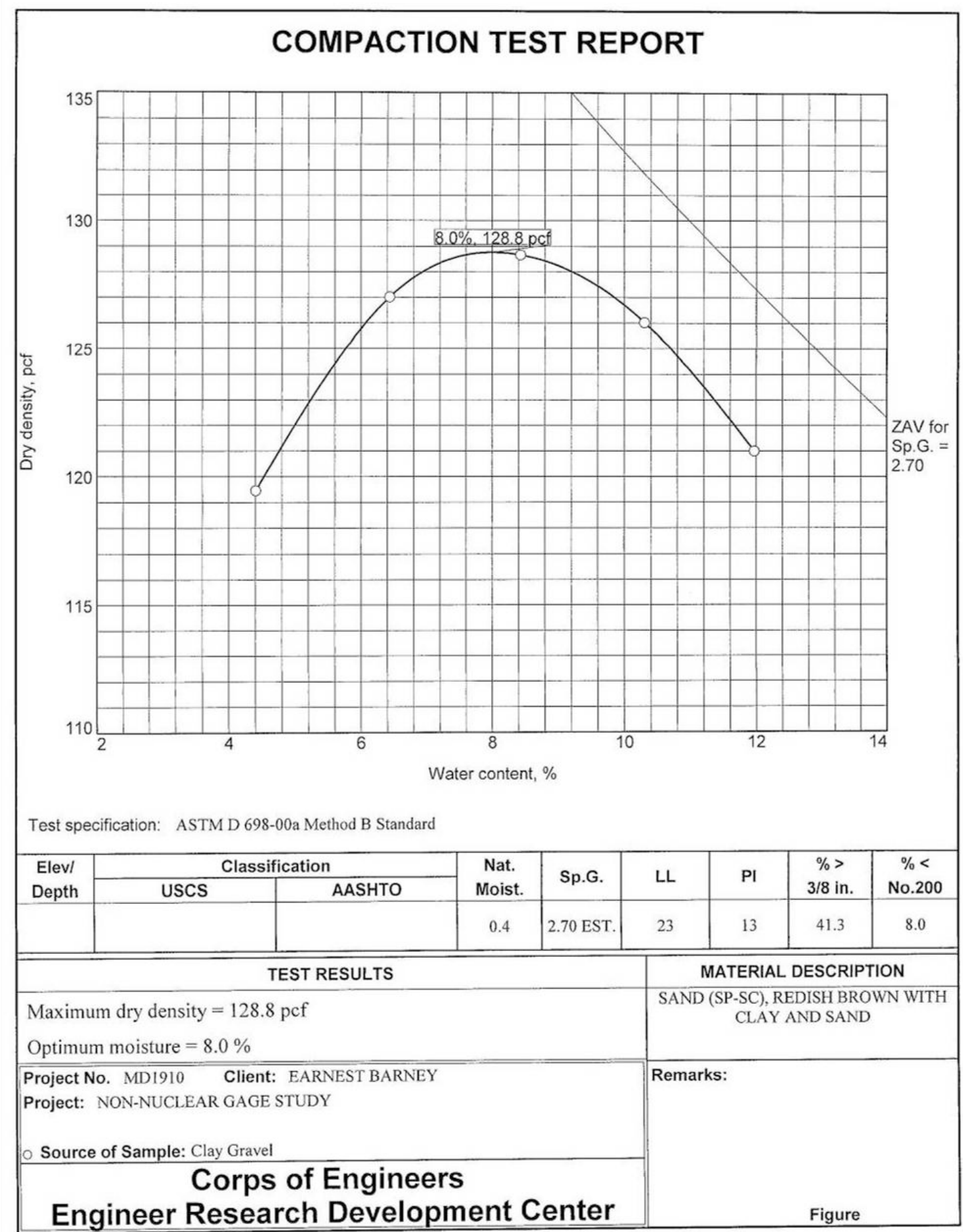

Tested By: CEC 


\section{SPECIFIC GRAVITY OF SOILS \\ ASTM D 854 \\ FLASK SET \# 1}

WORK ORDER NO. MD1812

Project: Non-Nuclear Gauge

Date: $4 / 18 / 12$

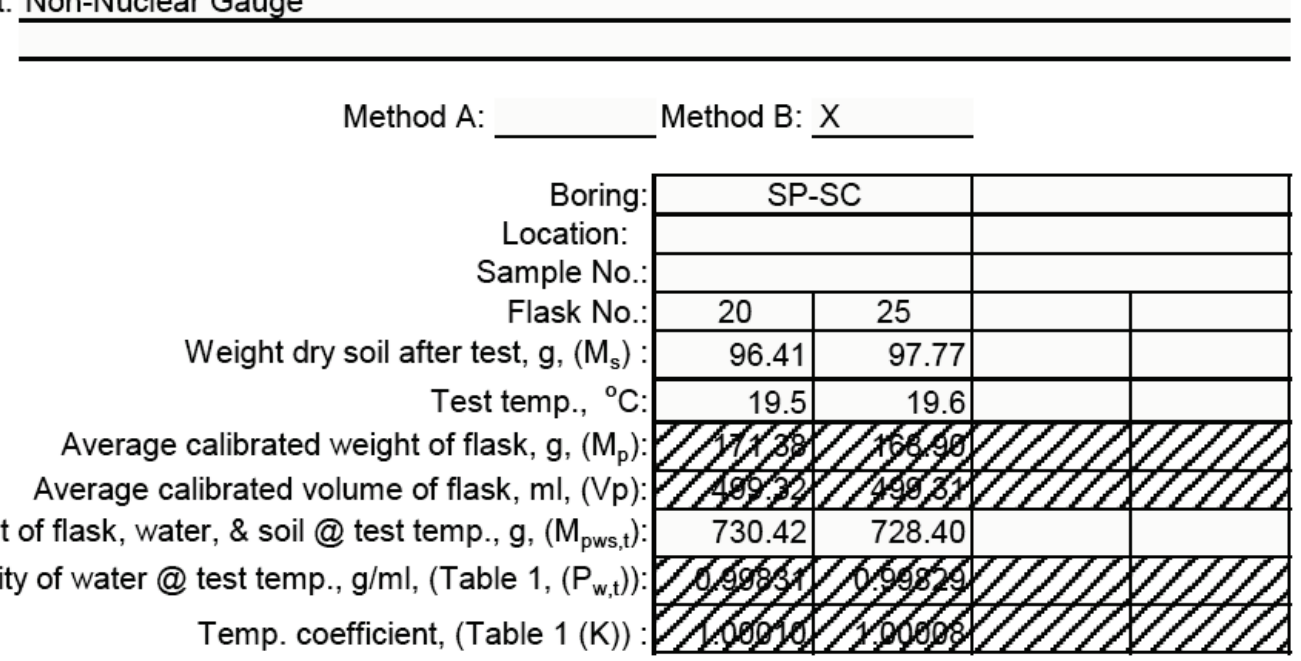

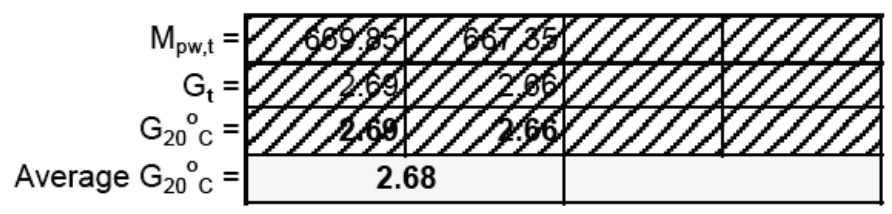

Formulas: Weight of flask \& water @ test temp., $g=M_{p w, t}=M_{p}+\left(V_{p} X P_{w, t}\right)$

Specific gravity of soil @ test temp. $=G t=M_{s} /\left(M_{p w, t}-\left(M_{p w s, t}-M_{s}\right)\right)$

Specific gravity of soil @ $20^{\circ} \mathrm{C}=\mathrm{KX} \mathrm{G}_{\mathrm{t}}$

Visual Classification: Clayey Sand (SC), Reddish Brown

Percent passing No. 4 sieve: $\frac{100}{100}$

Was any soil or material excluded from the specimen? $\quad$ Yes $\quad$ No $X$

Description of soil or material excluded:

Remarks:

Technician: AT

Computed by:

AT

Checked by: LRC 


\section{B.14 Limestone}

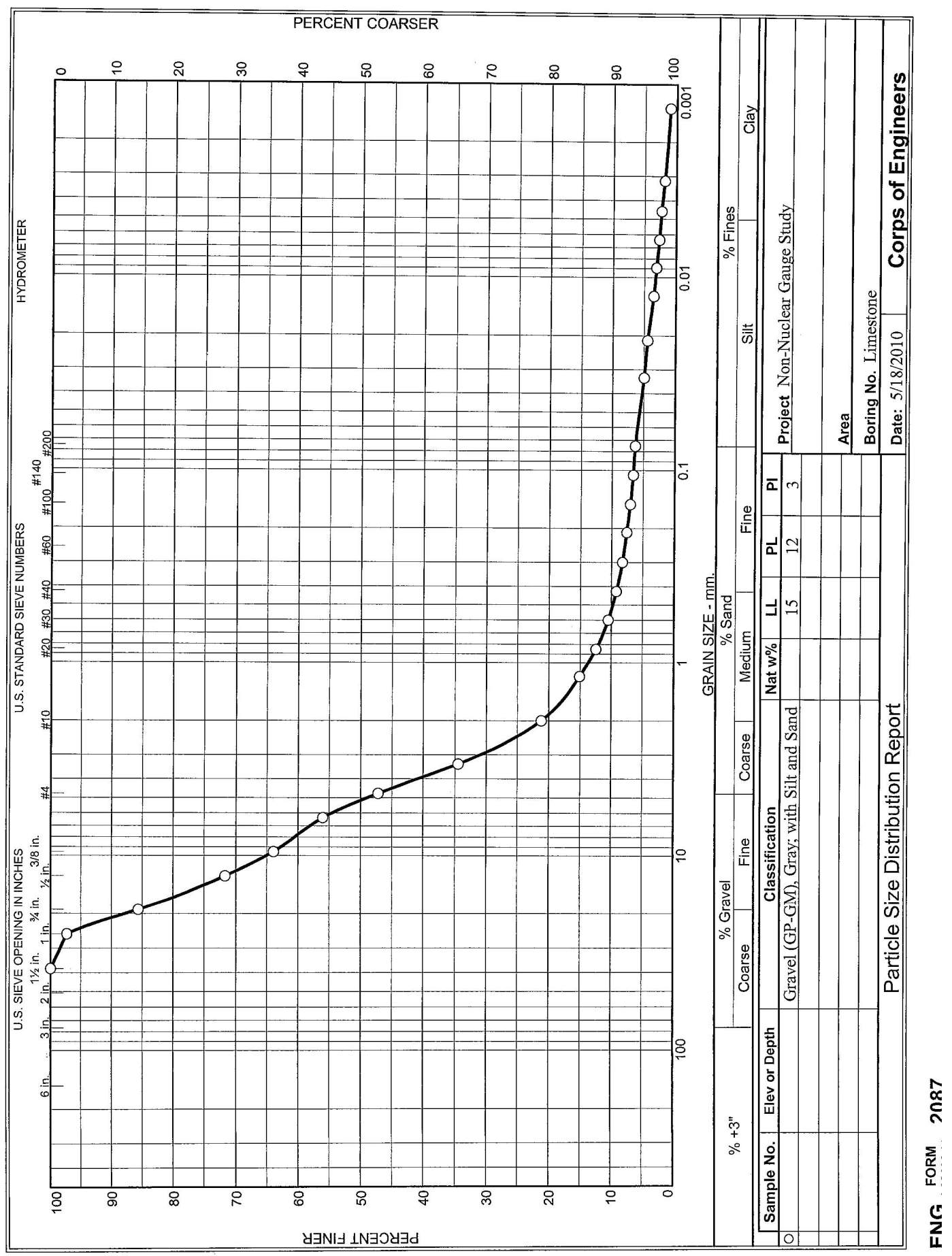




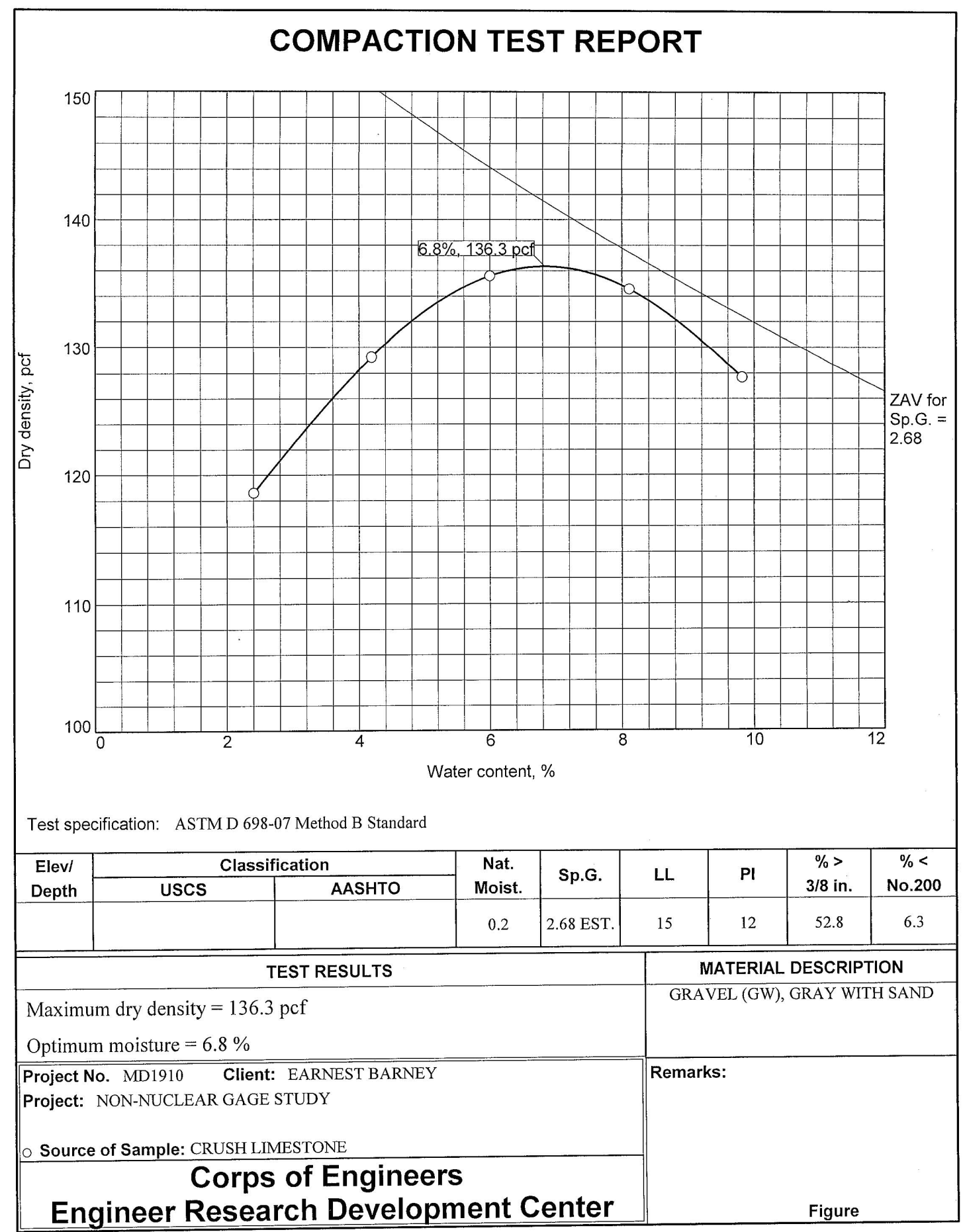

Tested By: CEC 
Client: Ernest Berney

Project: Non-Nuclear gage study

Project Number: MD1910A

Location: Limestone

Material Description: Silt (ML), Gray

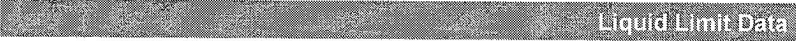

\begin{tabular}{r|c|c|c|c|c|c}
\hline Run No. & $\mathbf{1}$ & $\mathbf{2}$ & $\mathbf{3}$ & $\mathbf{4}$ & $\mathbf{5}$ & $\mathbf{6}$ \\
\hline Wet+Tare & 31.21 & 32.52 & 37.35 & 33.34 & & \\
\hline Dry+Tare & 29.23 & 30.44 & 34.69 & 31.06 & & \\
\hline Tare & 16.63 & 16.69 & 16.72 & 15.44 & & \\
\hline \# Blows & 17 & 24 & 29 & 32 & & \\
\hline Moisture & 15.7 & 15.1 & 14.8 & 14.6 & & \\
\hline
\end{tabular}

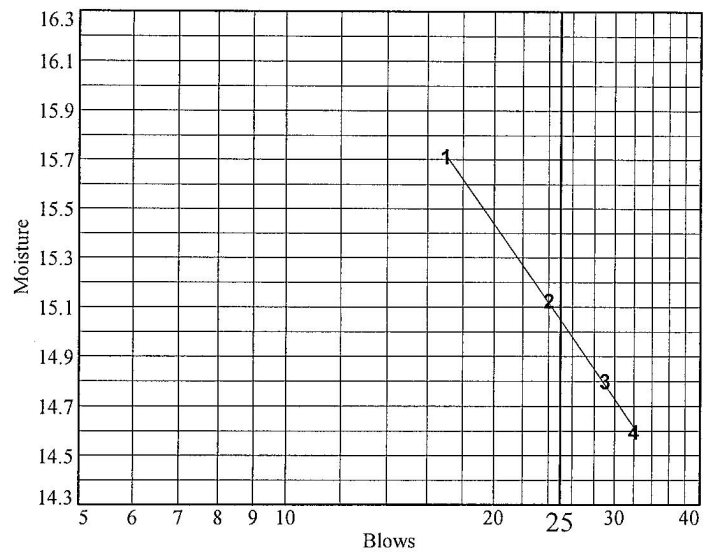

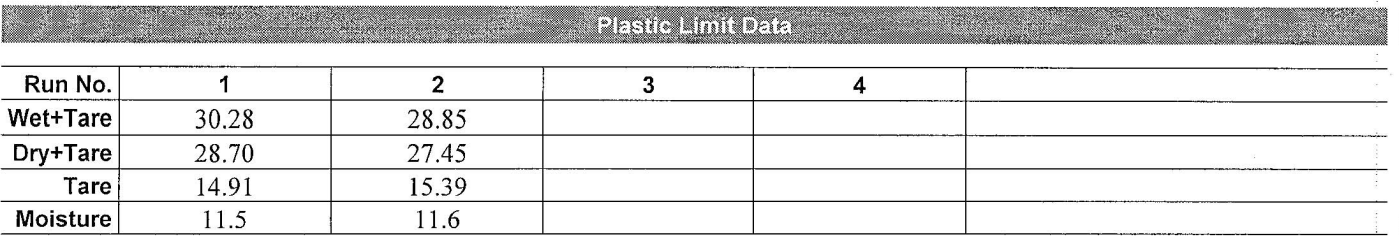


Client: Ernest Berney

Project: Non-Nuclear gage study

Project Number: MD1910A

Location: Limestone

Material Description: Silt (ML), Gray

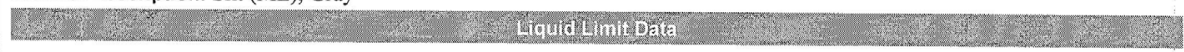

\begin{tabular}{r|c|c|c|c|c|c}
\hline Run No. & $\mathbf{1}$ & $\mathbf{2}$ & $\mathbf{3}$ & $\mathbf{4}$ & $\mathbf{5}$ & $\mathbf{6}$ \\
\hline Wet+Tare & 31.21 & 32.52 & 37.35 & 33.34 & & \\
\hline Dry+Tare & 29.23 & 30.44 & 34.69 & 31.06 & & \\
\hline Tare & 16.63 & 16.69 & 16.72 & 15.44 & & \\
\hline \# Blows & 17 & 24 & 29 & 32 & & \\
\hline Moisture & 15.7 & 15.1 & 14.8 & 14.6 & & \\
\hline
\end{tabular}

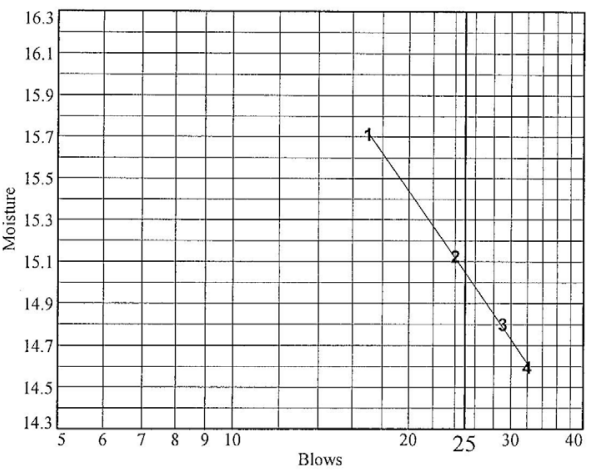

Liquid Limit $=\quad 15$

\begin{aligned} & Plastic Limit $= 12 \\ &$ Plasticity Index $=3 \\ &$\hline\end{aligned}

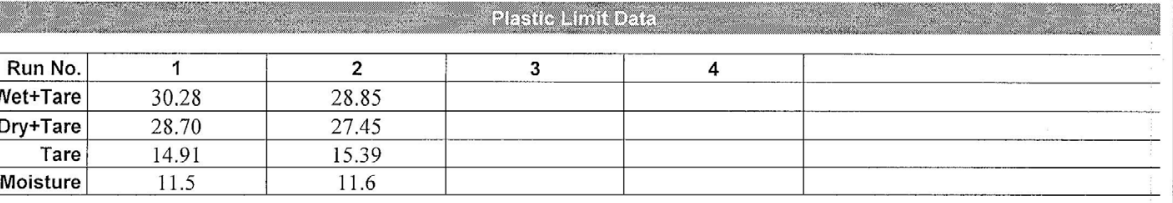




\section{Appendix C: Summary of Grain Size Data}

Table 9. Average of percent passing each sieve from 3 replicates for all soils and techniques evaluated.

\begin{tabular}{|c|c|c|c|c|c|c|c|c|c|c|c|c|c|}
\hline & ASTM & & & & & & & & & & & & \\
\hline Sieve & \multicolumn{13}{|c|}{ Percent Passing Average } \\
\hline Number & Sand & SM & $\mathrm{GC}$ & Lime & SC-1 & SC-2 & $\mathrm{CH}$ (ERDC) & $\mathrm{CH}-2$ & $\mathrm{CH}-3$ & $\mathrm{ML}$ & $\mathrm{CL}-1$ & $\mathrm{CL}-2$ & $\mathrm{CL}-3$ \\
\hline $1 "$ & 100.0 & 100.0 & 97.6 & 98.0 & 100.0 & 100.0 & 100.0 & 100.0 & 100.0 & 100.0 & 100.0 & 100.0 & 100.0 \\
\hline $1 / 2^{\prime \prime}$ & 99.7 & 100.0 & 88.1 & 80.4 & 98.1 & 100.0 & 99.6 & 99.5 & 99.2 & 98.6 & 100.0 & 100.0 & 98.4 \\
\hline 4 & 96.1 & 85.9 & 82.7 & 56.2 & 94.7 & 98.8 & 99.4 & 98.2 & 96.1 & 98.3 & 96.8 & 99.0 & 95.4 \\
\hline 10 & 87.1 & 81.4 & 80.3 & 34.2 & 90.7 & 97.6 & 98.9 & 96.2 & 94.3 & 97.5 & 95.3 & 97.8 & 91.8 \\
\hline 20 & 80.4 & 76.4 & 77.1 & 20.2 & 85.9 & 96.5 & 98.3 & 94.7 & 92.7 & 96.6 & 94.1 & 96.5 & 89.9 \\
\hline 40 & 57.0 & 62.6 & 51.5 & 14.0 & 79.3 & 90.5 & 96.9 & 90.8 & 89.8 & 95.5 & 91.1 & 94.0 & 87.1 \\
\hline 100 & 10.4 & 51.2 & 11.3 & 8.8 & 58.2 & 42.5 & 89.7 & 77.2 & 76.1 & 92.3 & 67.1 & 76.0 & 68.9 \\
\hline \multirow[t]{3}{*}{200} & 6.8 & 51.0 & 10.0 & 6.8 & 39.9 & 32.1 & 85.3 & 70.9 & 62.9 & 91.7 & 49.5 & 61.0 & 53.5 \\
\hline & & & & & & & & & & & & & \\
\hline & RSAK-W & & & & & & & & & & & & \\
\hline Sieve & \multicolumn{13}{|c|}{ Percent Passing Average } \\
\hline Number & Sand & SM & $\mathrm{GC}$ & Lime & SC-1 & SC-2 & $\mathrm{CH}$ (ERDC) & $\mathrm{CH}-2$ & $\mathrm{CH}-3$ & $\mathrm{ML}$ & $\mathrm{CL}-1$ & $\mathrm{CL}-2$ & $\mathrm{CL}-3$ \\
\hline $1 "$ & 100.0 & 100.0 & 100.0 & 100.0 & 100.0 & 100.0 & 100.0 & 100.0 & 100.0 & 100.0 & 100.0 & 100.0 & 100.0 \\
\hline $1 / 2^{\prime \prime}$ & 100.0 & 99.7 & 92.9 & 89.9 & 99.4 & 100.0 & 100.0 & 100.0 & 98.0 & 100.0 & 99.9 & 100.0 & 100.0 \\
\hline 4 & 96.3 & 88.2 & 88.5 & 66.3 & 96.2 & 99.1 & 99.7 & 98.6 & 96.7 & 99.9 & 99.0 & 98.7 & 97.7 \\
\hline 10 & 87.3 & 83.8 & 86.1 & 41.9 & 90.8 & 98.0 & 97.5 & 96.4 & 95.3 & 98.7 & 98.3 & 97.7 & 95.3 \\
\hline 20 & \begin{tabular}{l|l}
80.9 \\
\end{tabular} & 78.5 & 83.0 & 26.6 & 83.2 & 96.6 & 85.5 & 89.6 & 92.0 & 95.8 & 97.2 & 96.4 & 93.0 \\
\hline 40 & 54.7 & 62.8 & 56.7 & 16.8 & 65.2 & 86.8 & 65.9 & 75.6 & 85.3 & 90.2 & 94.5 & 93.6 & 89.4 \\
\hline 100 & 10.1 & 51.6 & 18.2 & 12.6 & 34.5 & 29.4 & 51.1 & 39.8 & 56.4 & 81.9 & 62.7 & 71.8 & 60.6 \\
\hline \multirow[t]{3}{*}{200} & 4.9 & 45.5 & 15.8 & 10.7 & 30.8 & 22.5 & 46.5 & 25.5 & 28.9 & 67.3 & 41.9 & 50.1 & 21.7 \\
\hline & & & & & & & & & & & & & \\
\hline & RSAK-D & & & & & & & & & & & & \\
\hline Sieve & \multicolumn{13}{|c|}{ Percent Passing Average } \\
\hline Number & Sand & SM & $\mathrm{GC}$ & Lime & SC-1 & SC-2 & $\mathrm{CH}$ (ERDC) & $\mathrm{CH}-2$ & $\mathrm{CH}-3$ & $\mathrm{ML}$ & $\mathrm{CL}-1$ & $\mathrm{CL}-2$ & CL-3 \\
\hline $1 "$ & 100.0 & 100.0 & 96.9 & 100.0 & 100.0 & 100.0 & 100.0 & 96.3 & 100.0 & 100.0 & 100.0 & 100.0 & 100.0 \\
\hline $1 / 2^{\prime \prime}$ & 100.0 & 100.0 & 90.3 & 83.5 & 98.8 & 100.0 & 100.0 & 96.3 & 99.1 & 100.0 & 100.0 & 100.0 & 99.7 \\
\hline 4 & 96.4 & 85.2 & 85.8 & 58.6 & 95.7 & 99.2 & 99.9 & 95.8 & 97.9 & 99.8 & 99.5 & 98.9 & 96.3 \\
\hline 10 & 87.1 & 80.4 & 83.1 & 33.9 & 93.4 & 98.8 & 99.9 & 95.5 & 97.1 & 98.9 & 98.3 & 97.5 & 94.2 \\
\hline 20 & 76.8 & 73.2 & 72.8 & 16.8 & 88.7 & 98.1 & 95.7 & 94.0 & 95.1 & 93.7 & 95.7 & 93.9 & 90.9 \\
\hline 40 & 40.6 & 52.5 & 38.1 & 9.7 & 80.1 & 93.4 & 68.8 & 79.3 & 88.4 & 81.8 & 91.2 & 88.5 & 86.1 \\
\hline 100 & 3.6 & 38.1 & 4.3 & 2.3 & 36.2 & 21.7 & 20.3 & 16.9 & 38.9 & 68.1 & 49.4 & 40.1 & 52.5 \\
\hline 200 & 0.7 & 16.3 & 1.9 & 0.3 & 2.9 & 2.1 & 1.6 & 1.7 & 3.7 & 36.7 & 5.9 & 5.0 & 5.3 \\
\hline
\end{tabular}


Figure 29. Comparison of percent passing each sieve between RSAK techniques and ASTM procedure for all soils tested.

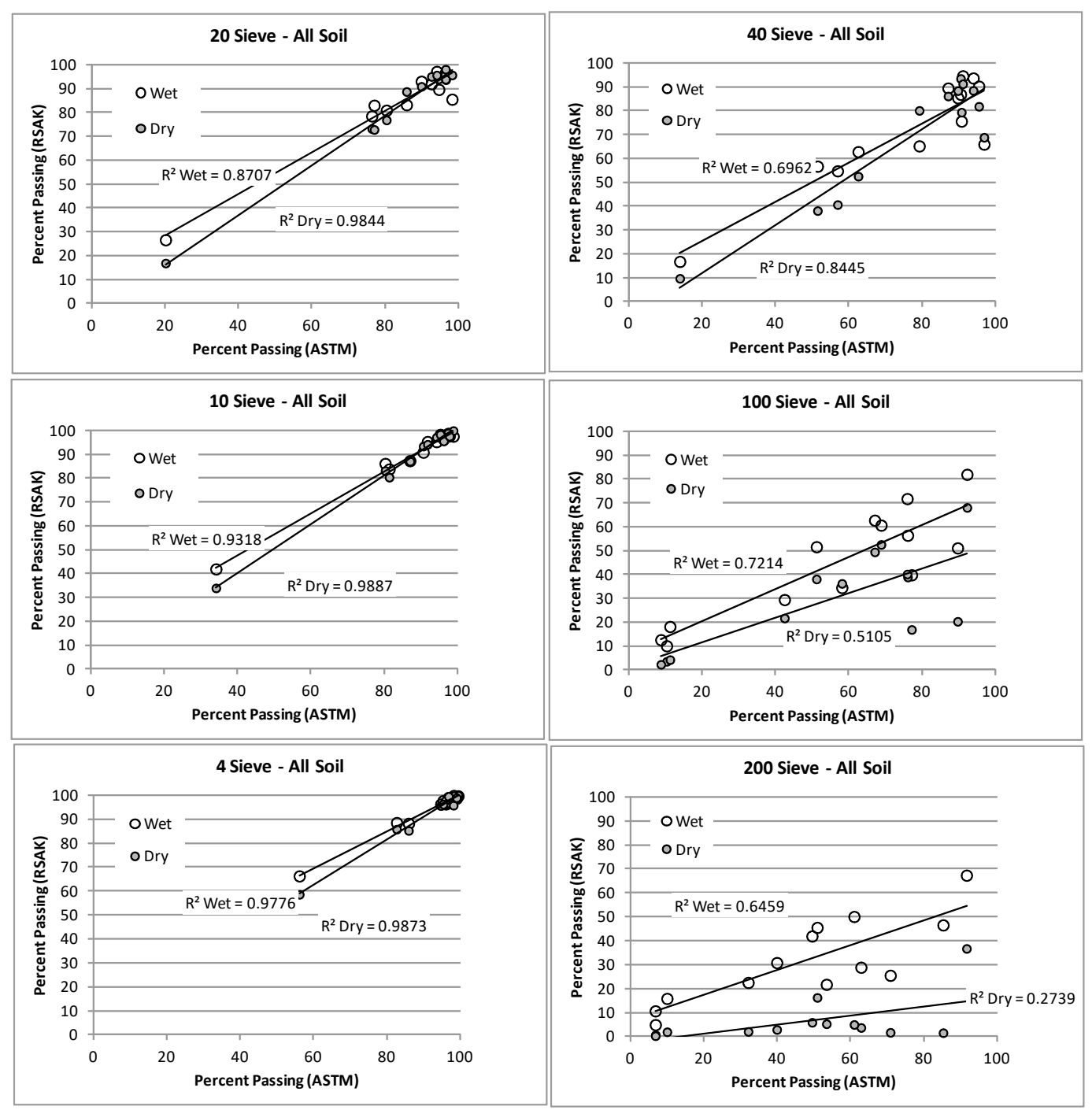


Figure 30. Comparison of percent passing each sieve between RSAK and ASTM procedure for soils classified as coarse grained ( $<50 \%$ fines).

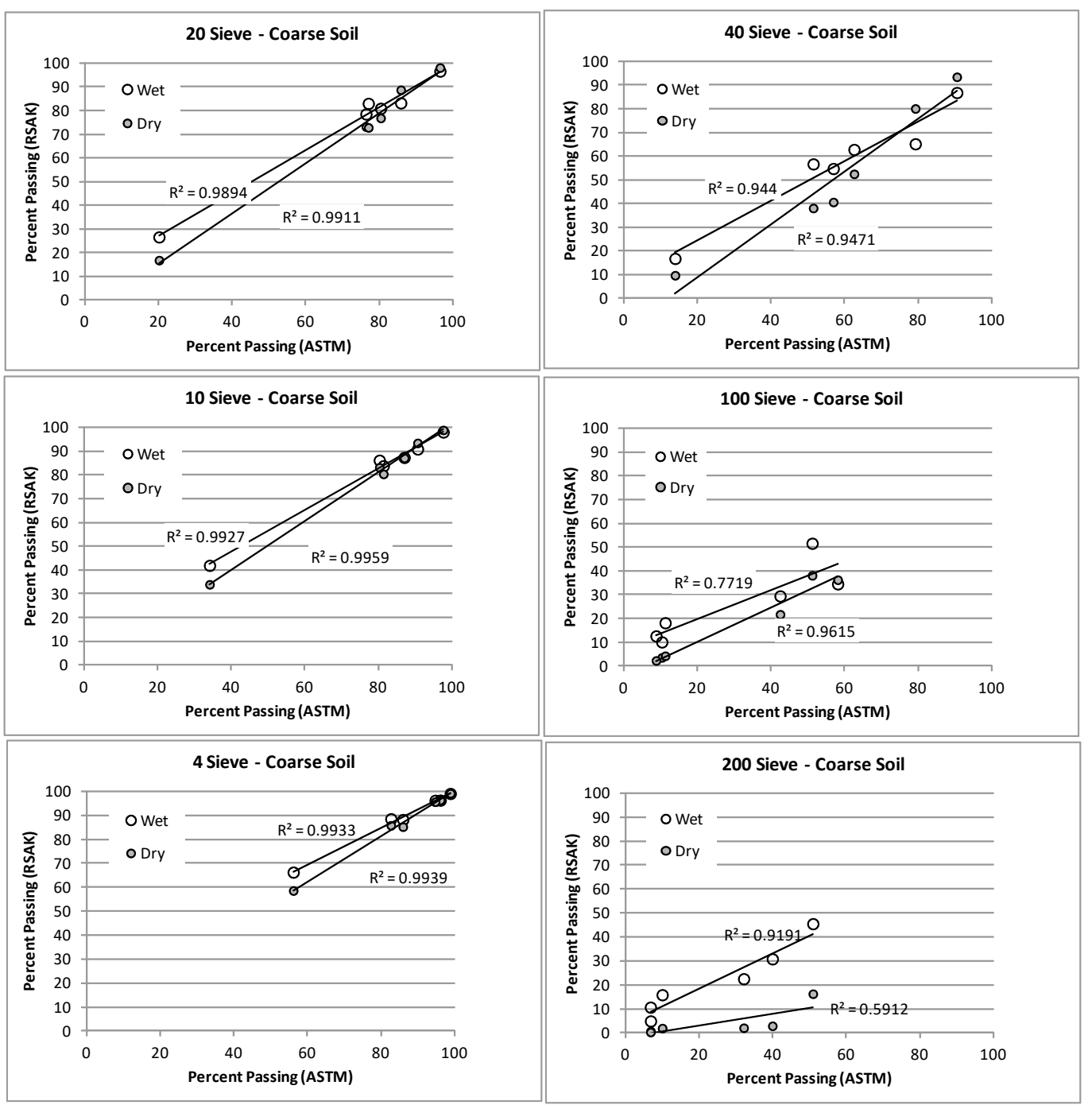




\section{Appendix D: Army Soils Kit LIN-V92959}

The following is the document detailing the specific components of the Army field soils kit. This kit also includes all necessary surveying and drafting equipment to perform the ground and site preparation that are not applicable to the soil engineering and classification determination. The figures listed in Chapter 2 illustrate only those portions of the Army Soils Kit that are necessary to perform the classification and engineering definitions. 
is

DIUI.16:6635-Y 8.CL-EUX $11 K$ SC 6635-98-CL-E02-HR

HAND RECEIPT CATALOG COVERING CONTENT OF:

Sets, Kits and Component List

TEST SET, SOIL

(NSN 6635-00-641-3643)

(LIN V92959)

(NSN 6635-00-926-1250) FOR MAP USE 
Hand Receip

SC 6635-98-CL-E02-HR

$$
\text { HEADQUARTERS }
$$

DEPARTMENT OF THE ARMY

Washington. D.C.. 19 April 1982

\author{
Hand Receipt Catalog \\ Covering Content Of:
}

Sets. Kits. and Outfits Components list

TEST SET, SOIL

(NSN 6635-00-641-3643)

(LIN V92959)

(NSN 6635-00-926-1250 FOR MAP USE)

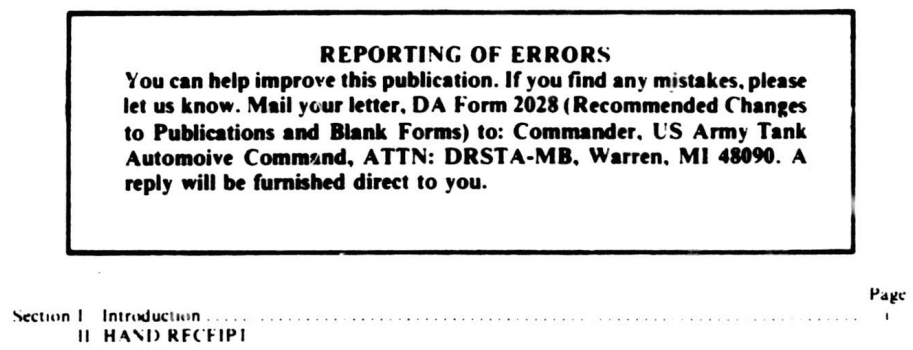

SECTION I

INTRODUCTION

1.Scope. This hand receipt cata log provides a listing on a preprinted DA Form 2062 (Hand Receipt) of accountable sets, kits. and outrits items related to Test Set. Soil.

receipt pages need not be counted under the inventory provicion of PAM 710-2-1. Items will be ordered as required. Local reproduction of the overprinted DA Form 2062 is authorized. Extra copies of the HR catalog ere

2.General. Section II of this catalog is an overprinted DA Form 2062 consisting of a listing of sets. kits. and outfit items extracted from SC $6635-98-C L-E 02$. The listing consists of exactly the same items and in the same seyuence as the components list listing. The overprinted DA Form 2062 will aid the property accountability officers in preparation of hand receipte required by PAM 710-2-1.

Those NSNs identified by an " $X$ " in the ARC on the hand 2062 is authorised
available through

Ci.mmander

2800 Eastern Boulevard

Baltimore. Maryland 21220

PAM 710-2-1. 


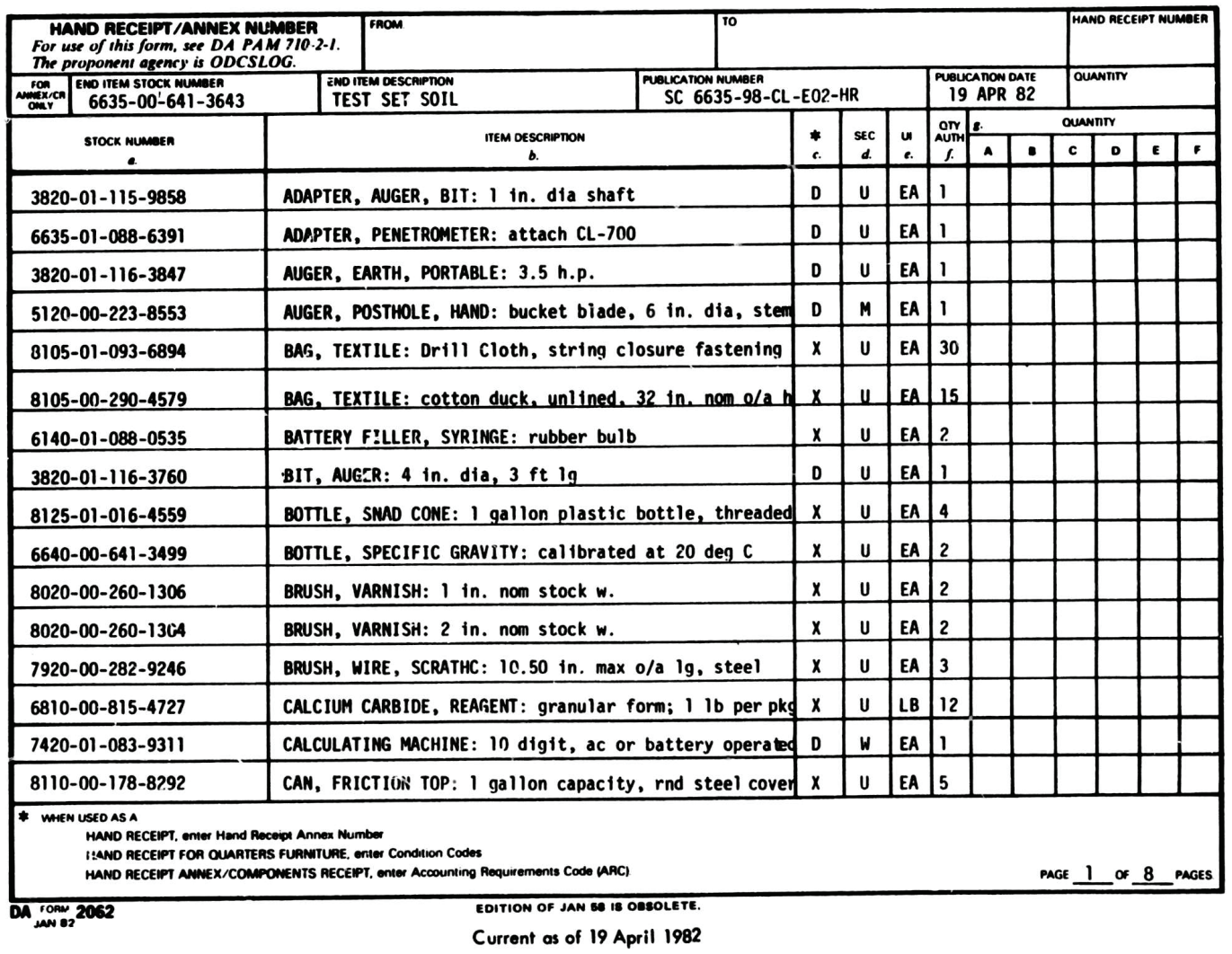

SC 6635-98-CL-EO2-HR

TEST SET SOIL

\begin{tabular}{|c|c|c|c|c|c|c|c|c|c|c|c|}
\hline & & & sec & & ons & 8 & & & & & \\
\hline $\begin{array}{c}\text { STOCK MUMBE } \\
\end{array}$ & b. & c. & d. & . & 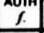 & $A$ & - & c & 0 & $E$ & $F$ \\
\hline $6635-01-106-7755$ & CHEST, SOIL TEST SET: (BEARINS RATIO EQ̨UIPMENT) & D & U & EA & 2 & & & & & & \\
\hline $6635-01-106-2732$ & CHEST, SOIL TEST SET: (SOIL SAMPLING EQUIPMERT) & D & U & EA & 1 & & & & & & \\
\hline $6635-00-371-9686$ & CHEST, SOIL TEST SET: rectangular shape & D & u & EA & 1 & & & & & & \\
\hline $5110-00-585-8428$ & CHISEL, BUTT, WOODWORKING: tang type, plastic handle & D & il & EA & 1 & & & & & & \\
\hline $8305-00-223-1270$ & CLOTH, DUCK: cotton, no. 4 olive drab; mildew & $x$ & U & YD & 5 & & & & & & \\
\hline $6635-00-371-9689$ & COLLAR SAMPLING: tubing, seamless, case harden & $x$ & is & EA & 1 & & & & & & \\
\hline $6635-00-355-6318$ & COMPACTION CYLINDER, SOIL: steel, 4 in. 1d, (98773) & $x$ & 0 & EA & 5 & & & & & & \\
\hline $6635-00-371-9692$ & COMPACTION CYLINDER, SOIL: steel, 6 in. id & D & u & EA & $2 n$ & & & & & & \\
\hline $6635-01-108-9580$ & COVER, TEST SIEVE: brass, 8 in. cyl shape, handle & $x$ & U & E.A & 1 & & & & & & \\
\hline $6635-01-088-6392$ & CUP, SOIL DISPERSION: four stationary baffles & $x$ & 0 & EA & 1 & & & & & & \\
\hline $6675-00-244-0445$ & CURVE, DRAFTING, IRREGULAR: french pattern 28 & $x$ & 0 & EA & 1 & & & & & & \\
\hline $6640-00-883-8516$ & CYLINDER, GRADUATED, LABORATORY: glass $100 \mathrm{ml}$, w/poun & $x$ & $u$ & EA & 2 & & & & & & \\
\hline $5340-00-135-4385$ & DISC, SOIL, SAMPLER: cast iron, cadmium plated & $x$ & u & EA & 2 & & & & & & \\
\hline $6640-00-421-5000$ & DISH, EVAPORATING: porcelain, bowl shaped rnd bottom & $x$ & 0 & EA & 10 & & & & & & \\
\hline $6640-00-421-6500$ & DISH, MOISTURE DETERMINATION: aluminUM:, $50 \mathrm{~mm}$ dia & $x$ & U & EA & 36 & & & & & & \\
\hline $6640-00-811-4431$ & DISH, MOISTURE DETERMINATION: a luminUm, $90 \mathrm{~mm}$ dia & $x$ & U & EA & 24 & & & & & & \\
\hline $3820-01-115-9868$ & EXTENSION, AUGER BIT: $3 \mathrm{ft} 1 \mathrm{~g} ;$ & D & u & EA & 6 & & & & & & \\
\hline $5110-00-239-7556$ & FILE, HAMD: American pattern; Three sq type, $8 \mathrm{in.1g}$ & D & $M$ & EA & 1 & & & & & & \\
\hline $5110-00-241-9138$ & FILE, HAND: Mill; single smooth cut face, $10 \mathrm{in.} \mathrm{gg}$ & D & M & EA & 1 & & & & & & \\
\hline $6635-00-933-0559$ & GROOVING TOOL, SOIL TEST: cadmium plated steel & $x$ & U & EA & 1 & & & & & & \\
\hline $4930-00-222-2680$ & GUN, FLUID, DIRECT DELIVERY: flexible metallic hose & $x$ & u & EA & 1 & & & & & & \\
\hline
\end{tabular}




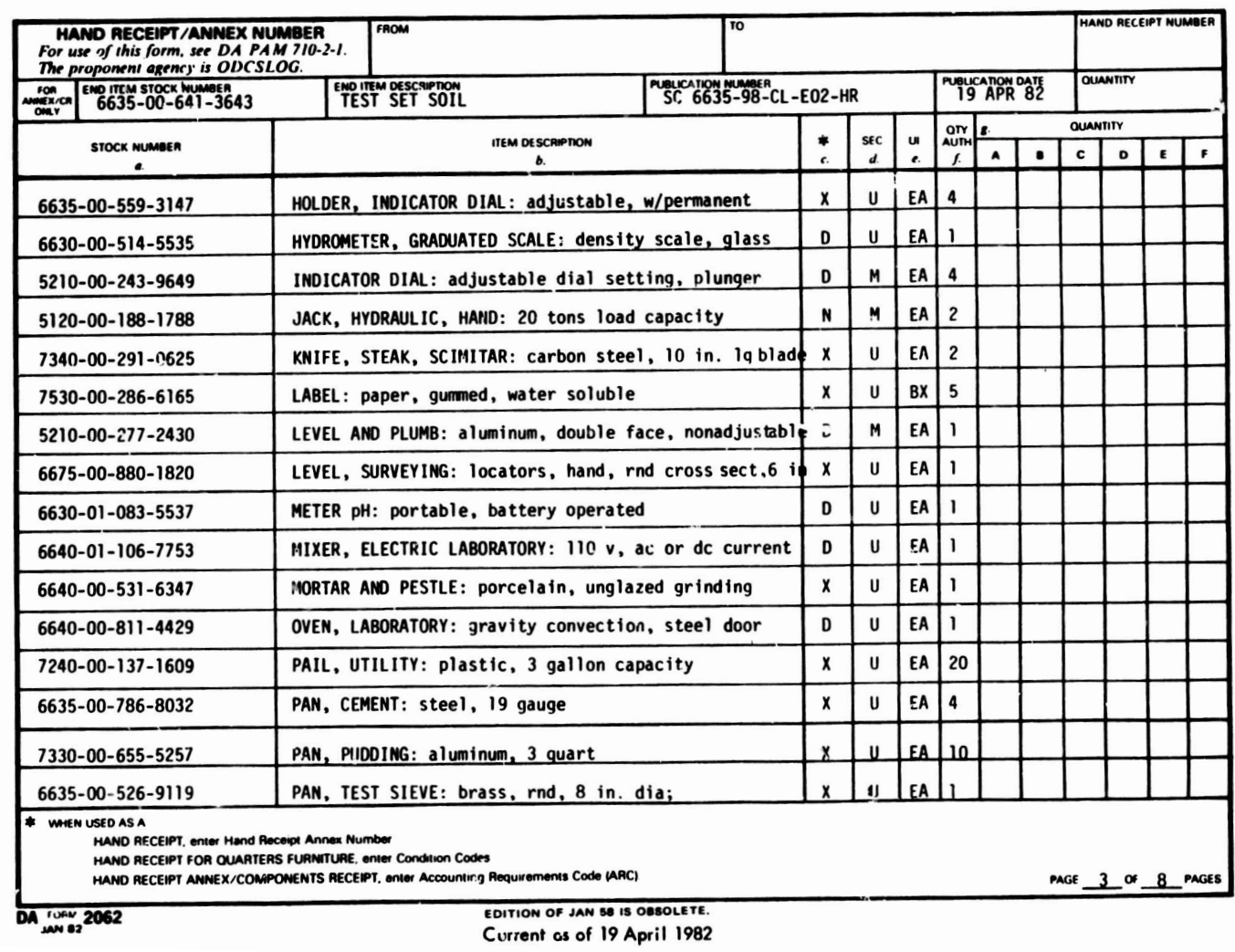

SC 6635-98-CL-EO2-HR TEST SET SOIL

\begin{tabular}{|c|c|c|c|c|c|c|c|c|c|c|c|}
\hline stock mumen & IEM Descmention & & 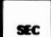 & $\omega$ & ons & 8. & & and & & & \\
\hline & o. & ? & 4 & .. & f. & 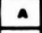 & 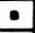 & c & - & $E$ & . \\
\hline $6640-00-252-5200$ & PAPER, FILTER: quantitative; 100 per box & $x$ & $\mathbf{U}$ & hD & 1 & & & & & & \\
\hline $7530-00-260-0618$ & PAPER, GRAPH: cross sect ruling tracing & $x$ & $\mathbf{u}$ & PG & 1 & & & & & & \\
\hline $7530-00-205-3676$ & PAPER, GRAPH: semilogarithmic ruling & $x$ & U & PG & $\mathbf{1}$ & & & & & & \\
\hline $7510-00-264-4612$ & PEMCIL: yellow, extra thk lead, 12 per pkg & $x$ & $\mathbf{u}$ & 02 & 1 & & & & & & \\
\hline $6635-00-986-4980$ & PENETROMETER: cres, pocket, solls classification & $x$ & $\mathbf{u}$ & EA & 1 & & & & & & \\
\hline $6640-00-641-3055$ & PESTLE LABORATORY: 2 piece, rubber tipped, w/wood & $x$ & 0 & EA & 1 & & & & & & \\
\hline $4710-00-595-0449$ & PIPE, METALLIC: seamless or welded, external thd end & $x$ & $\mathbf{u}$ & EA & 3 & & & & & & \\
\hline $6635-00-371-9695$ & PLATE, BASE, PERFORATED: California bearing test & D & u & EA & 20 & & & & & & \\
\hline $6635-00-786-8033$ & PLATE, FIELD DENSITY, SOIL TEST: cast aluminum alloy & $x$ & 0 & EA & 1 & & & & & & \\
\hline $5120-00-239-8251$ & PLIERS: Iineman's side cutter, $8 \mathrm{in.} \mathrm{gg}$ & D & M & EA & 1 & & & & & & \\
\hline $7240-00-248-9620$ & SAFETY CAN: red, 3 gallon capacity & $x$ & 0 & EA & 1 & & & & & & \\
\hline $6670-00-494-3845$ & SCALE, BEAM INDICATING: sp gr determination & D & 0 & EA & 1 & & & & & & \\
\hline $6670-00-494-3604$ & SCALE, BEAM INDICATIHS: $1,610 \mathrm{gm}, 3$ weight beams & N & U & EA & 1 & & & & & & \\
\hline $6670-00-514-4117$ & SCALE, BEAM INDICATING: $21,100 \mathrm{gm} 2$ weight beams & D & $\mathbf{u}$ & EA & 1 & & & & & & \\
\hline $6675-00-238-3498$ & SCALE, DRAFTIMG: wood and plastic & $x$ & u & EA & 1 & & & & & & \\
\hline $7330-00-153-9760$ & SCOOP, KITCHEN: cres $7.8 \mathrm{in.} 1 \mathrm{~g}$ & $x$ & 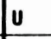 & EA & 2 & & & & & & \\
\hline $5120-00-222-8852$ & SCREMORIVER, FLAT TIP: plastic handle; $4 \mathrm{in.} \mathrm{lg}$ blade & D & M & EA & 1 & & & & & & \\
\hline $5120-00-293-0315$ & SCREWORIVER, FLAT TIP: plastic handle; 6 in. ig blade & D & M & EA & 1 & & & & & & \\
\hline $6635-00-225-7102$ & SHAKING MACHINE, TESTING SIEVE LABORATORY: hand & D & u & EA & 1 & & & & & & \\
\hline $6635-00-641-3586$ & SIEVE, TEST: rnd, brass frame, Size No. 200 & $x$ & $u$ & EA & 2 & & & & & & \\
\hline $6635-00-641-3584$ & SIEVE, TEST: rnd, brass frame, Size No. 100 & $x$ & u & EA & 2 & & & & & & \\
\hline
\end{tabular}




\begin{tabular}{|c|c|c|c|c|c|c|c|c|c|c|}
\hline $\begin{array}{l}\text { HAND REEEIPT/ANMEX NUMBEE } \\
\text { For use of this form, see DAP PAM 710.2.1. } \\
\text { The proponent agency is ODCSLOG. }\end{array}$ & 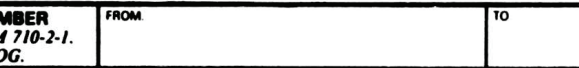 & \multicolumn{6}{|c|}{ To } & \multicolumn{3}{|c|}{ PONO MECEHT WUMBER } \\
\hline 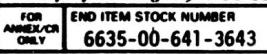 & $\begin{array}{l}\text { Proucation MUMBER } \\
\text { SC } 6635-98-C L-E\end{array}$ & 02-H & & & & APOOW & & \multicolumn{3}{|l|}{ owwiriv } \\
\hline stock munaen & \multirow{2}{*}{$\begin{array}{l}\text { IIEM OEscremenom } \\
\text { b. }\end{array}$} & * & $\mathbf{s a c}$ & $\mathbf{u}$ & $\mathrm{om}$ & & & \multicolumn{3}{|l|}{ owwnn } \\
\hline - & & : & 2 & . & and & A & - & 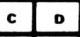 & $\epsilon$ & F \\
\hline $6635-00-526-6187$ & SIEVE, TEST: rnd, brass frame, Size No. 80 & $x$ & u & EA & 1 & & & & & \\
\hline $6635-00-641-3583$ & SIEVE, TEST: rnd, brass frame, Size No. 60 & $x$ & u & EA & 1 & & & & & \\
\hline $6635-00-641-7367$ & SIEVE, TEST: rnd, brass frame, Size No. 50, 297 micr & $x$ & $u$ & EA & 1 & & & & & \\
\hline $6635-00-641-3582$ & SIEVE, TEST: rnd, brass frame, Size No. $40,420 \mathrm{micr}$ & $x$ & $\mathbf{u}$ & EA & $?$ & & & & & \\
\hline $6635-00-641-7353$ & SIEVE, TEST: rnd. brass frame, Size No. 30, $590 \mathrm{micr}$ & $x$ & u & EA & ו & & & & & \\
\hline $6635-00-641-7354$ & SIEVE, TEST: rnd, brass frame, Size No. 20 & $x$ & u & EA & 1 & & & & & \\
\hline $6635-00-641-7355$ & SIEVE, TEST: rnd, brass frame, Siżê No. 16 & $x$ & u & EA & 1 & & & & & \\
\hline $6635-00-641-3591$ & SIEVE, TEST: rnd, brass frame, Size No. 10 & $x$ & u & EA & 1 & & & & & \\
\hline $6635-00-641-7364$ & SIEVE, TEST: rnd, brass frame, Size No. 8 & $x$ & u & EA & 1 & & & & & \\
\hline $6635-01-105-6844$ & SIEVE, TEST: rnd, brass frame, Size No. 200 & $x$ & u & EA & 2 & & & & & \\
\hline $6635-01-105-6843$ & SIEVE, TEST: rnd, brass frame, Size No. 40 & $x$ & u & EA & 2 & & & & & \\
\hline $6635-00-641-7357$ & SIEVE, TEST: rnd, brass frame, Size No. 4 & $x$ & u & EA & 3 & & & & & \\
\hline $6635-00-641-7358$ & SIEVE, TEST: rnd, brass frame, Size No. 3 & $x$ & u & EA & 1 & & & & & \\
\hline $6635-00-641-7361$ & SIEVE, TEST: rnd, brass frame, Size $3 / 4 \mathrm{in}$. & $x$ & u & EA & 1 & & & & & \\
\hline $6635-00-641-7350$ & SIEVE, TEST: rnd, brass frame, Size 1 in. & $x$ & $u$ & EA & 1 & & & & & \\
\hline $6635-00-641-3596$ & SIEVE, TEST: rid, brass frame. Size $1.1 / 2$ in & $x$ & u & EA & 1 & & & & & \\
\hline 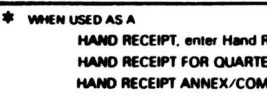 & 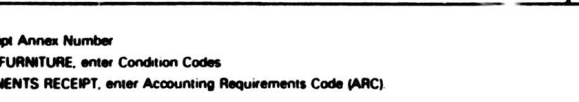 & & & & & & & 5 o & 8 & \\
\hline
\end{tabular}

SC 6635-98-CL-E02-HR

TEST SET SOIL

\begin{tabular}{|c|c|c|c|c|c|c|c|c|c|c|c|}
\hline stock mumeen & MEM DESCRAPTION & & SEC & un & and & 8. & & OUAN & & & \\
\hline & & c. & d. & e. & 5. & A & $\bullet$ & c & 0 & $E$ & $F$ \\
\hline $6635-00-514-4149$ & SIEVE, TEST: rnd, brass frame, size No. 2 in. & $x$ & $\mathbf{u}$ & EA & 1 & & & & & & \\
\hline $7520-00-868-4734$ & SLIDE RULE: Single face, plastic body & $x$ & $u$ & EA & 1 & & & & & & \\
\hline $6810-00-597-5287$ & SODIUM HEXAMETAPHOSPHATE, TECHINCAL: granular or flake & $x$ & $\mathrm{u}$ & LB & 12 & & & & & & \\
\hline $6810-00-270-8177$ & SODIUM HYDROXIDE, TECHINICAL: flake or powder form & $x$ & u & CN & 1 & & & & & & \\
\hline $6640-00-171-5198$ & SPATULA LABORATORY: cres blade, wood handle & $x$ & u & EA & 2 & & & & & & \\
\hline $7340-00-240-7080$ & SPOON, FOOD SERVICE: 15.25 in. $1 \mathrm{~g}$ & $x$ & u & EA & 2 & & & & & & \\
\hline $6645-00-250-4680$ & STOPWATCH: pocket type & $x$ & U & EA & 1 & & & & & & \\
\hline $5210-00-282-2150$ & STRAIGHT EDGE: steel std, 24 in. $1 \mathrm{~g}$ & $\mathbf{D}$ & M & EA & 1 & & & & & & \\
\hline $6635-00-371-9698$ & SUPPORT, TRIPOD, DIAL: indicator clamp, California & $x$ & u & $E A$ & 1 & & & & & & \\
\hline $8135-00-292-2345$ & TAG, SHIPPING: rectanqular, cloth, white; (81348) & $x$ & U & $M X$ & 100 & & & & & & \\
\hline $6635-00-514-4013$ & TAMPER, COMPACTION, SOIL TESTING: w/rammer, 2 in. dia & $x$ & $\mathbf{u}$ & EA & 2 & & & & & & \\
\hline $5210-00-221-1888$ & TAPE, MEASURING: $100 \mathrm{ft}$ measuring capacity, handcrank & D & M & EA & 1 & & & & & & \\
\hline $52 i 0-00-245-0301$ & TAPE, MEASURING: 78.75 in. measuring capacity, null & $\mathbf{D}$ & $M$ & EA & 2 & & & & & & \\
\hline $6635-00-641-3496$ & TESTING MACHINE, SOIL LIQUID LIMIT: brass cup & $\mathbf{D}$ & $\mathrm{U}$ & EA & 1 & & & & & & \\
\hline $6630-00-226-0920$ & TEST PAPER AND COLOR CHART: hydrogen ion & $x$ & U & EA & 1 & & & & & & \\
\hline $6635-00-411-3727$ & TEST SET, SOIL, FIELD: California bearing ratio & D & $\mathbf{U}$ & SE & 1 & & & & & & \\
\hline $6635-00-411-3728$ & TEST SET, SOIL, LABORATORY: California bearing ratio & D & $\mathbf{u}$ & SE & 1 & & & & & & \\
\hline $6635-00-976-3463$ & TEST SET, SOIL: MOISTURE DETERMINATION & D & U & EA & 1 & & & & & & \\
\hline $6635-00-542-1284$ & TEST SET, SOIL TRAFFICABILITY: $c / 0$ the following: & & & & & & & & & & \\
\hline $6635-00-679-5760$ & CARRYING CASE, TEST SET, SOIL TRAFFICABILITY & D & u & EA & 1 & & & & & & \\
\hline $5120-00-240-5300$ & KEY, SOCKET, HEAD SCREW: heX & 0 & M & EA & 1 & & & & & & \\
\hline
\end{tabular}




\begin{tabular}{|c|c|c|c|c|c|c|c|c|c|c|}
\hline 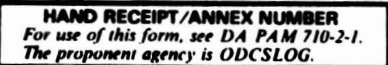 & 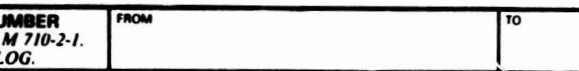 & \multicolumn{6}{|c|}{$\sqrt{10}$} & \multicolumn{3}{|c|}{ HANO RECERPT NUWOEA } \\
\hline 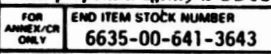 & $\begin{array}{l}\text { Puaucation múber } \\
\text { SC. } 6635-98-C\end{array}$ & $L-E 0$ & & & \begin{tabular}{|l} 
Puencic \\
19
\end{tabular} & $\begin{array}{l}\text { CAAOND } \\
\text { APR }\end{array}$ & & \\
\hline STOCK MUMEEEn & \multirow{2}{*}{$\begin{array}{c}\text { Irem ot schiprion } \\
\text { b. }\end{array}$} & $*$ & $\mathrm{sec}$ & u & orr & & & \multicolumn{3}{|l|}{ omantiry } \\
\hline. & & & $d$ & . & 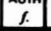 & A & - & o & $E$ & \\
\hline $6635-00-679-5761$ & PEMETROMETER: soil, cir base & D & u & EA & 1 & & & & & \\
\hline $5635-00-679-5762$ & REMOLDIMG SET, SOIL COMPACTION & 0 & $u$ & EA & 1 & & & & & \\
\hline $6635-00-679-5764$ & SAMPLER, SOIL & D & 0 & EA & 1 & & & & & \\
\hline $5120-00-287-2504$ & SCREMORIVER, FLAT TIP: plastic handle, 5 in. $1 \mathrm{~g}$ & 0 & M & EA & 1 & & & & & \\
\hline $5120-00-187-7124$ & WRENCH, OPEN END: steel & D & M & EA & 2 & & & & & \\
\hline $5120-00-277-1483$ & WRENCH PIPE: Iron, 6 in. ag & D & M & EA & 1 & & & & & \\
\hline $5120-00-288-8746$ & WRENCH, SPAMNER: steel & D & $m$ & EA & 1 & & & & & \\
\hline $6635-00-807-3717$ & TESTER, SOIL DENSITY, SAND METHOD: brass or steel & $x$ & $u$ & EA & 3 & & & & & \\
\hline $6685-01-088-0548$ & THERHOMETER, SELF-INDICATING, LIQUID IN GLASS: & $x$ & $u$ & EA & 1 & & & & & \\
\hline $6640-00-444-8000$ & TONGS, LABORATORY: crucible, double bent, (96906) & $x$ & u & EA & 1 & & & & & \\
\hline $5140-01-018-2719$ & TOOL BOX, PORTABLE: 2 tray & D & M & $E A$ & 1 & & & & & \\
\hline $7210-00-243-1019$ & TOWEL, HAND: cotton, huck weave & $x$ & $M$ & EA & 12 & & & & & \\
\hline $6675-00-190-5867$ & TRIANGLE, DRAFTING: plastic, right angle; 30 deg-60 & $x$ & u & EA & 1 & & & & & \\
\hline $6675-00-190-5862$ & TRIANGLE, DRAFTING: plastic, right angle; 45 deg, 8 in & $x$ & $u$ & EA & 1 & & & & & \\
\hline $5120-00-223-9477$ & TROWEL: pointer unit & 0 & M & EA & 2 & & & & & \\
\hline $4020-00-243-3155$ & TWIAE, FIBROUS: cotton, cable lay & & & & & & & & & \\
\hline \multicolumn{11}{|c|}{ 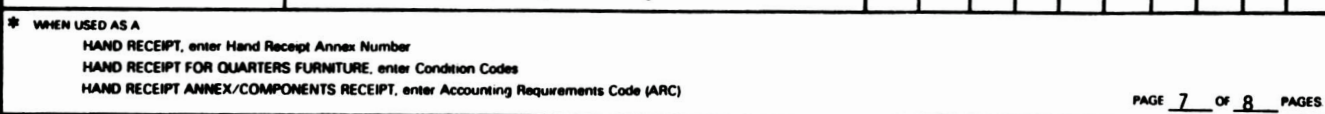 } \\
\hline 0.2062 & 982 & & & & & & & & & \\
\hline
\end{tabular}

SC 6635-98-CL-E02-HR

TEST SET SOIL

\begin{tabular}{|c|c|c|c|c|c|c|c|c|c|c|c|}
\hline STOCK MUMDER & ITEM OESCMPPnOW & 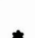 & sac & n & om & e. & & and & & & \\
\hline e. & b. & : & c. & . & c. & 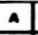 & - & c & D & $E$ & $=$ \\
\hline $6635-00-371-9702$ & WEIGHT, CAL IFORNIA BEARING TEST LEAD: 5 lb. & D & $\mathbf{u}$ & EA & 40 & & & & & & \\
\hline $5120-00-264-3796$ & WRENCH, ADJUSTABLE: single head & D & M. & EA & 1 & & & & & & \\
\hline $5120-00-277-1477$ & WRENCH PIPE: adjustable jaw & D & M & EA & 2 & & & & & & \\
\hline & & & & & & & & & & & \\
\hline & & & & & & & & & & & \\
\hline & & & & & & & & & & & \\
\hline & & & & & & & & & & & \\
\hline & & & & & & & & & & & \\
\hline & & & & & & & & & & & \\
\hline & & & & & & & & & & & \\
\hline & & & & & & & & & & & \\
\hline & & & & & & & & & & & \\
\hline & & & & & & & & & & & \\
\hline & & & & & & & & & & & \\
\hline & & & & & & & & & & & \\
\hline & & & & & & & & & & & \\
\hline & & & & & & & & & & & \\
\hline & & & & & & & & & & & \\
\hline & & & & & & & & & & & \\
\hline & & & & & & & & & & & \\
\hline & & & & & & & & & & & \\
\hline
\end{tabular}


Bv Order of the Secretary of the Army:

Official:

E. C. MEYER

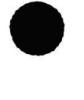
General. United States Arm Chief of Siaff

M JOYCE

Brigadier General. United Siales $4 \mathrm{rm}$ ।

The Adjutant General

\section{Dirtaribution:}

To be distributed in eceordance with DA Form 12-21A, requirements for FSC Group 6635-CL.

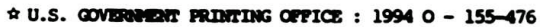




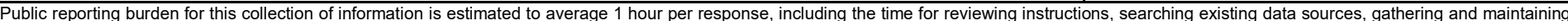

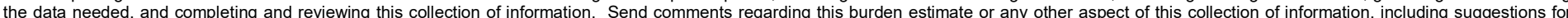

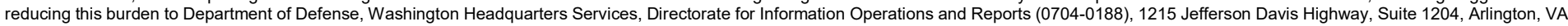

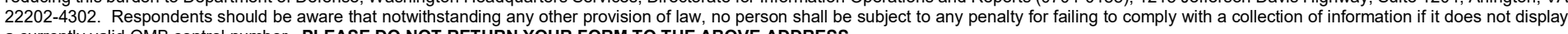
a currently valid OMB control number. PLEASE DO NOT RETURN YOUR FORM TO THE ABOVE ADDRESS.
1. REPORT DATE (DD-MM-YYYY) 2. REPORT TYPE
3. DATES COVERED (From - To)

January 2018 Final

\section{TITLE AND SUBTITLE}

Revised Rapid Soils Analysis Kit (RSAK) - Wet Methodology

5a. CONTRACT NUMBER

5b. GRANT NUMBER

5c. PROGRAM ELEMENT NUMBER

\section{AUTHOR(S)}

Ernest S. Berney IV, Naveen B. Ganesh, and David R. Daily

5d. PROJECT NUMBER

354894

5e. TASK NUMBER

5f. WORK UNIT NUMBER

\section{PERFORMING ORGANIZATION NAME(S) AND ADDRESS(ES)}

8. PERFORMING ORGANIZATION REPORT NUMBER

Geotechnical and Structures Laboratory

U.S. Army Engineer Research and Development Center

ERDC TR-18-1

3909 Halls Ferry Road

Vicksburg, MS 39180-6199

\section{SPONSORING / MONITORING AGENCY NAME(S) AND ADDRESS(ES)}

National Ground Intelligence Center

Combat Analysis Center

Charlottesville, VA 22911

10. SPONSOR/MONITOR'S ACRONYM(S)

NGIC

11. SPONSOR/MONITOR'S REPORT NUMBER(S)

\section{DISTRIBUTION / AVAILABILITY STATEMENT}

Approved for public release; distribution is unlimited.

\section{SUPPLEMENTARY NOTES}

\section{ABSTRACT}

ERDC research on crater formation from detonation of improvised explosive devices identified the significance of soil type on crater shape and size. Military Explosive Ordinance Disposal (EOD) teams required an expedient means of classifying soil from small field samples, according to the Unified Soil Classification System, to help identify characteristics of buried explosives. The existing Rapid Soils Analysis Kit (RSAK), developed at ERDC, was modified to shrink its cube volume, improve its accuracy, and adapt it to the EOD mission. As such the RSAK was changed from a dry, pulverization-based (D-RSAK) system to a wet, wash-based (W-RSAK) system similar to that used in a commercial laboratory to improve accuracy of determining fines content. Modifications were focused on increasing speed and accuracy from the original D-RSAK. This report presents comparisons of classification results on 14 different soil types by both the traditional laboratory, dry-based and wet-based systems to demonstrate the strengths and weaknesses of the new $\mathrm{W}$ RSAK procedure. The kit in its current configuration with the wet process was demonstrated to significantly improve classification estimations. Revised software to process the data obtained from the W-RSAK equipment was developed using Matlab and Android platforms to enable deployment on multiple software platforms.

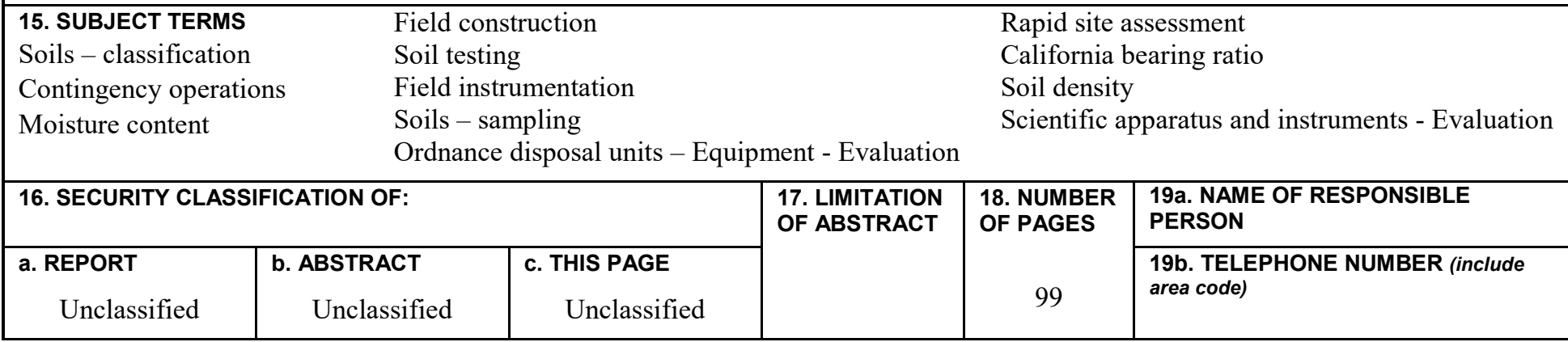

